\title{
DETECCIÓN DE EMISIONES OTOACÚSTICAS TRANSITORIAS POR ESTIMULACIÓN LINEAL Y NO LINEAL DE BAJ AS INTENSIDADES
}

\author{
Presenta: \\ Ing. J esús Gutiérrez Salazar \\ Trabajo para obtener el título de \\ Maestro en Ciencias de Ingeniería Biomédica
}

Asesores:

M. C. Miguel Cadena Méndez

M. I. Juan Manuel Cornejo Cruz

\author{
Sinodales \\ M. C. Caoupolican Muñoz Gamboa \\ M. C. G. Gabriel Gentiletti Faenze \\ M. C. Miguel Cadena Méndez \\ UNIVERSIDAD AUTÓNOMA METROPOLITANA \\ POSGRADO EN INGENIERÍA BIOMÉDICA \\ MÉXICO, D. F. \\ 2004
}




\section{DETECCIÓN DE EMISIONES OTOACÚSTICAS TRANSITORIAS POR ESTIMULACIÓN LINEAL Y NO LINEAL DE BAJAS INTENSIDADES}

\section{Presenta:}

Ing. Jesús Gutiérrez Salazar

Trabajo para obtener el título de Maestro en Ciencias de Ingeniería Biomédica

\section{Asesores:}

M. C. Miguel Cadena Méndez

M. I. Juan Manuel Cornejo Cruz

Sinodales:

M. C. Caupolican Muñoz Gamboa

M. C. G, Gabriel Gentiletti Faenze

M. C. Miguel Cadena Méndez

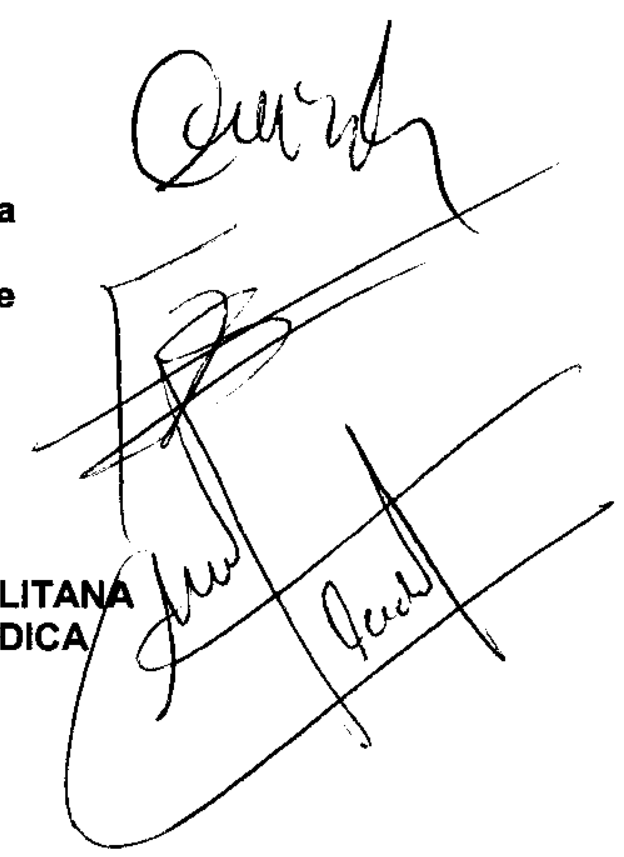




\section{Agradecimientos}

El presente trabajo se realizó en el Laboratorio de Audiología, del departamento de Ingeniería Eléctrica, del área de Ciencias Básicas e Ingeniería de la Universidad Autónoma Metropolitana, unidad Iztapalapa.

Quiero agradecer al CONACYT por la beca otorgada para la realización de este trabajo, a mis asesores M.C. Miguel cadena Méndez y M. I. Juan Manuel cornejo Cruz, que han sabido transmitir en mí los conocimientos necesarios para la realización de esta tarea y conducirme por la senda del conocimiento, porque con su apoyo he llevado a buen término esta recopilación de resultados, al M. C. Gerardo Gabriel Gentiletti Faenze, que con su gran sentido de compañerismo, me ayudó de manera muy significativa en la realización del presente escrito, a los maestros del Laboratorio de Audiología, compañeros del postgrado de Ingeniería Biomédica y amigos, por sus comentarios y sugerencias que enriquecieron el contenido de este trabajo.

Mi agradecimiento de manera muy especial a mi esposa que siempre estuvo a mi lado apoyándome incondicionalmente durante el desarrollo de las diferentes actividades que llevaron a la conclusión el presente trabajo, a mis padres y hermanos que son una parte

fundamental en mi vida, un refugio y apoyo en todo momento en este largo peregrinar de la vida. Por eso ahora quiero hacerlos partícipes de este logro en esta etapa de mi formación académica. 


\section{INDICE}

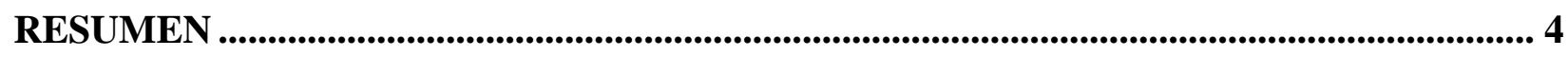

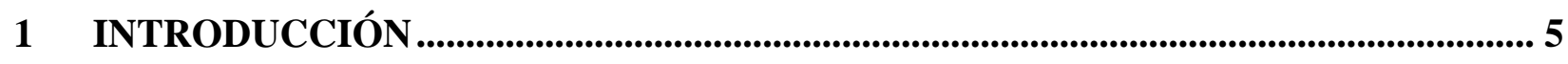

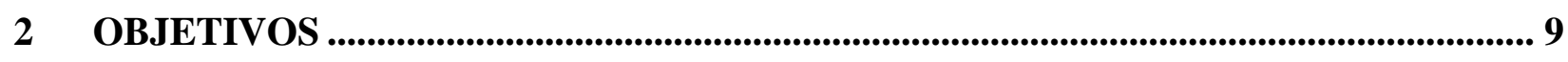

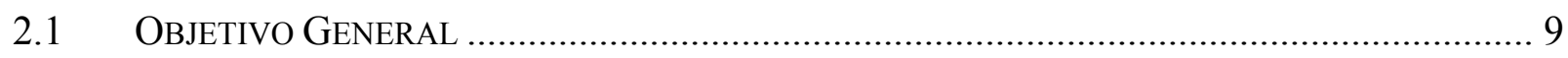

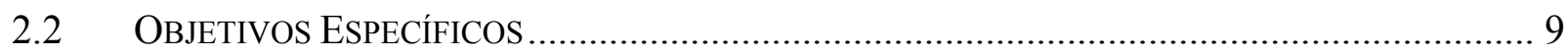

3 ANTECEDENTES ................................................................................................................ 10

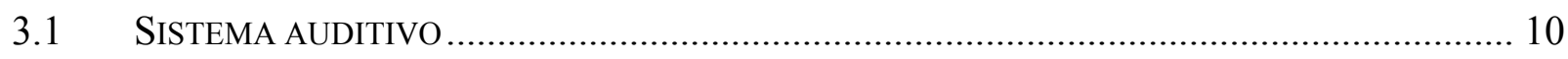

3.2 El SISTEMA AUDITIVO PERIFÉRICO Y LA AUDICIÓN...................................................... 10

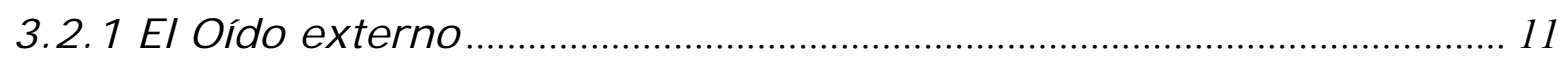

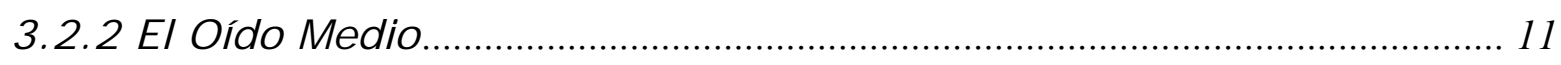

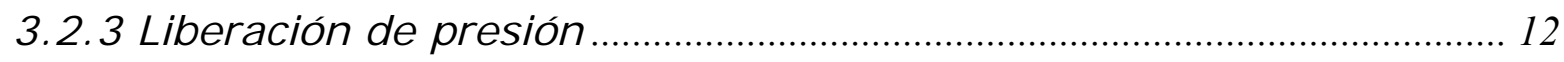

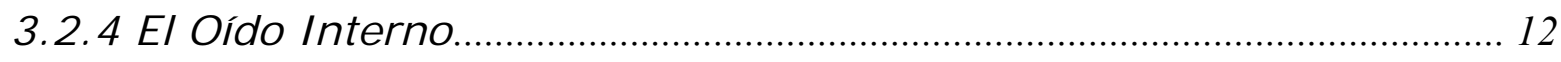

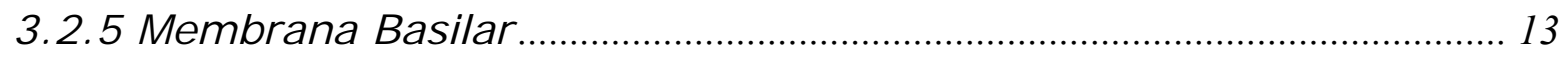

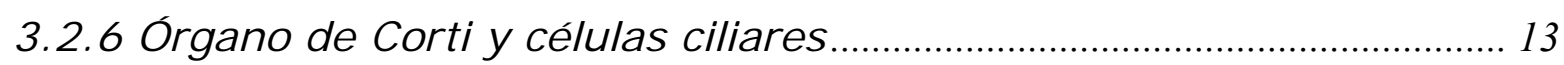

3.3 RESPUESTA EN FRECUENCIA Y LOCALIZACIÓN DE LAS FUENTES DE SONIDO .................... 14

3.3.1 Propagación del sonido y acople de impedancias ................................. 14

3.3.2 Respuesta en frecuencia del oído externo y el oído medio................ 15

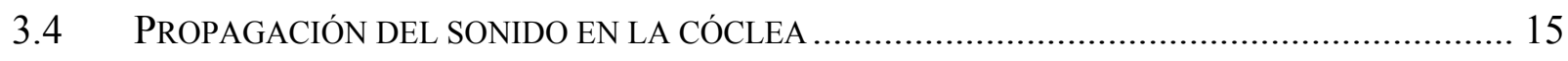

3.4.1 Ondas viajeras y transformación de frecuencia a posición................ 16

3.4.2 Mecanismo de transducción......................................................................... 18

3.4.3 Células ciliares y potenciales eléctricos ………………......................... 19

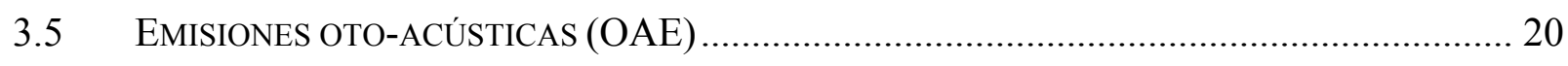

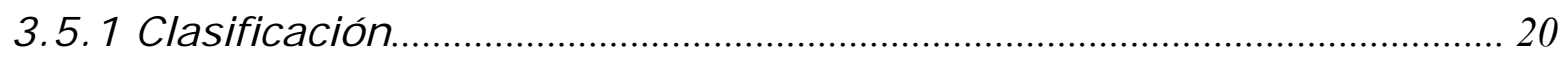




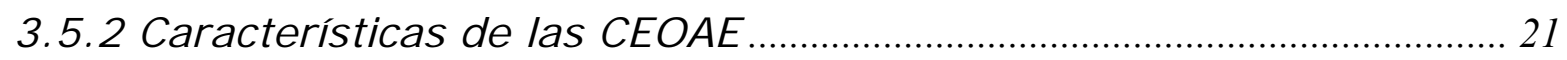

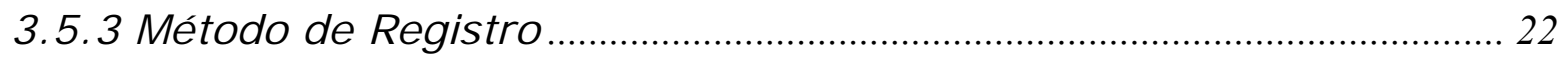

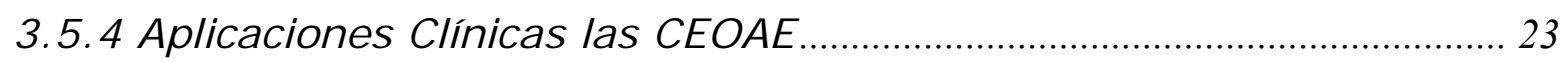

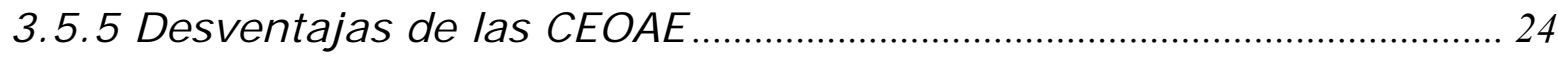

4 CONSIDERACIONES SOBRE LA ESTIMULACIÓN Y LA SEÑAL ADQUIRIDA. 25

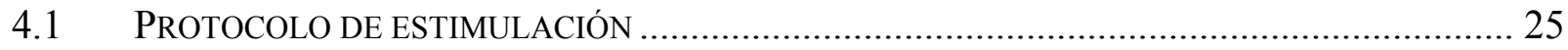

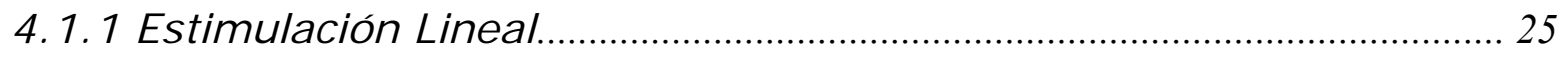

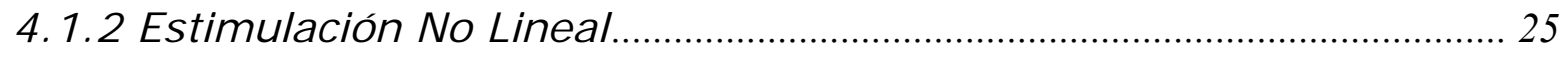

4.2 AlgoritMo de CoRRELACIÓN CRUZADA ……............................................................ 30

4.2.1 Algoritmo de Correlación Cruzada............................................................. 30

4.3 ALGORITMO FSP (FISHER - SINGLE POINT) ……………......................................... 31

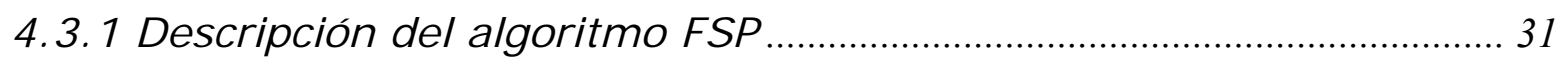

5 MATERIAL Y MÉTODO DEL PROCEDIMIENTO DE EXPERIMENTACIÓN..... 34

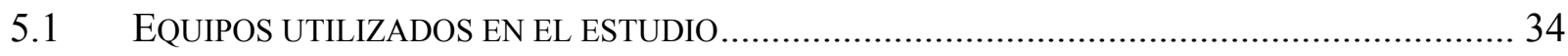

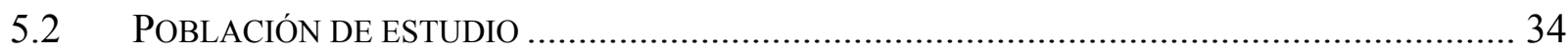

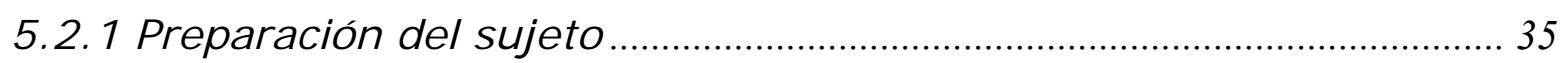

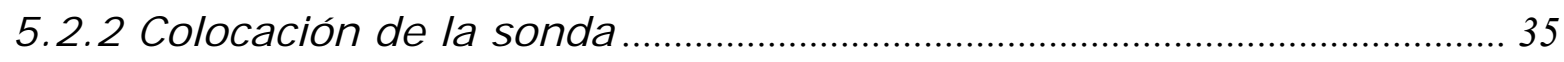

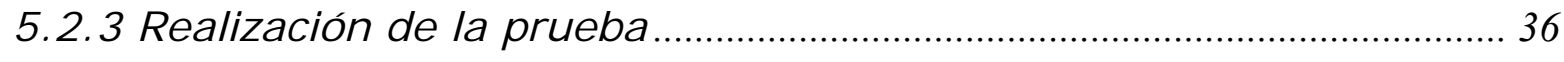

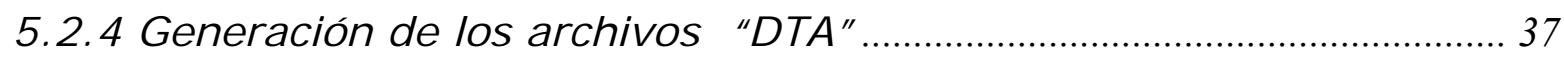

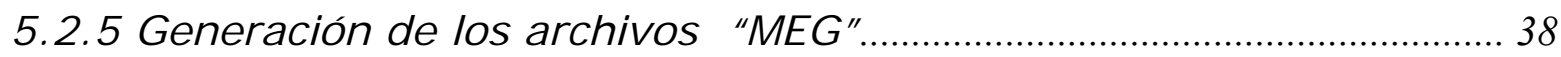

5.2.6 Detección alterna de las OAE: Selección de los parámetros de captura de datos y validación del software alterno de detección.......................................................... 40

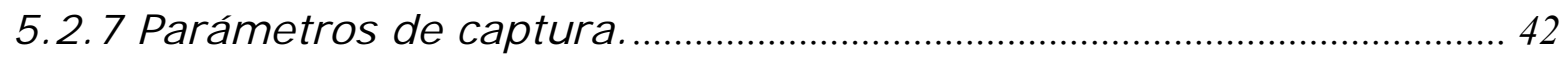

5.2.8 Número de épocas y lógica de fin de prueba......................................... 43

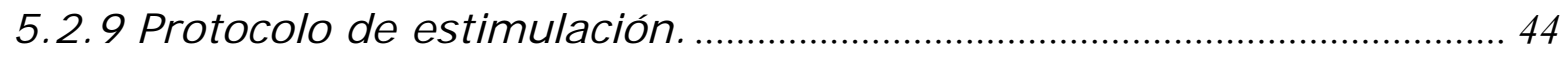

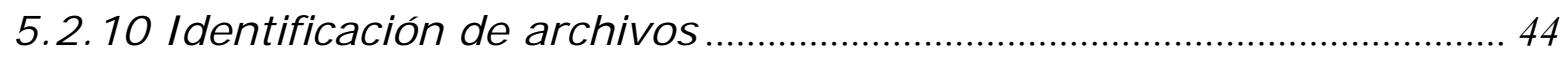

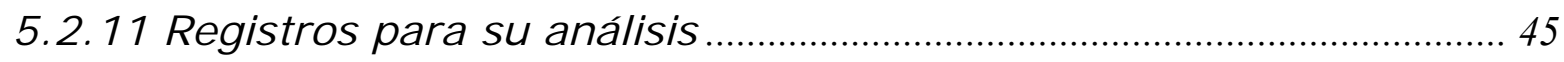

5.2.12 Análisis de los datos adquiridos con el protocolo modificado......... 45 
7 DISCUSIÓN

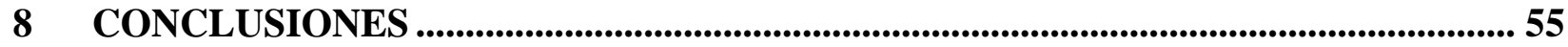

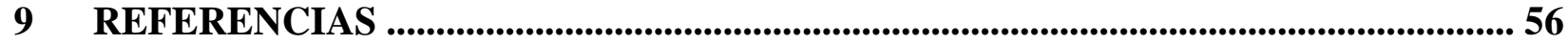




\section{Resumen}

En el presente trabajo se busca determinar en una población de sujetos con audición normal, la mínima intensidad de estimulación necesaria para la obtención de Emisiones Otoacústicas Transitorias Evocadas por Click's (CEOAE del inglés Click Evoked Otoacoustic Emissions), utilizando los protocolos de estimulación lineal y no lineal.

En una primera etapa las CEOAE se registraron y analizaron de acuerdo al procedimiento clínico usual, tal y como viene implementado en el ILO-96 de Otodynamics. Posteriormente estos resultados fueron reproducidos con software escrito ex profeso, a fin de validar el análisis de datos realizado en este trabajo. La segunda etapa consistió del registro de la respuesta coclear para diferentes intensidades de estimulación (35 a $80 \mathrm{~dB}$ SPLPe), empleando los protocolos de estimulación lineal y no lineal. La tercera etapa consistió en la búsqueda de CEOAE, mediante los algoritmos de Correlación Cruzada y FSP.

Para una población compuesta por partes iguales de hombres y mujeres, se analizaron un total de 40 oídos sanos. Una mitad de esta población fue estimulada con un protocolo lineal y la otra mitad con un protocolo no lineal. Las intensidades de estimulación fueron 80, 70, 60, 50, 40 y $35 \mathrm{~dB}$ SPL Pe; construyéndose promedios de 260 épocas para las tres primeras intensidades y de 420 para las tres últimas. Para comprobar que los algoritmos no detectan CEOAE falsas (falsos negativos), se realizaron registros sobre la cavidad de prueba de $2 \mathrm{cc}$ verificando así la ausencia de las mismas.

El protocolo de estimulación lineal presenta señales de mayor amplitud que las obtenidas con el protocolo de estimulación no lineal, también presenta mejores resultados al utilizar la ventana de análisis de 7.5-18 ms posteriores al estímulo.

Todos los registros realizados fueron almacenados en una base de datos conteniendo archivos DTA y MEG para posteriores análisis. 


\section{Introducción}

Actualmente la importancia que tiene realizar un programa de detección temprana de hipoacusia en recién nacidos está fuera de toda duda, por todas las consecuencias negativas que ésta representa para el adecuado desarrollo físico y psicológico del infante que la padece[1]-[4]. En nuestro país aún no se cuenta con estudios que proporcionen datos concretos sobre las discapacidades auditivas a edad temprana, mientras que en otros países las instituciones de salud pública han recomendado los estudios auditivos antes de los tres o seis meses de edad; como consecuencia, en nuestro país, la hipoacusia en sus diferentes grados (leve, moderada, profunda) no se detecta a edades tempranas (6 meses), ya que las exploraciones se efectúan hasta los 2 años de edad, cuando los padres o educadores sospechan el problema ante la falta de respuesta a estímulos sonoros o por retrasos en la adquisición del lenguaje [3].

Las pruebas audiométricas conductuales no son útiles para una exploración de la función auditiva a edad temprana, por lo que se recurre a pruebas audiológicas objetivas [5]. Actualmente existen dos técnicas objetivas para el análisis del sistema auditivo, estas son los Potenciales Evocados Auditivos de Tallo Cerebral (siglas en inglés: ABR) y Emisiones Oto-acústicas (siglas en inglés: $\mathrm{OAE}$ ). Se les llama objetivas porque no requieren de la participación activa del sujeto, las cuales son ideales para la exploración auditiva de los recién nacidos.

Utilizando los ABR es posible hacer inferencias sobre el funcionamiento de una parte de la cóclea y las vías nerviosas auditivas hasta corteza cerebral. Los ABR presentan una insuperable alta sensibilidad y muy buena especificidad, lograda a expensas de una prueba de mayor duración y complejidad [5][6]; por otro lado, las OAE analizan el funcionamiento del oído interno, más precisamente de las células ciliadas externas y como se registran en el canal auditivo externo también se puede obtener información del estado del oído medio. Éstas son útiles como un método objetivo, rápido, económico y no invasivo [1]-[3][7][19][21].

Muchos clínicos utilizan sólo los ABR para detectar algún problema de audición, aunque otros prefieren usar primero las OAE y puede observarse que hay una discrepancia entre cual de las dos técnicas debe utilizarse para analizar el sistema auditivo [1][2][7]. Las dos técnicas son útiles, pero desafortunadamente cada una analiza sólo una parte del sistema auditivo. Por esta razón cuando se requiere analizar el sistema auditivo completo es necesario utilizar los dos métodos de exploración mencionados anteriormente, debido a que ambas técnicas son complementarias [1][7]. En muchos de los casos, después de haberse realizado uno de estos estudios pasan varias semanas o incluso meses para la realización del otro.

En diferentes estudios realizados en países del primer mundo como Inglaterra, España y Estados Unidos de Norte América, sugieren que de mil niños que nacen vivos, tres nacen con hipoacusia profunda y hasta cinco veces más lo hacen con algún grado de hipoacusia [5]. Es por esto que desde el año 1993 el Instituto Nacional de Salud de Estados Unidos (National Institutes of Health) y en 1998 por la Conferencia del Desarrollo del Consenso Europeo sobre la Exploración Auditiva Neonatal (European Consensus Statement on infant screening) sustentan la necesidad de un método de exploración universal de la capacidad auditiva, el cual se debe realizar antes de los tres meses de vida, para identificar la presencia de discapacidades auditivas[2][5]; en España la 
Comisión para la Detección Precoz de la Hipoacusia (CODEPEH, 1996), recomienda realizar el estudio en caso de detectarse algún indicador de riesgo del recién nacido [3][5].

De acuerdo a los datos proporcionados por el INEGI del XII Censo General de Población y Vivienda 2000, se recolectó información sobre el porcentaje de la población con cualquier discapacidad de tipo severa, sin tomar en cuenta la edad de la persona, esto quiere decir que en esta población se encontraron desde niños hasta ancianos. Es importante recalcar que no se tomaron en cuenta las personas que presentaron cualquier discapacidad leve o moderada. En este estudio se identificaron 1 millón 795 mil personas con discapacidad, de las cuales el cuarto lugar con $15.7 \%$ de las discapacidades son de tipo auditivo (281,815 personas); aunque el tercer lugar lo ocupan los problemas mentales, se observa que tienen casi la misma cantidad de discapacitados (16.1\%), por otra parte, las discapacidades del lenguaje presentaron el $4.9 \%$ de la población; sin embargo, la mayoría de estos últimos problemas son consecuencia de problemas auditivos no detectados antes de la etapa en que el niño debe desarrollar el lenguaje, que es aproximadamente de 3 años de edad.

En nuestro país aún no se cuenta con una cultura de salud pública que exija o al menos que proponga la realización de estudios, para la detección de problemas auditivos en recién nacidos que presenten factores de riesgo y mucho menos un estudio universal; por este motivo no se llevan a cabo estudios que proporcionen datos de cuantos niños nacen con algún tipo de hipoacusia y su detección es a edades de alrededor de los 2 o 3 años de vida [3][5].

La siguiente tabla muestra los datos proporcionados por el INEGI, en la cual, se observa que nacen más de dos millones y medio de niños anualmente, desde 1990.

Nacimientos registrados, 1990-2001

\begin{tabular}{|c|c|c|c|c|c|c|c|}
\hline \multicolumn{1}{|c|}{ Indicador } & 1990 & 1991 & 1992 & 1993 & 1994 & 1995 \\
\hline Nacimientos registrados & 2735312 & 2756447 & 2797397 & 2839686 & 2904389 & 2750444 \\
\hline Indicador & 1996 & 1997 & 1998 & 1999 & 2000 & 2001 \\
\hline Nacimientos registrados & 2707718 & 2698425 & 2668428 & 2769089 & 2798339 & 2767610 \\
\hline
\end{tabular}

Si tomamos como referencia los estudios realizados en los países primer-mundistas, los cuales reportan que cinco de cada mil niños que nacen vivos, presentan algún tipo de problema auditivo desde leve a severo; se puede estimar que en México, existen aproximadamente 13,500 nuevos casos de infantes con problemas auditivos cada año, si se toma como base 2,700,000 de nacimientos de niños vivos anualmente, que muy probablemente no serán detectados hasta que presenten algún retrazo del habla. Sin embargo, en los países del primer mundo la calidad de vida es muy superior a la que se tiene en este país, por lo cual, esta cifra pude incrementarse sustancialmente; esto se podría comprobar si se realizara un estudio con esta finalidad.

Algunos estudios han reportados que una capacidad auditiva disminuida durante la infancia y en particular durante el primer año de vida, compromete el desarrollo del lenguaje; aunque menos documentado, este problema también afecta adversamente el desarrollo del sistema nervioso 
auditivo y puede tener un efecto perjudicial en el desarrollo social, psicológico y cognitivo del infante [4][5].Una consecuencia de esto es el aumento del costo de la rehabilitación para la familia o la asistencia social de salud.

Otro aspecto importante que se debe tomar en cuenta es el grado de rehabilitación que alcanza un niño al que se le detectó hipoacusia de manera tardía (después de los tres años d edad); en este caso la recuperación alcanzada está por debajo del grado de recuperación de un niño al que se le detectó la hipoacusia de manera temprana. Cuando la detección es temprana al niño se le puede atender con ayudas auditivas, desde antes de la etapa crítica (edad en la cual el infante inicia el aprendizaje del lenguaje) para el desarrollo del lenguaje y de esta manera recibir estimulación acústica para su adecuado desarrollo cognitivo. La hipoacusia no tiene que ser necesariamente importante (de tipo severa) para producir una merma del desarrollo del lenguaje [2]. El tiempo ideal para la realización de un diagnóstico inicial de la hipoacusia es durante los tres primeros meses de vida, por que el tratamiento adecuado no debería comenzar después de los seis meses de vida [5].

Actualmente hay equipos comerciales utilizados por los médicos, que incorporan las dos técnicas de exploración sólo que de manera independiente una de otra; por otro lado hay discrepancia entre médicos para la utilización de ABR o OAE ya que por la propia naturaleza de cada una de las señales, es muy aventurado seleccionar a una técnica como mejor que la otra.

Con la de finalidad explorar toda la vía auditiva en una sola sesión de estudio, dentro del Laboratorio de Audiología de la Universidad Autónoma Metropolitana, unidad Iztapalapa, se han desarrollado actividades que pretende unificar ambas técnicas de registro [1][5]. Si se alcaza este objetivo, el resultado sería una mejora de la sensibilidad y especificidad en la detección de problemas auditivos desde el oído medio hasta la vía auditiva, ya que como se mencionó anteriormente ambas técnicas son complementarias. Además de que se disminuiría el tiempo de estudio para cada sujeto, con lo que desminuiría también su costo.

Con el fin de contribuir a un macro-proyecto del Laboratorio de Audiología - UAM-I el cual tiene como meta realizar registros de los ABR y OAE de manera simultánea; este trabajo tiene como objetivo analizar distintas intensidades de estimulación que evocan las OAE utilizando para ello estímulos acústicos breves (click), ya que las intensidades comunes de estimulación para generar los ABR (35 dB nHL), son distintas a las utilizadas para las OAE (76 dB SPL Pe). Con el propósito de utilizar un estímulo equivalente para ambos métodos (ABR y OAE) se realiza el análisis de las OAE a distintas intensidades de estimulación, pues el estudio de ABR ya se llevó a cabo, bajo el contexto del macro-proyecto del Laboratorio de Audiologia - UAM-I [5].

Las diferentes intensidades del estímulo utilizadas en este trabajo son: 80, 35, 40, 50, 60, y $70 \mathrm{~dB}$ SPL Pe, realizadas en ese orden. Se exploraron también, dos protocolos de estimulación para analizar las características lineales y no lineales de las Emisiones Oto-acústicas Transitorias Evocadas por Click (CEOAE del inglés Click Evoked Otoacoustic Emissions). El primero de los protocolos de estimulación utilizados, consiste del envío de cuatro click's del mismo tamaño y polaridad, para resaltar las partes lineales de las CEOAE (estimulación lineal), el segundo de los protocolos, envía primeramente tres click's de una polaridad y amplitud determinada y el cuarto click es de polaridad opuesta y una amplitud tres veces mayor a los primeros, con el fin de 
resaltar las no linealidades de las CEOAE (estimulación no lineal). Para cada sesión de registro del evento estímulo-respuesta, se registraron 260 épocas para los primeros estímulos $(80,70$ y 60 $\mathrm{dB}$ SPL Pe) y 420 para los tres últimos (50, 40 y $35 \mathrm{~dB}$ SPL Pe), para ambos protocolos de estimulación esto se realizó con el fin de mejorar la relación señal ruido.

Para analizar los registros de las señales obtenidas, se utilizan los algoritmos de Correlación Cruzada y FSP programado en ambiente Matlab®. Con estos algoritmos, se evalúa la intensidad de estimulación mínima suficiente para determinar la presencia de las CEOAE y además se trata de determinar cual protocolo de estimulación es el adecuado para este propósito. 


\section{Objetivos}

En el Laboratorio de Audiologia de la Universidad Autónoma Metropolitana, unidad Iztapalapa, se desarrolla una novedosa técnica de "Exploración Universal de la Capacidad Auditiva de Recién Nacidos (EUCARN)"; esta técnica pretende realizar en forma simultánea los registros de ABR y de CEOAE. Aunque actualmente estas pruebas están disponibles, en equipos comerciales, se realizan de manera separada, debido a las características propias de registro de cada una. Ambas pruebas son complementarias debido a que exploran partes diferentes del sistema auditivo.

Desarrollar esta técnica es muy importante ya que la exploración de la vía auditiva se volvería rápida y económica, al analizar en un solo estudio toda la vía auditiva. Este tipo de estudio aprovecharía las bondades de las pruebas de ABR y CEOAE en una sola herramienta, valiosa en la exploración de la vía auditiva.

\subsection{Objetivo General}

Bajo el contexto anterior, el propósito del presente trabajo, es la determinación de la intensidad mínima suficiente para la obtención de CEOAE en sujetos con audición normal.

\subsection{Objetivos Específicos}

Conocer la forma de onda típica de la CEOAE en sujetos normales.

Identificación del tipo de análisis seguido por ILO-96, para determinar la presencia de CEOAE y su posterior comparación fuera de línea, con un análisis de datos realizado con software escrito ex profeso.

Elaboración de un diseño experimental, para la identificación de las CEOAE en la respuesta acústica.

Generación de una base de datos de sujetos sanos, conteniendo sus CEOAE para distintas intensidades y protocolos de estimulación. 


\section{Antecedentes}

La energía del sonido se transmite en el aire como una serie de compresiones y rarefacciones de las moléculas del medio. Los sonidos que el oído humano puede escuchar mejor, son los que se encuentran en el rango de frecuencias de 1000 a $4000 \mathrm{~Hz}$ [8][10][12], aunque, el rango de frecuencias audibles se extiende de 20 a $20000 \mathrm{~Hz}$ [1][11][12] .

La generación de sensaciones auditivas en el ser humano es un proceso complejo, el cual se desarrolla en tres etapas básicas:

- Captación y procesamiento mecánico de las ondas sonoras.

- Conversión de la señal acústica (mecánica) en impulsos nerviosos y transmisión de dichos impulsos hasta los centros sensoriales del cerebro.

- Procesamiento neural de la información codificada en forma de impulsos nerviosos.

Las dos primeras etapas se llevan a cabo en el oído propiamente dicho, mientras que la tercera etapa, se encuentra ubicada en el cerebro, en donde se producen las diversas sensaciones auditivas [1][10][12].

\subsection{Sistema auditivo}

Puede ser dividido en dos sub-sistemas: periférico y central. El sistema auditivo periférico convierte la energía mecánica del estímulo sonoro en códigos neurales (señales electroquímicas) que son interpretados por el sistema auditivo central como símbolos de sonidos específicos (sensaciones). En la región central se dan lugar a procesos cognitivos mediante los cuales se asigna un contexto y un significado a los sonidos. El sistema auditivo incluye propiedades lineales (pasivas) y no lineales (activas) [1][10] .

\subsection{El sistema auditivo periférico y la audición}

El sistema auditivo periférico se subdivide a su vez en: oído externo, oído medio y oído interno. El oído externo captura la energía sonora como ondas de presión que son convertidas en movimiento mecánico por la membrana timpánica. Este movimiento es transformado a través del oído medio y transferido al oído interno, donde es analizado en frecuencia y convertido en código neural que son enviados por el octavo nervio craneal (o nervio auditivo) al sistema auditivo central $[1][10]$.

La energía sonora se propaga a través de estas zonas y sufre distintas transformaciones durante el proceso (mecánica $\rightarrow$ hidraulica $\rightarrow$ electroquímica). Tanto el procesamiento mecánico de las ondas sonoras como la conversión de éstas en señales electroquímicas son procesos no lineales [1] [13] [14]. En la figura 3.1. se pueden apreciar el sistema auditivo periférico así como las partes que lo componen. 


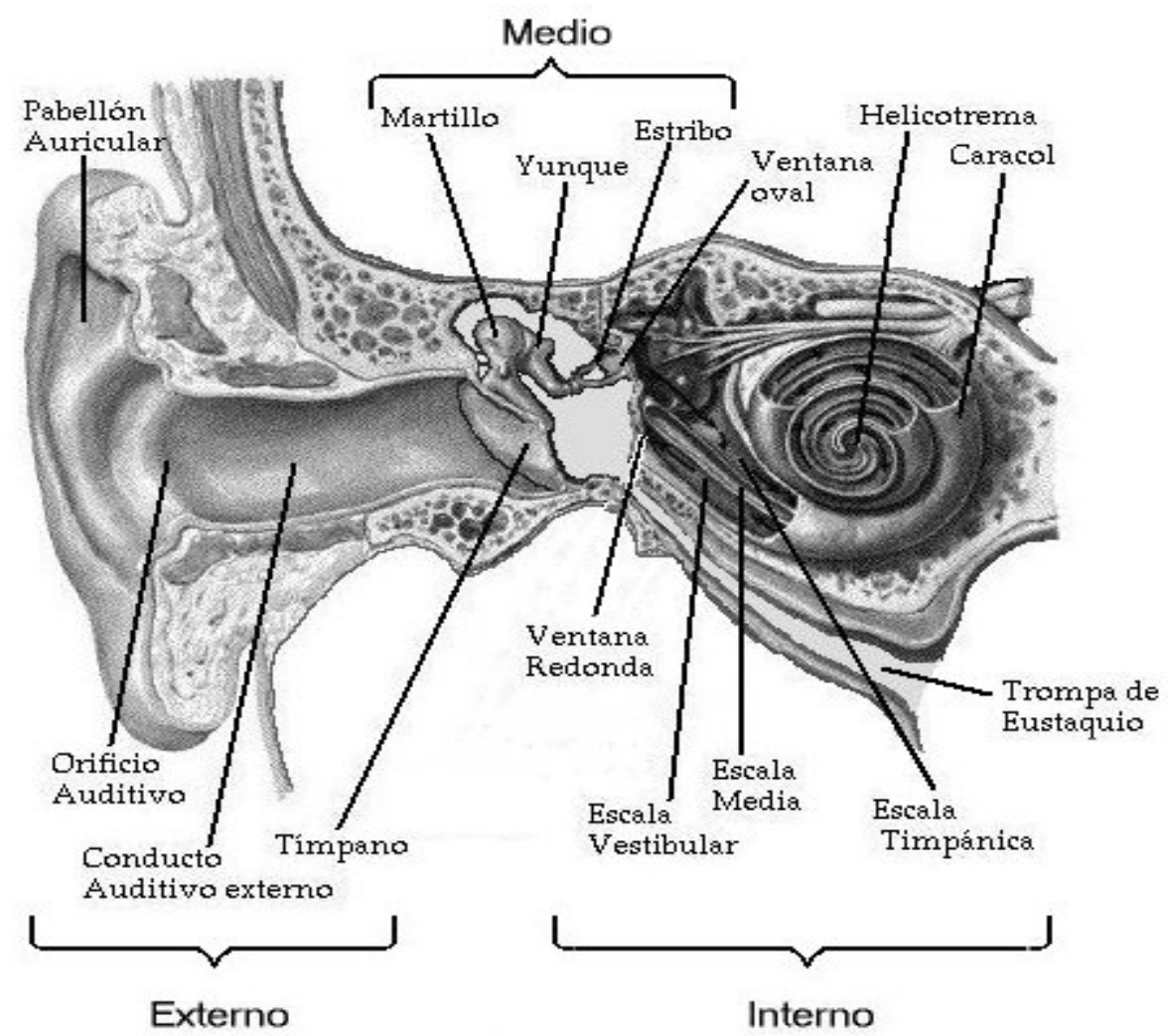

Fig. 3. 1. El sistema auditivo periférico y sus principales partes de las que esta compuesto.

\subsubsection{El Oído externo}

Está compuesto por el pabellón auricular u oreja y el conducto auditivo externo (ver la figura 3.1). El pabellón auricular está formado de piel y cartílago, que se caracteriza por tener diversas protuberancias, surcos y depresiones; este recolecta las ondas sonoras del ambiente y las conduce hacia al oído medio. El conducto auditivo externo sirve como una guía para la onda acústica, está abierto en el extremo del pabellón (inicio) y termina en la membrana timpánica; en el adulto tiene aproximadamente $25 \mathrm{~mm}$ de largo y $7 \mathrm{~mm}$ de diámetro, se estrecha hacia la mitad y se vuelve a ampliar cerca del tímpano, las dos terceras partes internas son óseas, mientras que el primer tercio es cartilaginoso [1][10][12].

\subsubsection{El Oído Medio}

El oído medio se muestra en la figura. 3.1, está constituido por una cavidad llena de aire, dentro de la cual se encuentran tres huesos pequeños (cadena oscicular), denominados martillo, yunque y estribo, unidos entre sí en forma articulada. Uno de los extremos del martillo se encuentra adherido al tímpano, mientras que la base del estribo está en contacto con el fluido de la escala vestibular a través de la ventana oval orificio que constituye la vía de entrada del sonido al oído interno, a su vez la escala timpánica desemboca en la cavidad del oído medio a través de otra abertura (ventana redonda) sellada por una membrana flexible [1][10][12]. 


\subsubsection{Liberación de presión}

La cavidad del oído medio se comunica con el exterior del cuerpo a través de la trompa de Eustaquio, la cual es un conducto que llega hasta las vías respiratorias (nasofaringe), es un canal de hueso recubierto por tejido blando de unos $35 \mathrm{~mm}$ de longitud. Las funciones que tiene es igualar la presión del aire a ambos lados del tímpano, permitir el paso de aire externo esencial para el metabolismo de los tejidos del oído medio y drenar los fluidos hacia la nasofaringe $[1][10][12]$.

\subsubsection{EI Oído I nterno}

El oído interno representa el final del procesamiento mecánico del sonido, en él se llevan a cabo tres funciones primordiales: filtrado (la señal sonora), transformación y generación probabilística (impulsos nerviosos) [1][10][13][14]. Esta formado por el laberinto óseo; Este se divide en tres partes: (a) los canales semicirculares (superior, lateral y posterior), (b) el vestíbulo y (c) la cóclea. Las dos primeras secciones alojan los órganos sensoriales del sistema vestibular, responsable del balance y postura del cuerpo. La cóclea o caracol es un conducto rígido en forma de espiral de unos $35 \mathrm{~mm}$ de longitud, enrollado sobre si mismo [1][10][12].

El interior del conducto coclear está dividido en sentido longitudinal por la membrana basilar y la membrana de Reissner, las cuales forman tres compartimientos o escalas (vestibular, media y timpánica) como se observa en la figura 3.2. La Escala Vestibular y la Escala Timpánica contienen un mismo fluido (perilinfa), puesto que se interconectan por una pequeña abertura situada en el vértice del caracol llamada helicotrema. La Escala Media se encuentra aislada de las otras dos escalas y contiene endolinfa la cual tiene concentración alta de potasio $\left(\mathrm{K}^{+}\right)$y baja en sodio $\left(\mathrm{Na}^{+}\right)[1][10][12]$.

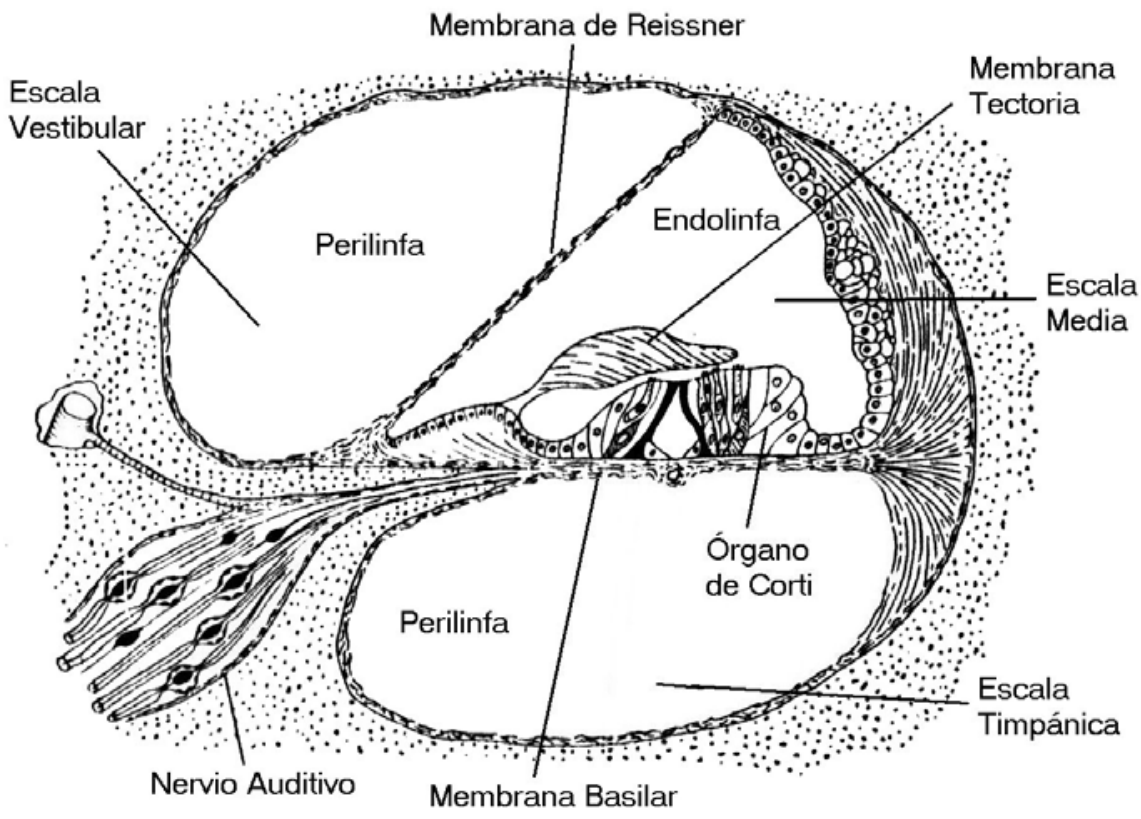

Fig. 3. 2. Corte transversal de la cóclea, donde pueden distinguirse las tres secciones en las cuales se divide, así como la ubicación del órgano de Corti y la membrana basilar. 


\subsubsection{Membrana Basilar}

La membrana basilar separa la rampa Timpánica y Media, se extiende desde el centro óseo de la cóclea hasta su pared externa. Se compone de fibras de tejido conectivo inmersas en una matriz acelular, las fibras están sujetas por sus extremos basales en la estructura ósea de la cóclea pero están libres en sus extremos distales. Como las fibras son rígidas y libres por un extremo, pueden vibrar como las lengüetas de una armónica. El ancho de la membrana basilar varía a lo largo del conducto coclear: es 10 veces más ancha en la base que en el ápice. Además es más rígido en la base que en el ápice, con rigidez variable de alrededor de dos órdenes de magnitud [1][10][11].

\subsection{6 Órgano de Corti y células ciliares}

Sobre la membrana basilar y en el interior de la escala media se encuentra el órgano de Corti (ver la figura 3.3), el cual se extiende desde el vértice hasta la base de la cóclea, el cual contiene las células sensoriales para la audición: las células ciliadas internas (IHC) y células ciliadas externas (OHC) que actúan como transductores de señales sonoras a impulsos nerviosos.

Se les llama ciliadas porque en la superficie superior de cada una de éstas células, presentan un "paquete" de "cilios", que en realidad son unas barras rígidas constituidas principalmente de actina, llamado estereocilia, las cuales se ubican en filas de longitudes crecientes. Las IHC se observan en una sola hilera (3500), mientras que las $\mathrm{OHC}$ se encuentran entre tres y cuatro hileras (20000) [1][10][11][16][21].

Sobre las células ciliares se ubica la membrana tectoria, dentro de la cual se alojan las prolongaciones o cilios de las células ciliares externas. Ambos tipos de células presentan conexiones o sinapsis con las fibras nerviosas aferentes (que transportan impulsos hacia el cerebro) y eferentes (que transportan impulsos provenientes del cerebro), las cuales conforman el nervio auditivo. Sin embargo, la distribución de las fibras es muy desigual: más del $90 \%$ de las fibras aferentes inervan a las IHC, mientras que las fibras eferentes inervan a las OHC. No obstante, si se lesionan las células externas mientras las internas permanecen funcionales, se produce una gran pérdida auditiva [1][10][11].

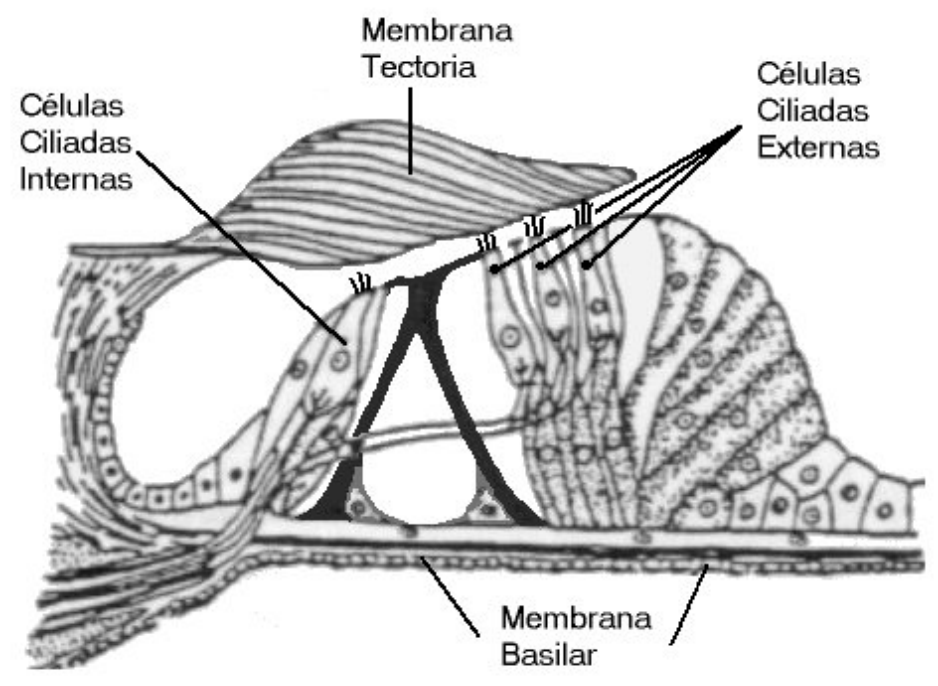

Fig. 3. 3. El Órgano de Corti y sus partes principales. 


\subsection{Respuesta en frecuencia y localización de las fuentes de sonido}

El pabellón auricular, junto con la cabeza y los hombros, contribuye a modificar el espectro de la señal sonora. El conducto auditivo influye en la respuesta en frecuencia del sistema auditivo. Dada la velocidad de propagación del sonido en el aire (aprox. $334 \mathrm{~m} / \mathrm{s}$ ), dicha longitud corresponde a 1/4 de la longitud de onda de una señal sonora de unos $4 \mathrm{kHz}$. Este es uno de los motivos por los cuales el aparato auditivo presenta una mayor sensibilidad a las frecuencias cercanas a los $4 \mathrm{kHz}[1]$.

Las señales sonoras que entran al conducto auditivo externo sufren efectos de difracción debidos a la forma del pabellón auricular y la cabeza, y estos efectos varían según la dirección de incidencia y el contenido espectral de la señal; si se altera el espectro sonoro debido a la difracción ("picos" y "valles"), estas alteraciones son usadas por el sistema auditivo para determinar la procedencia del sonido en el llamado "plano medio" (plano imaginario perpendicular a la recta que une ambos tímpanos) [1][10].

\subsubsection{Propagación del sonido y acople de impedancias}

Los sonidos son conducidos a través del conducto auditivo hasta el tímpano. Los cambios de presión en la pared externa de la membrana timpánica, asociados a la señal sonora, hacen que dicha membrana vibre siguiendo las oscilaciones de dicha señal. Las vibraciones del tímpano se transmiten a lo largo de la cadena oscicular (huesecillos), la cual opera como un sistema de palancas, de forma tal que la base del estribo vibra en la ventana oval.

La base del estribo se encuentra en contacto con uno de los fluidos contenidos en el oído interno (perilinfa); por lo tanto, el tímpano y la cadena de huesecillos actúan como un mecanismo que transforma las vibraciones del aire en vibraciones del fluido. La cadena oscicular actúa como un transformador de impedancias, permitiendo que la energía acústica sea transferida con poca pérdida hacia la ventana oval del oído interno. En la figura 3.4 se muestra un esquema de este proceso [1][10].

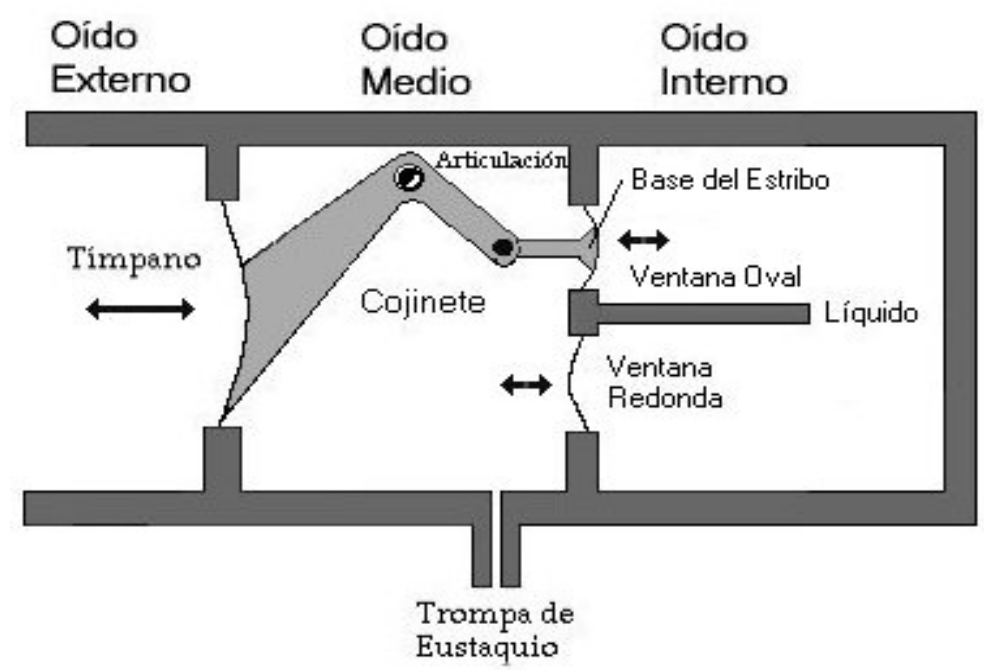

Fig. 3. 4. Esquema de la transmisión del sonido a través del oído medio, las flechan indican el desplazamiento del tímpano, la ventana oval y la ventana redonda. 
La fuente sonora en el aire produce una señal de baja presión y alta velocidad de volumen, mientras las propiedades mecánicas del oído interno demandan una señal de alta presión y baja velocidad de volumen. La transformación de impedancias es producida de dos maneras: el área de la membrana timpánica es mayor que la de la base del estribo y la otra, la longitud del martillo y el yunque produce una palanca cuya longitud es mayor del lado de la membrana timpánica que del lado de la ventana oval. En el humano la transformación de impedancias es de 20:1 y el máximo acoplamiento se obtiene en el rango de frecuencias medias, en torno a $1 \mathrm{kHz}$ [1][10][11][12].

\subsubsection{Respuesta en frecuencia del oído externo y el oído medio}

El conjunto formado por el oído externo y el oído medio forman un sistema cuya respuesta en frecuencia es de tipo pasa-bajos, como se muestra en la figura 3.5. En el intervalo cercano a los 4 $\mathrm{kHz}$ se observa un pequeño efecto de ganancia, debido a las características del conducto auditivo. Esta respuesta sólo es válida cuando el sistema se comporta de modo lineal.

Cuando se aplican sonidos de gran intensidad al tímpano ( $>90 \mathrm{~dB}$ SPL), los músculos tensores del tímpano y el estribo se contraen de forma automática (reflejo timpánico o auditivo), modificando la característica de transferencia del oído medio y disminuyendo la cantidad de energía entregada al oído interno, tiene como propósito proteger a las células receptoras del oído interno frente a sobrecargas que puedan llegar a destruirlas.

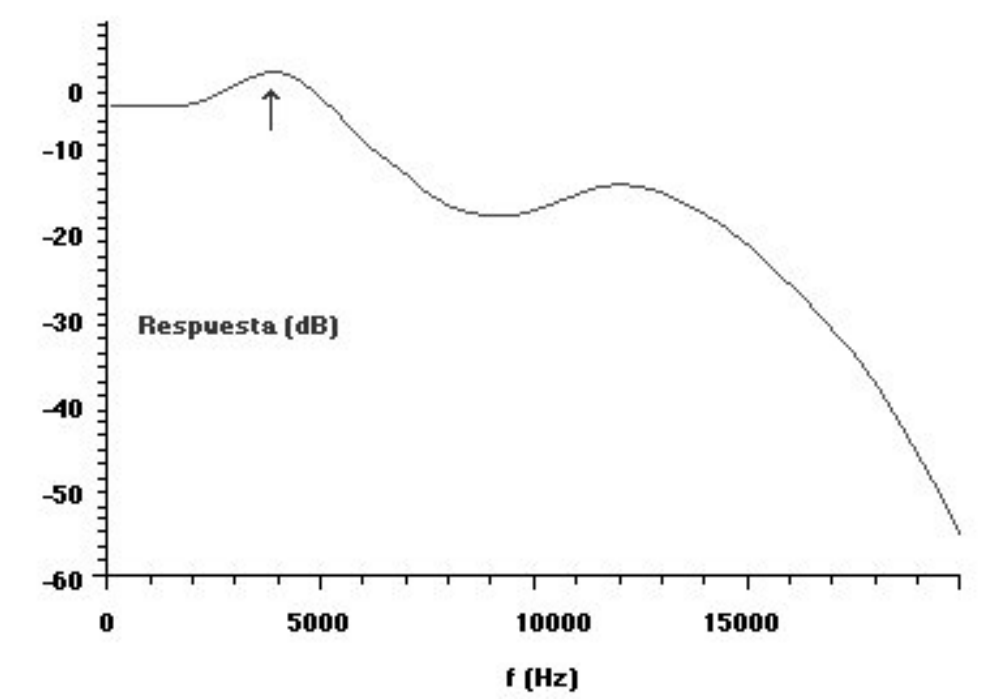

Fig. 3. 5. Este es el espectro en frecuencia combinado del oído externo e interno; la flecha indica la ganancia que se presenta gracias a las características del conducto auditivo externo, alrededor de $4000 \mathrm{~Hz}$.

\subsection{Propagación del sonido en la cóclea}

Las oscilaciones del estribo provocan oscilaciones en el fluido de la Escala Vestibular (perilinfa), como se observa en la figura. 3.4; aquí se lleva a cabo la transformación de energía mecánica en hidráulica. La membrana de Reissner, la cual separa los fluidos de la escala Vestibular y la escala Media, es sumamente delgada y en consecuencia, los líquidos en ambas escalas pueden tratarse como uno solo desde el punto de vista de la dinámica de los fluidos. 
Las oscilaciones en la perilinfa de la escala Vestibular se transmiten a la endolinfa y de ésta a la membrana basilar; esto es indicado por las flechas en la figura 3.6; la membrana basilar a su vez, provoca oscilaciones en el fluido de la escala timpánica. Puesto que tanto los fluidos como las paredes de la cóclea son incompresibles, es preciso compensar el desplazamiento de los fluidos; esto se lleva a cabo en la membrana de la Ventana Redonda, la cual permite "cerrar el circuito hidráulico". La propagación de las oscilaciones del fluido en la escala vestibular a la timpánica no sólo se lleva a cabo a través de la membrana basilar; para sonidos de muy baja frecuencia, las vibraciones se transmiten a través de la abertura situada en el vértice de la cóclea (helicotrema) [10].

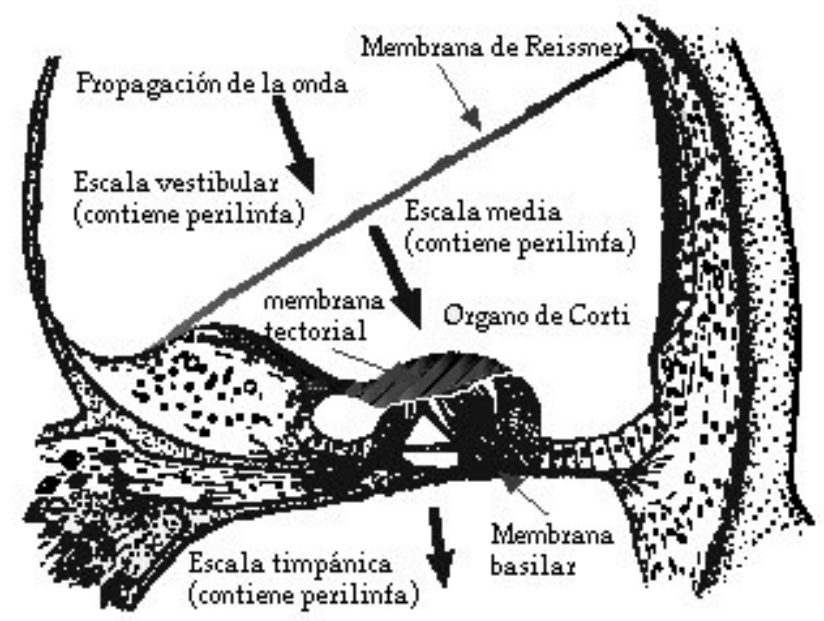

Fig. 3. 6. Las flechas muestran el sentido de la propagación del movimiento, en el interior de la cóclea.

La membrana basilar es una estructura cuyo espesor y rigidez no es constante: cerca de la Ventana Oval, la membrana es gruesa y rígida, pero a medida que se acerca hacia el vértice de la cóclea se vuelve más delgada y flexible; esta variación de la rigidez afecta la velocidad de propagación de las ondas sonoras a lo largo de ella y es responsable en gran medida de un fenómeno muy importante: la selectividad en frecuencia del oído interno. La selectividad en frecuencias se refiere a que cada célula responde mejor a un angosto rango de frecuencias (ver la figura 3.8) [1][9][15].

\subsubsection{Ondas viajeras y transformación de frecuencia a posición}

Las ondas de presión generadas en la perilinfa a través de la Ventana Oval tienden a desplazarse a lo largo de la Escala Vestibular. Debido a que el fluido es incompresible la membrana basilar se deforma, así, la ubicación y amplitud de dicha deformación varía en el tiempo a medida que la onda de presión avanza a lo largo de la cóclea.

Para comprender el modo de propagación de las ondas de presión, supóngase que se excita el sistema auditivo con una señal tal como un "click", inicia una "onda viajera":

La membrana basilar vibrará pero la amplitud de la vibración irá en aumento a medida que se aleja de la ventana oval (debido a la variación en la velocidad de propagación), hasta llegar a un 
punto en el cual la deformación de la membrana basilar sea máxima; en ese punto de "resonancia", la membrana basilar es acústicamente "transparente" (es decir, se comporta como si tuviera un orificio), de modo que la amplitud de la vibración y por ende, la transmisión de la energía de la onda al fluido de la Escala Timpánica es máxima en dicho punto, a partir de esa región, la onda no puede propagarse eficientemente, de modo que la amplitud de la vibración se atenúa muy rápidamente a medida que se acerca al helicotrema. Esto puede apreciarse en la figura 3.7 donde se señala la "onda viejera" sobre la membrana basilar [10][21].

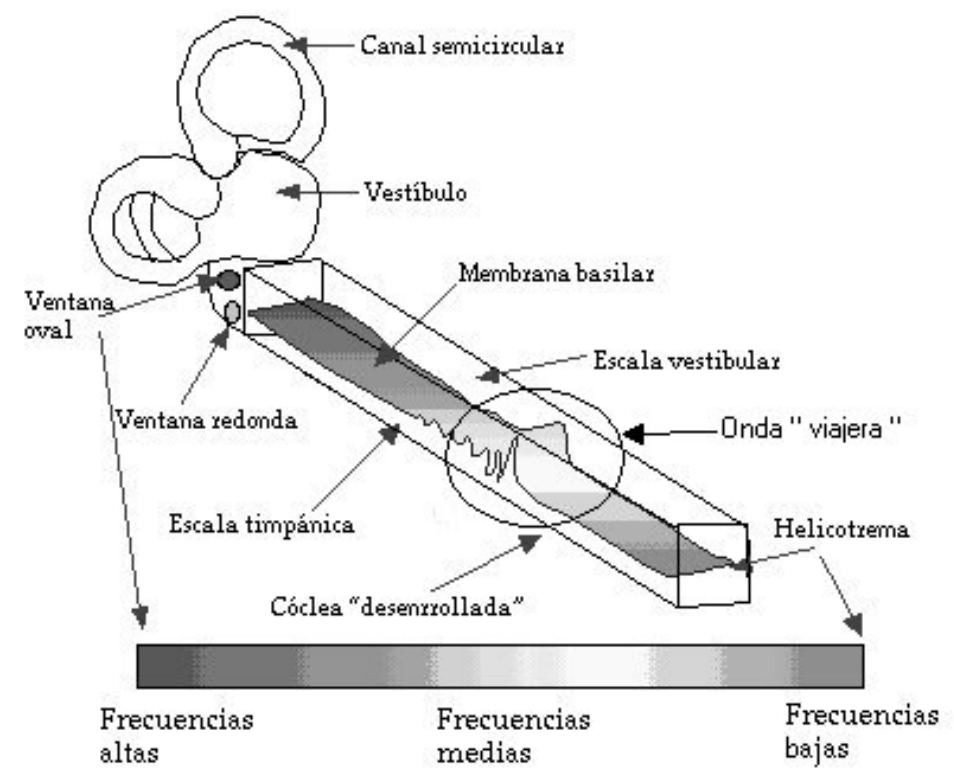

Fig. 3. 7. La membrana basilar observada en un instante de tiempo después de aplicarle el estímulo acústico, donde se observa el desplazamiento de la onda viajera, que va desde la base hasta el helicotrema.

En la figura 3.8 (A) se observa la amplitud de oscilación de la membrana basilar en dos instantes de tiempo, junto con la envolvente de la onda viajera, en función de la distancia al estribo. La ubicación del máximo de la envolvente de la onda viajera depende de la frecuencia de la señal sonora, como puede observarse en la figura 3.8 (B): mientras menor es la frecuencia del tono, mayor es la distancia que viaja la onda a lo largo de la membrana basilar antes de ser atenuada, y viceversa. De esta forma, la membrana basilar dispersa las distintas componentes de una señal de espectro complejo en posiciones bien definidas respecto a la ventana oval [1] [10].

La membrana basilar tiene una estructura distribuida, que actúa como una línea de retraso, como se sugiere por la naturaleza de la onda viajera. La combinación de sus propiedades mecánicas produce una respuesta que demuestra un desplazamiento dependiente de la distancia cuando el oído es estimulado. Como las altas frecuencias contenidas en un estímulo sonoro se atenúan a medida que la onda se desplaza hacia el helicotrema, la membrana basilar se puede considerar a como un filtro pasa-bajos. Por otro lado, si se midiese la respuesta en frecuencia en un punto dado de dicha membrana, se obtendría una respuesta de tipo pasa-banda [1][10]. 
Amplitud

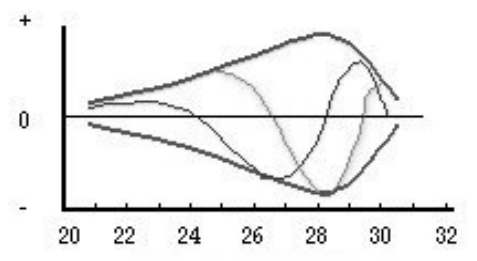

Distancia al estribo en $(\mathrm{mm})$
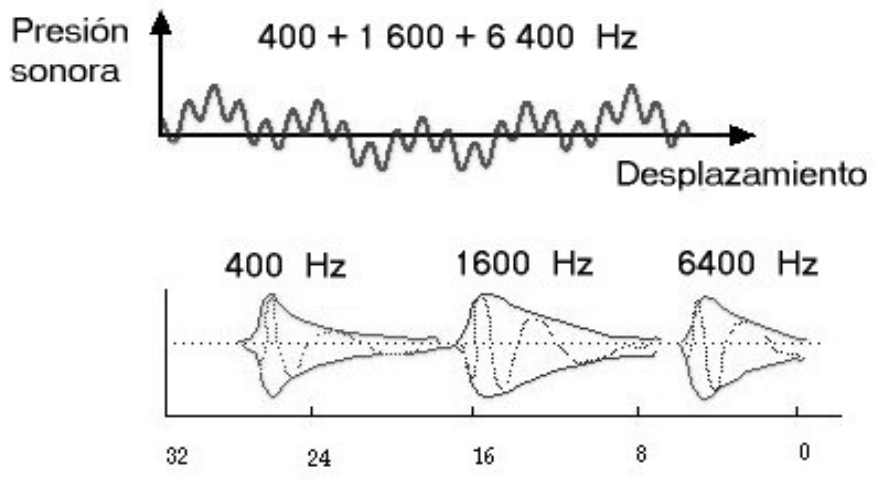

Distancia a la ventan oval $(\mathrm{mm})$

\section{( A )}

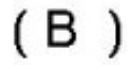

Fig. 3. 8. La envolvente máxima de la membrana basilar depende de la frecuencia de estímulo; cerca de la base responde a altas frecuencias mientras que cerca del ápice lo hace para bajas frecuencias.

\subsubsection{Mecanismo de transducción}

El proceso de transducción o conversión de señal mecánica a electroquímica se desarrolla en el órgano de Corti, situado sobre la membrana basilar; las vibraciones de la membrana basilar hacen que ésta se mueva en sentido vertical, a su vez la membrana Tectoria ubicada sobre las células ciliares (los transductores), vibra igualmente; sin embargo, dado que los ejes de movimiento de ambas membranas son distintos, el efecto final es el de un desplazamiento "lateral" de la membrana Tectoria con respecto a la membrana basilar. Como resultado, los cilios de las OHC se "doblan" hacia un lado u otro como se muestra en la figura 3.9. En el caso de las IHC, aun cuando sus cilios no están en contacto directo con la membrana Tectoria, los desplazamientos del líquido y su alta viscosidad (relativa a las dimensiones de los cilios) hacen que dichos cilios se doblen también en la misma dirección [1][10][21].

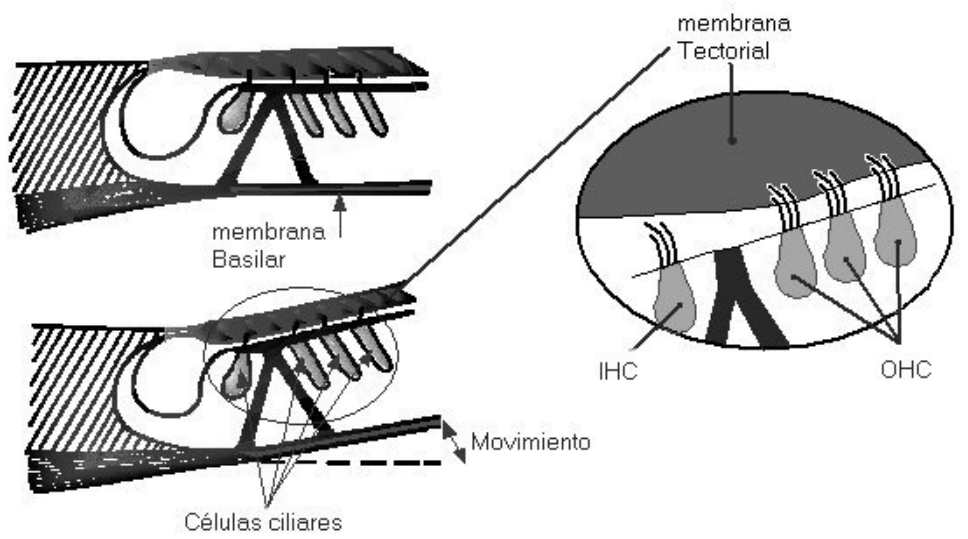

Fig. 3. 9. Detalle del movimiento de los cilios al moverse la membrana basilar; en el detalle se muestra como los cilios de las $\mathrm{OHC}$ se encuentran inmersos en la membrana Tectoria. 


\subsubsection{Células ciliares y potenciales eléctricos}

Los movimientos de los cilios (aproximadamente $100 \mathrm{~nm}$ ) [9] en una dirección determinada, hacen que la conductividad de la membrana de las células ciliares aumente debido a las diferencias de potencial existentes (la perilinfa: $0 \mathrm{mV}$, endolinfa: $+80 \mathrm{mV}$ ), los cambios en la membrana celular modulan una corriente eléctrica que fluye a través de las células ciliares. La consiguiente disminución en el potencial interno de las células internas provoca la activación de las terminales nerviosas aferentes, generándose un impulso nervioso que viaja hacia el cerebro. Por el contrario, cuando los cilios se doblan en la dirección opuesta, la conductividad de la membrana disminuye y se inhibe la generación de dichos impulsos. El movimiento voltajedependiente en la transducción de las células ciliares del oído interno es el componente fundamental del proceso de la audición [9][10][21].

En el proceso de la audición, la generación de impulsos nerviosos es un fenómeno probabilístico y además se comporta como un rectificador de media onda, puesto que la probabilidad de activación de las fibras nerviosas "sigue" a las porciones "positivas" de la señal sonora (desplazamientos hacia "arriba" de la membrana basilar), mientras que se hace cero en las porciones "negativas" de la onda.

Las IHC son los verdaderos "sensores" del oído por tener más conexiones con las fibras aferentes; por el contrario, el papel de las OHC operan como elementos móviles que pueden modificar las oscilaciones en la membrana basilar, es decir, actúan como un control automático de ganancia: Las OHC para intensidades elevadas de señales, el movimiento del fluido que rodea a los cilios de estas células es suficiente para doblarlos y se saturan. Sin embargo cuando los niveles de la señal son bajos, el desplazamiento de los cilios de las IHC, son muy pequeños para activarlas, en este caso, las $\mathrm{OHC}$ se a "largan" aumentando la magnitud de las oscilaciones hasta que se saturan. Este es un proceso no lineal de realimentación positiva de la energía mecánica [1] [9][10][11][21].

Este nuevo modelo del mecanismo de transducción nos indica que el conjunto formado por la membrana basilar y sus estructuras anexas forman un sistema activo, no lineal y con realimentación, esto permite explicar dos fenómenos asociados al oído interno: el "tono de combinación (Productos de Distorsión)", generado a partir de dos tonos de distinta frecuencia por un elemento no lineal y las OAE, las cuales consisten en tonos generados en el oído interno en forma espontánea o estimulada que pueden llegar a ser audibles.

\section{- Células Ciliadas Internas}

Las IHC no están adheridas a la membrana tectoria, así su respuesta al movimiento de la membrana es proporcional al cambio de velocidad más que al desplazamiento mismo, debido a que los cilios de las células ciliadas están bañadas por la endolinfa. Cuando la membrana vibra selectivamente en respuesta a tonos puros, la estereocilia se curva un poco lo que se despolarizan en respuesta al evento mecánico. Así la organización tonotópica de la membrana basilar es transferida a las células ciliadas y al resto del sistema auditivo. El sistema auditivo está organizado tonotópicamente, es decir, cada porción de la cóclea analiza una frecuencia del estímulo, por esto la cóclea puede ser mapeada a través de niveles sucesivos del estímulo. La 
sintonía del sistema auditivo depende de las características mecánicas de la membrana basilar modificada por la actividad de las OHC [10].

- Células Ciliadas Externas

Las OHC tienen cilios que están adheridos a la membrana tectoria, ellas no transfieren información al cerebro pero modulan su acción mecánica por información recibida por éste. Las OHC juegan un papel activo en los procesos del oído interno. Primero, las OHC cambian su longitud en respuesta a neurotransmisores. Segundo, la observación de las células de Henson, células pasivas que están íntimamente conectadas a las $\mathrm{OHC}$, muestran que las vibraciones espontáneas son producidas por las células de Henson y probablemente también por las OHC. Esas vibraciones presentan picos espectrales que son apropiados en frecuencia a su localización en la membrana basilar. Tercero, la acción de las OHC como amplificadores, conduce a emisiones oto-acústicas espontáneas y un cambio en la respuesta del sistema auditivo. Cuarto, una excitación de corriente alterna (AC) sobre las $\mathrm{OHC}$ de mamíferos produce cambios en longitud [10].

\subsection{Emisiones oto-acústicas (OAE)}

Cuando un estímulo acústico golpea el tímpano, se inicia un movimiento oscilatorio en la estructura oscicular del oído medio que a su vez se trasmite al oído interno, después ocurre una "reflexión" parcial de la onda desde la cóclea, generando un movimiento en el tímpano como respuesta al estímulo (OAE).

David Kemp publicó la primer descripción científica de las OAE en 1978, también demostró que éstas están reducidas o ausentes en casos con ciertos tipos de pérdida auditiva [18]. Las OAE son sonidos de bajo nivel, producidos por el oído interno como parte del proceso normal de la audición y pueden ser medidas con un micrófono muy sensible colocado en el canal auditivo externo [18] - [21].

Las OAE describen la respuesta que la cóclea emite en forma de energía acústica; aunque más propiamente hablando, proporcionan información acerca del estado de las $\mathrm{OHC}$, quienes son las responsables de proporcionar una fuente activa de energía mecánica que influye en el movimiento de la membrana basilar [10][19].

\subsubsection{Clasificación}

Los diferentes tipos de OAE están estrechamente relacionados al mismo proceso de generación, que es la base de la función de transducción de una señal en la cóclea; las diferentes clases de OAE son distinguidas para separar el tipo de respuesta sólo como un medio de organizar la creciente literatura en este campo del conocimiento.

Las OAE pueden ser clasificadas de acuerdo a varios esquemas [19]. Primero: las OAE pueden ser clasificadas respecto a su latencia siguiente al inicio del estímulo. Segundo: las OAE pueden ser clasificadas con respecto a la estabilidad de los patrones observados en el dominio de 
frecuencia. De acuerdo a este esquema, algunas emisiones tienen patrones relativamente estables en frecuencia. Tercero: define los tipos de OAE de acuerdo al tipo de estimulación acústica que las evoca.

Para clasificar las OAE de acuerdo al tipo de estímulos que las provocan, se distinguen dos clases: las espontáneas (SOAE), que se presenta sin estimulación externa y las transitorias (TEOAE), evocadas por diferentes tipos de estimulación acústica. Estas últimas pueden ser además divididas en tres subclases de acuerdo al tipo particular de estimulación que la produce: transitorias evocadas por click's (CEOAE) o tonos (TBOAE), por estímulo en frecuencia (SFOAE) y productos de distorsión (DPOAE); los procedimientos de registro son únicos para cada clase de OAE [19][20]. En el presente trabajo se utilizaron las EOA evocadas por click para continuar con la línea de investigación del laboratorio de audiología de la Universidad Autónoma Metropolitana, unidad Iztapalapa.

\subsubsection{Características de las CEOAE}

Las CEOAE presentan características típicas como crecimiento lineal y no lineal, saturación para niveles moderados de estimulación, dispersión en frecuencia y latencia con respecto al estímulo que las evoca. Con estímulos como click se puede obtener una cantidad máxima de información de banda ancha $(0-10.0 \mathrm{kHz})$ [19][22]; aunque es claro que la respuesta producida por ese estímulo puede ser difícil de detectar en algunos oídos, probablemente porque la interferencia de la fase de los componentes vecinos de OAE se cancelan [19]. En seguida se listan las características más importantes.

\section{1.- Prevalencia en sujetos sanos.}

\section{a). Adultos:}

o Han sido medidas en $98 \%$ de oídos con audición normal, parecen ser una propiedad general del sistema auditivo periférico humano, aunque algunos oídos con audición normal no las presentan.

o En oídos con pérdidas auditivas mayor a $30 \mathrm{~dB}$ HL no se detectan [18].

- Los dos oídos de un sujeto tienden a mostrar CEOAE similares con respecto a la forma de onda, número de frecuencias dominantes, duración y detección del umbral.

o No presentan una morfología definida, sin embargo son consistentes en el tiempo (se mantienen sin variar significativamente en el sujeto).

o Crecimiento no lineal; ocurre para niveles de estímulo mayores a $30 \mathrm{~dB}$ SL.

- Las CEOAE se pueden registrar a diferentes ventanas de tiempo, desde unos pocos milisegundos hasta varios cientos de milisegundos, posteriores a la presentación del estímulo. Así se ha seleccionado de manera empírica una ventana de observación de 20 ms para registrarlas. 
o La sobreestimulación a una frecuencia determinada (cuando se utilizan tonos), causa un decremento en la amplitud de las TEOAE para la frecuencia utilizada (saturación).

\section{b) infantes:}

- Las características de las CEOAE de los infantes y neonatos son similares a los reportados en adultos.

o El espectro de frecuencia despliega mayor cantidad de componentes de alta frecuencia que las obtenidas en el adulto.

o Son de mayor amplitud con respecto al adulto.

\section{2.- Componentes de frecuencia:}

o Debido al amplio espectro del estímulo (click), las CEOAE contienen varios componentes de frecuencias que presentan distintas latencias, amplitudes, duración y umbral.

- En la mayoría de los oídos normales, las CEOAE están dominadas por unas pocas frecuencias específicas en el rango de 0.5 a $4.0 \mathrm{kHz}$ que pueden variar en número y frecuencia de un sujeto a otro.

o Las componentes de frecuencias se suman linealmente. La respuesta al estímulo click puede ser reproducida en gran medida por la suma de las respuestas de tonos individuales localizados en las frecuencias dominantes.

\section{3.- Latencia:}

Determinar latencias de manera precisa no es posible cuando se analiza una respuesta no lineal compleja tal como CEOAE. Los valores de latencia de CEOAE reportados en la literatura están en el rango de 10-16 ms para frecuencias alrededor de $1 \mathrm{kHz}$. La latencia específica de las CEOAE es substancialmente mayor que aquellas medidas de los potenciales de acción compuestos

o Cuando se utilizan estímulos de banda ancha (clicks), las componentes de altas frecuencias de estimulación producen CEOAE con latencias cortas, las bajas frecuencias de estimulación producen CEOAE con latencias largas.

o Cada ciclo del tono de estimulación evoca componentes de TEOAE que se suman linealmente para resultar en latencias constantes.

\subsubsection{Método de Registro}

El componente principal de todos los sistemas dedicados a medir las CEOAE es una sonda acústica que incorpora un micrófono muy sensible y una pequeña bocina para presentar el estímulo acústico, esta sonda se acopla en el canal auditivo externo, como se muestra en la figura 3.10. Debido a que la magnitud de la respuesta de la mayoría de las OAE es de muy bajo nivel, la 
sensibilidad y el ruido de fondo del micrófono son de importancia crítica para determinar la calidad del sistema de medición de las CEOAE [17][19].

El ruido acústico de fondo en el canal auditivo es generado por el ruido del cuerpo que es de baja frecuencia. Esos ruidos, asociados con el flujo sanguíneo, respiración, contracción muscular y el movimiento del juego mandibular, son responsables del relativo alto ruido de fondo intrínseco en la región de frecuencia inferior a $400 \mathrm{~Hz}$ [19].

La sonda acústica para medir las CEOAE, debe incorporar un medio para presentar el estímulo (bocina), idealmente con una respuesta en frecuencia relativamente plana, en el rango de 0.3 a 8 $\mathrm{kHz}$, donde pueden ser obtenidas las CEOAE por el micrófono de registro, ubicado junto con la bocina en el extremo de la "sonda", que a su vez se coloca en el canal auditivo externo [19].

Para el registro de CEOAE comúnmente se usan estímulos acústicos transitorios rectangulares de $80 \mu \mathrm{sec}$ (clicks). La señal es adquirida por el micrófono en un ancho de banda de $0.3 \mathrm{a} 8.0 \mathrm{kHz}$, luego es promediada de forma síncrona con la presentación del estímulo [17][19].

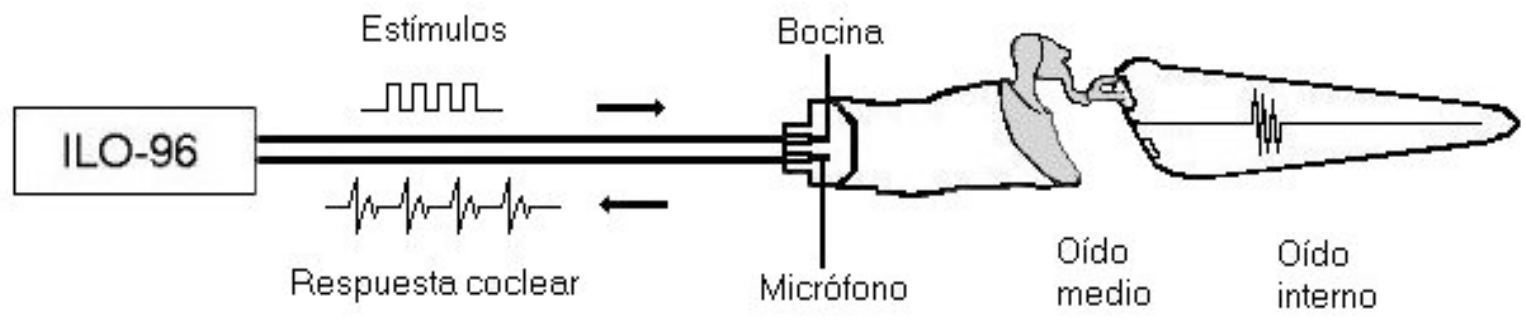

Figura 3.10. Esquema simplificado del método de registro de las CEOAE. Se puede apreciar que el micrófono utilizado para registrar la respuesta coclear y la bocina para emitir el estímulo, se encuentran en el extremo de la sonda que se coloca en el canal auditivo externo.

\subsubsection{Aplicaciones Clínicas las CEOAE}

Las CEOAE poseen un gran potencial para el estudio no invasivo y objetivo de los mecanismos de la función coclear. El atributo no invasivo del método de registro, permite realizar repetidas medidas sobre periodos largos de tiempo, sin interferir con el modo normal de funcionamiento de la cóclea y tal procedimiento promete ser una importante herramienta de investigación en la ciencia auditiva [19].

Las CEOAE sólo requiere de la cooperación pasiva del paciente para su registro y siendo una técnica rápida, precisa y objetiva. El resultado de las CEOAE "no determina el nivel de la pérdida auditiva", sino detecta la presencia o ausencia de respuesta coclear. La ausencia de CEOAE o su presencia disminuida significa un daño auditivo; su capacidad para detectar pérdida auditiva tiene una especificidad aproximada del 80\% [19].

La mayoría de las disfunciones auditivas periféricas, involucran hipoacusia inducida por ruido, ototóxicos o pérdidas auditivas hereditarias, originándose principalmente en los componentes sensoriales de la cóclea. Las CEOAE pueden complementar la mayoría de los métodos clínicos estándares (ABR) al contribuir con nuevas técnicas para la medición audiométrica del estado del sistema auditivo periférico [19]. 
Como las CEOAE analizan la parte periférica del sistema auditivo y el estudio de ABR analizan la parte de la vía auditiva central, ambos estudio son complementarios para analizar todo el sistema auditivo. Las tecnologías de ABR y CEOAE han sido exitosamente utilizadas en exploraciones universales de la capacidad auditiva y ambos son registros no invasivos de la actividad fisiológica que se basan en una función auditiva normal. También ambas medidas están altamente correlacionadas con el grado de "sensibilidad auditiva periférica" [1].

Siendo los ABR una herramienta de evaluación de la vía auditiva central y que no depende de la colaboración del paciente, representan junto con las técnicas de CEOAE, la herramienta ideal para la evaluación de la vía auditiva en recién nacidos, permitiendo así la identificación temprana de disfunciones auditivas en esta población, así el unificar estas técnicas de análisis se puede mejorar la objetividad y sensibilidad del análisis del sistema auditivo completo [1][5].

\subsubsection{Desventajas de las CEOAE}

Las CEOAE son sensibles a la disfunción de las OHC y esta técnica puede ser usada para detectar pérdidas auditivas sensoriales. Las CEOAE, son registros fiables cuando se obtienen en repuestas a estímulos de intensidades altas (80 dBsPL), sin embargo, las CEOAE son sensibles a obstrucciones del canal externo y a secreciones del oído medio. Por esta razón, las disfunciones a nivel Tallo Cerebral (conductivas) temporales pueden causar un resultado de prueba "positivo" cuando exista una adecuada función coclear. Por otro lado, debido a que las CEOAE son respuestas mecánicas generadas dentro de la cóclea, la evaluación con CEOAE no detecta disfunciones nerviosas en el octavo nervio o la vía auditiva del tallo cerebral. Por esta razón, infantes con neuropatías o desordenes de conducción no serán detectados por las CEOAE [19][21]. 


\section{Consideraciones sobre la estimulación y la señal adquirida}

\subsection{Protocolo de estimulación}

Se refiere a la manera de presentar el estímulo acústico para la obtención de las emisiones otoacústicas. Con la finalidad de analizar las características de las CEOAE en el presente trabajo se consideraron dos protocolos de estimulación: lineal y no lineal. En ambos protocolos la polaridad de la estimulación cambia aleatoriamente a fin de evitar ondas estacionarias en el interior del conducto auditivo externo.

El estímulo acústico que el ILO-96 presenta desde el inicio del registro es un click, pulso cuadrado de $80 \mu$ s de duración, que posee un espectro de banda suficientemente ancha para permitir la obtención de una respuesta coclear en el intervalo de 500 a $6000 \mathrm{~Hz}$ [17].

\subsubsection{Estimulación Lineal}

La estimulación lineal consiste en presentar cuatro clicks del mismo tamaño y de la misma polaridad como se muestra en la figura 4. 1, cuando cambia la polaridad de la estimulación, se invierte el "paquete" de los cuatro estímulos. En este modo de estimulación se realzan las características lineales de la CEOAE, que de acuerdo a la literatura presentan un crecimiento lineal para niveles bajos y medios de estimulación, esto es entre 40 y 60 dB SPL Pe; para intensidades mayores las CEOAE se saturan. La desventaja de este protocolo es que las CEOAE se contaminan muy fácilmente con la parte final del estímulo y no se puede determinar con seguridad donde termina el estímulo y donde comienza la respuesta coclear, ya que se suma la parte final del estímulo y el principio de la respuesta coclear en los primeros milisegundos posteriores al estímulo [23].

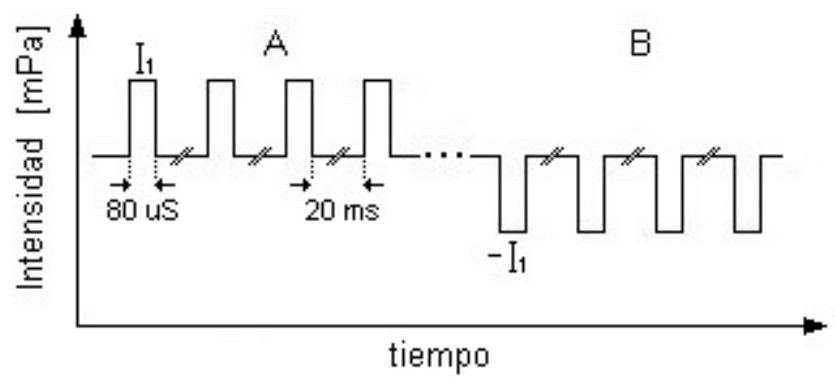

Figura 4. 1. Representación de los paquetes presentados en el protocolo de estimulación Lineal. $I_{1}$ e $I_{2}$ son de la misma amplitud pero de polaridad opuesta, los clicks del primer paquete (A) son de polaridad positiva y los del segundo (B) son de polaridad negativa.

\subsubsection{Estimulación No Lineal}

La estimulación no lineal consiste en la presentación de tres clicks de tamaño y polaridad determinada más un cuarto click tres veces mayor a los primeros y de polaridad opuesta, como se 
muestra en la figura 4.2. Estudios realizados sobre la relación de 3:1 que guarda este protocolo de estimulación refieren que con esta relación se obtiene la óptima relación señal-ruido (SNR) para la señal adquirida [23][25][21][23].

El procedimiento de estimulación no lineal, cancela la parte lineal de la OAE para resaltar la parte no-lineal de la misma. Estos procedimientos que utilizan cancelación lineal proporcionan también la verificación de la existencia de las CEOAE. Las técnicas de cancelación lineal están basadas en el crecimiento no-lineal de las CEOAE que muestran una fuerte saturación para niveles de estímulos moderados y altos (mayores de $60 \mathrm{~dB}$ SPL) [19].

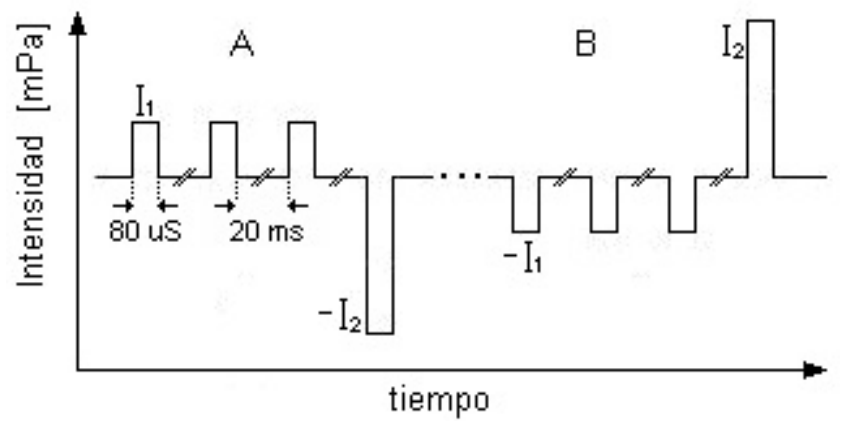

Figura 4. 2. Representación de los estímulos individuales que forman los paquetes presentados en el protocolo de estimulación No-Lineal. $I_{2}$ es 3 veces mayor que $I_{1}$; en (A) $\mathrm{I}_{1}$ es positivo e $\mathrm{I}_{2}$ negativo, en (B) las polaridades son opuestas.

Este protocolo de cancelación de componentes lineales fue utilizada por Kemp y colaboradores, de tal manera que el artefacto del estímulo y su interferencia, que contamina nuestra señal de interés, se cancelan después de la presentación de cada grupo de cuatro clicks [19][23][25].

\subsubsection{El método no lineal}

Se desarrolló para poder analizar las propiedades no lineales de las OAE. Se fundamente en el hecho de que los "artefactos" acústicos poseen un comportamiento lineal, sin embargo la respuesta colcear es de naturaleza "no-lineal". Ahora, considerando las respuestas producidas por un tren de estímulos con tres clicks de intensidad $\mathbf{I}_{\mathbf{1}} \mathrm{y}$ un cuarto click con una intensidad $\mathbf{I}_{2}=-3 \mathbf{I}_{1}$. Se asume que las respuestas producidas por los dos estímulos de intensidad $\mathbf{I}_{\mathbf{1}}$ e $\mathbf{I}_{\mathbf{2}}$ son $\mathbf{R}_{\mathbf{1}}(\boldsymbol{t})$ y $\mathbf{R}_{\mathbf{2}}(\boldsymbol{t})$ respectivamente. Si la respuesta $\mathbf{R}_{\mathbf{C}}(\boldsymbol{t})$ para cualquier estímulo dado no esta linealmente relacionada con el estímulo de entrada, puede escribirse como la suma de la parte lineal $\mathbf{L}(\boldsymbol{t})$ y de una parte no-lineal $\mathbf{N L}(\mathbf{t})$.

$$
\mathrm{R}_{\mathrm{X}}(t)=\mathrm{L}(t)+\mathrm{NL}(t)
$$

La cancelación de la parte lineal $\mathbf{L}(\boldsymbol{t})$ puede ser obtenida al promediar las respuestas elicitadas mediante el siguiente algoritmo sea:

$$
\mathrm{R}_{1}(t)=\mathrm{L}_{1}(t)+\mathrm{NL}_{1}(t)
$$


la respuesta a los estímulos de amplitud y polaridad $\mathrm{I}_{1}$. Así mismo

$$
\mathrm{R}_{2}(t)=\mathrm{L}_{2}(t)+\mathrm{NL}_{2}(t)
$$

la respuesta a los estímulos de amplitud y polaridad $\mathrm{I}_{2}$.

La respuesta derivada no lineal (RDNL), es el promedio de las ecuaciones (2) y (3)

$$
R D N L(t)=\frac{3 R_{1}(t)+R_{2}(t)}{4}
$$

donde por ser un sistema invariante en el tiempo (superposición)

$$
R D N L(t)=\frac{3\left[L_{1}(t)+N L_{1}(t)\right]+L_{2}(t)+N L_{2}(t)}{4}
$$

tomando en cuenta que la parte lineal de la respuesta será proporcional a la intensidad del estímulo y su signo, tenemos: $\mathrm{L}_{2}(t)=-3 \mathrm{~L}_{1}(t)$, por lo tanto (5) se puede reescribir como:

$$
R D N L(t)=\frac{3\left[L_{1}(t)+N L_{1}(t)\right]-3 L_{1}(t)+N L_{2}(t)}{4}
$$

Simplificando

$$
R D N L(t)=\frac{3 N L_{1}(t)+N L_{2}(t)}{4}
$$

Ahora, si suponemos que las respuestas están saturadas, entonces

$$
\mathrm{NL}_{2}(t) \approx-\mathrm{NL}_{1}(t)
$$

Así al sustituir (8) en la ecuación (7) el promedio de $\operatorname{RDNL}(t)$ estaría dado por

$$
\operatorname{RDNL}(t) \approx \mathrm{NL}_{1}(t) / 2
$$

En el método propuesto por Kemp e implementado en el equipo de registro "ILO-96" la respuesta final es multiplicada por un factor de 2 , de manera que la respuesta final es

$$
\operatorname{RDNL}(t) \approx \mathrm{NL}_{1}(t)
$$

Las suposiciones esenciales en las cuales el método se basa son:

i) Aditividad de los componentes lineal y no-lineal de la respuesta

ii) Saturación de la respuesta con el nivel de estímulo.

i) La aditividad de los componentes lineal y no-lineal de la respuesta, es decir la respuesta $\mathbf{R}_{\mathbf{x}}(t)$ para un estímulo dado puede ser descompuesta en la suma de una parte lineal $\mathbf{L}(t)$ y una parte nolineal $\mathbf{N L}(\boldsymbol{t})$. Sin embargo el método RDNL no sólo cancela la señal $\mathbf{L}(\mathbf{t})$, sino también la señal NL(t). 
ii) Esta suposición se basa en considerar que las respuestas están saturadas para ambos estímulos, $\left(\mathrm{NL}_{1} \approx \mathrm{NL}_{2}\right)$.

Sin embargo, utilizando la promediación clásica, se ha visto que las CEOAE se saturan sólo para niveles de intensidad media a alta, pero para respuestas de intensidades baja a media $(<20 \mathrm{dBSL})$ se comporta linealmente.

En este caso la suposición ii ya no se cumple, en cambio tenemos que $\mathrm{NL}_{1} \neq \mathrm{NL}_{2}$, y el resultado final del método $\operatorname{RDNL}(t)$ toma la siguiente expresión:

$$
R D N L(t)=\frac{3 N L_{1}(t)+N L_{2}(t)}{2}
$$

Es decir, para niveles de intensidad media a baja, la salida del método $\operatorname{RDNL}(t)$ es una suma ponderada sólo de las componentes remanentes no canceladas después del proceso de promediación coherente por estimulación no-lineal.

\subsubsection{Promediación coherente}

La SNR es un parámetro importante en la estimación de señales embebidas en ruido, esto es, la relación de la energía de la señal con respecto al energía del ruido. La técnica de promediación coherente es una técnica estándar utilizada para mejorar la relación SNR de señales bioeléctricas repetitivas tal como los $A B R$ y las $O A E$, entre otras.

Cuando un estímulo sensorial (luz o sonido) se presenta a un sujeto, se evoca una respuesta eléctrica y se asume que esta respuesta está sincronizada a la presentación del estímulo, para mejorar la relación señal ruido se incrementa el número de respuestas utilizadas en el promedio. El modelo matemático utilizado aquí, esta basado en el estudio de Potenciales Evocados (PE), pero pueden ser aplicados a otro tipo de datos como lo sugiere Jonathan Raz et al [24].

La señal de respuesta $\boldsymbol{R}(\boldsymbol{t})$ que es obtenida luego de aplicar un estímulo de tipo click, se modela como la suma de dos componentes:

1. La señal de OAE "S $\boldsymbol{S}_{O A E}(t)$ ", considerada deterministica y sincronizada con el estímulo

2. El ruido " $n(t)$ " generado por la actividad del corazón, juego mandibular, movimientos musculares, externos y otros.

Es decir que para el $k$-ésimo estímulo tendremos:

$$
R_{k}(t)=S_{O A E}(t)+n_{k}(t)
$$

Donde se asume que $S_{\text {OAE }}(t)$ se repite de la misma manera para cada presentación del estímulo (por lo que no depende de $\boldsymbol{k}$ ) y que el ruido $\boldsymbol{n}_{k}(\boldsymbol{t})$ es estadísticamente independiente en cada evento y con media cero. 
El proceso de promediación de señales se expresa como sigue:

Si $R_{i}(t)$ es la señal análoga que sigue de la $i$-ésima estimulación, entonces esta señal puede ser representada por una secuencia de muestras tomadas en el tiempo $t_{n}$ como:

$$
\left\{\boldsymbol{R}_{k}\left(t_{n}\right)\right\}=\left[R_{i}\left(t_{0}\right), R_{i}\left(t_{1}\right), \cdots, R_{k}\left(t_{M-1}\right)\right] \quad(\mathrm{i}=1 \ldots \mathrm{N})
$$

donde $M$ es el número de muestras y $N$ el número de observaciones (épocas).

La secuencia de valores esperados de tal conjunto de observaciones es:

$$
\mathrm{E}\left\{R_{k}\left(t_{n}\right)\right\}=\left\{\bar{R}\left(t_{n}\right)\right\}=\left[\bar{R}\left(t_{0}\right), \bar{R}\left(t_{1}\right), \cdots, \bar{R}\left(t_{N-1}\right)\right]
$$

Donde $\bar{R}\left(t_{n}\right)$ es el valor esperado para la muestra tomada en el tiempo $t=t_{\boldsymbol{n}}$ (medido relativo a la aplicación del estímulo). Si la respuesta consiste de señal $\boldsymbol{S}_{\text {OAE }}(t)$ mas ruido $n(t)$, entonces el valor esperado para un tiempo en particular $t_{n}$ es

$$
\begin{aligned}
\bar{R}\left(t_{n}\right) & =\mathrm{E}\left[\left\{R_{i}\left(t_{n}\right)\right\}\right] \\
& =\mathrm{E}\left[\left\{\boldsymbol{S}_{O A E}\left(t_{n}\right)+n_{i}\left(t_{n}\right)\right\}\right] \\
& =\boldsymbol{S}_{\text {OAE }}\left(t_{n}\right)+\overline{\mathbf{n}}\left(t_{n}\right)
\end{aligned}
$$

donde según las hipótesis se cumple

$$
\mathrm{E}\left\{n\left(t_{n}\right)\right\}=\overline{\mathbf{n}}\left(t_{n}\right) \rightarrow 0
$$

y el promedio de la respuesta evocada queda dado por

$$
\bar{R}\left(t_{n}\right)=S_{\text {OAE }}\left(t_{n}\right)
$$

Si N respuesta son medidas, el promedio obtenido es

$$
\frac{1}{N} \sum_{k=1}^{N} R_{k}\left(t_{n}\right)=S_{O A E}\left(t_{n}\right)+\frac{1}{N} \sum_{k=1}^{N} n_{k}\left(t_{n}\right)
$$

El último término de la ecuación es sólo función del ruido y puede ser interpretado, para cada instante $\boldsymbol{t}$ posterior al estímulo, como un estimador de media. Tal promedio resulta en una nueva variable aleatoria que tiene (bajo las hipótesis asumidas) valor medio cero y varianza de $\sigma^{2} / N$. Por lo tanto, el efecto de la promediación coherente produce una reducción de la varianza del ruido por un factor $\mathrm{N}$, mientras que mantiene constante la amplitud de la señal deseada. En cuanto a la relación señal a ruido (SNR), ésta se ve mejorada en un factor de $\sqrt{N}$. 


\subsection{Algoritmo de Correlación Cruzada}

La función de correlación cruzada es un algoritmo que describe la semejanza de un grupo de datos con respecto a otro. Se utiliza para detectar una "señal coherente" inmersa en ruido.

\subsubsection{Algoritmo de Correlación Cruzada}

Considere el par de registros $X(t)$ y $Y(t)$ mostrados en la figura 4.3-A. Un estimado de la función de correlación cruzada, $\mathrm{R}_{\mathrm{XY}}(\tau)$ puede ser obtenido al tomar el promedio del producto de los dos valores $\mathrm{X}(t)$ y $\mathrm{Y}(t+\tau)$ sobre el tiempo de observación $\mathrm{T}$. El resultado puede aproximarse en una función de correlación cruzada cuando $\mathrm{T}$ se aproxima al infinito. Esto es:

$$
R_{X Y}(\tau)=\frac{\lim }{T \rightarrow \propto} \frac{1}{T} \int_{0}^{T} X(t) Y(t+\tau) d t
$$

La función $\mathrm{R}_{X Y}(\tau)$ es siempre una función de valor real que puede ser positivo o negativo. Además, $R_{X Y}(\tau)$ no tiene necesariamente un máximo para $\tau=0$, como lo es para la función de auto-correlación. Una gráfica típica de la correlación cruzada versus desplazamiento en el tiempo $\left[\mathrm{R}_{\mathrm{XY}}(\tau)\right.$ versus $\left.\tau\right]$, para un par de registros en el tiempo se muestra en la figura 4.3-B. Note que los picos indican la existencia de correlación entre $X(t)$ y $\mathrm{Y}(t)$ para un tiempo específico de desplazamiento, $\tau_{0} \mathrm{y} \tau_{1}$.

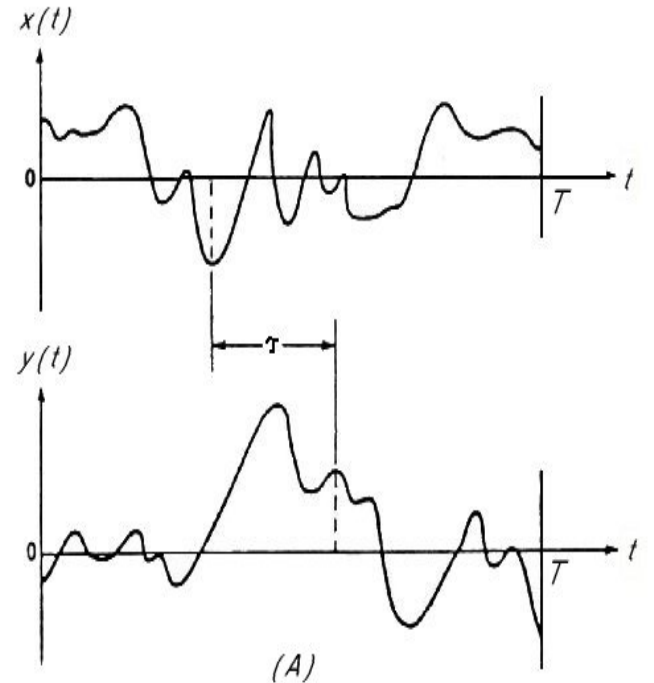

(A)

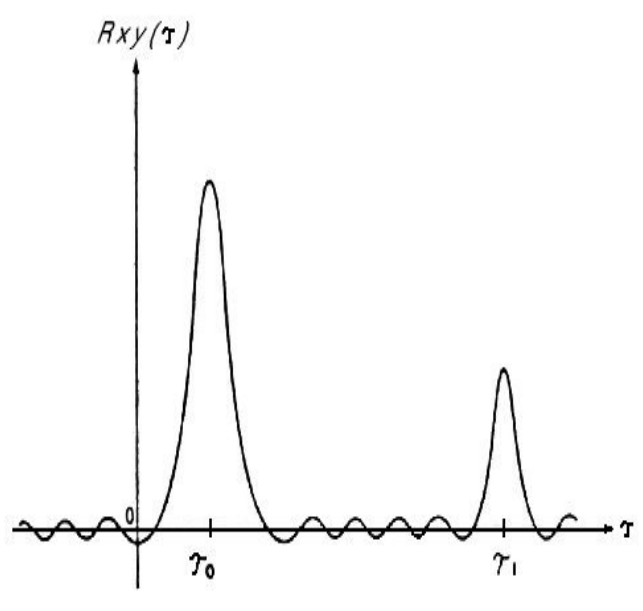

(B)

Figura 4. 3. La figura presenta dos señales adquiridas (A) y su semejanza (B) obtenidas por medio de la correlación cruzada.

Una estimación de la función de correlación cruzada discreta para un retrazo de $\mathrm{r}=0,1,2, \ldots \mathrm{m}$, es definida como:

$$
R_{X Y}[n]=\frac{1}{N-r} \sum_{r=1}^{N-r} X[n] Y[n+r]
$$

Esta estimación puede ser usada como un "cuantificador" para determinar la semejanza entre dos señales. 
En general, la función de correlación requiere normalización para producir una estimación precisa. Esta normalización se realiza dividiendo la amplitud de la función de correlación cruzada por la raíz cuadrada del producto de las funciones de auto-correlación (para X y Y) en $n=0$. La forma normalizada toma valores entre -1 y 1 , donde los valores absolutos próximos a 1 , representan alta "correlación” (el valor 1 significa que ambas señales son iguales) [26][27].

\subsection{Algoritmo Fsp (Fisher - single point)}

Este algoritmo se utiliza con el objetivo de determinar si una respuesta de OAE está presente en la señal adquirida, mediante la estimación de su SNR. El primer trabajo donde se utiliza una relación de varianzas de la señal $\left(\hat{\sigma}_{S}{ }^{2}\right)$ y un punto único de cada época para estimar la varianza del ruido $\left(\hat{\sigma}_{n}{ }^{2}\right.$ ), fue el desarrollado por Elberling et al [28]; éste fue denominado FSP (del inglés: Fisher, single point).

Para este algoritmo, el valor de la potencia de la señal es estimado mediante la varianza del promedio de varias épocas $\left(\hat{\sigma}_{S}{ }^{2}\right)$, mientras que la potencia del ruido es cuantificada por la varianza de un punto único en el ensamble de las épocas $\left(\sigma_{n}{ }^{2}\right)$. Así la relación señal a ruido es estimada por:

$$
S \hat{N R}=\frac{\hat{\sigma}_{S}{ }^{2}}{\hat{\sigma}_{n}{ }^{2}}
$$

El valor de $\hat{\sigma}_{S}{ }^{2}$ será mayor que el del $\hat{\sigma}_{n}{ }^{2}$ en un oído normal, mientras que en un oído sin emisiones, estas magnitudes tendrán valores similares, haciendo que $S \hat{N R}$ se aproxime a 1 [28].

El método FSP fue utilizado en un estudio multicéntrico, financiado por el Instituto Nacional de Salud (NIH) de Estados Unidos. En este estudio se usó un valor de 3.1 como "punto de corte" para los valores de FSP. Un oído que obtenía un FSP $>3.1$ fue considerado normal (pass) mientras que un oído con un FSP de 3.1 o menor fue "referido" (refer) a estudios más completos [28][29][30].

\subsubsection{Descripción del algoritmo FSP}

Para iniciar, consideremos un punto único, a un tiempo $\boldsymbol{t}_{s p}$ respecto al inicio de cada época y a $\boldsymbol{S}_{\boldsymbol{k}}$ como el valor de dicho punto en la k-ésima época. La dependencia del tiempo se elimina ya que todos los puntos se toman en un mismo tiempo $\boldsymbol{t}_{s p}$, que es fijo para cada época registrada. En la figura 4.4 se muestra como se construye el vector (de ensamble) $\boldsymbol{s p}$ a partir de los puntos tomados de cada época en el tiempo fijo $\boldsymbol{t}_{s p}$. 


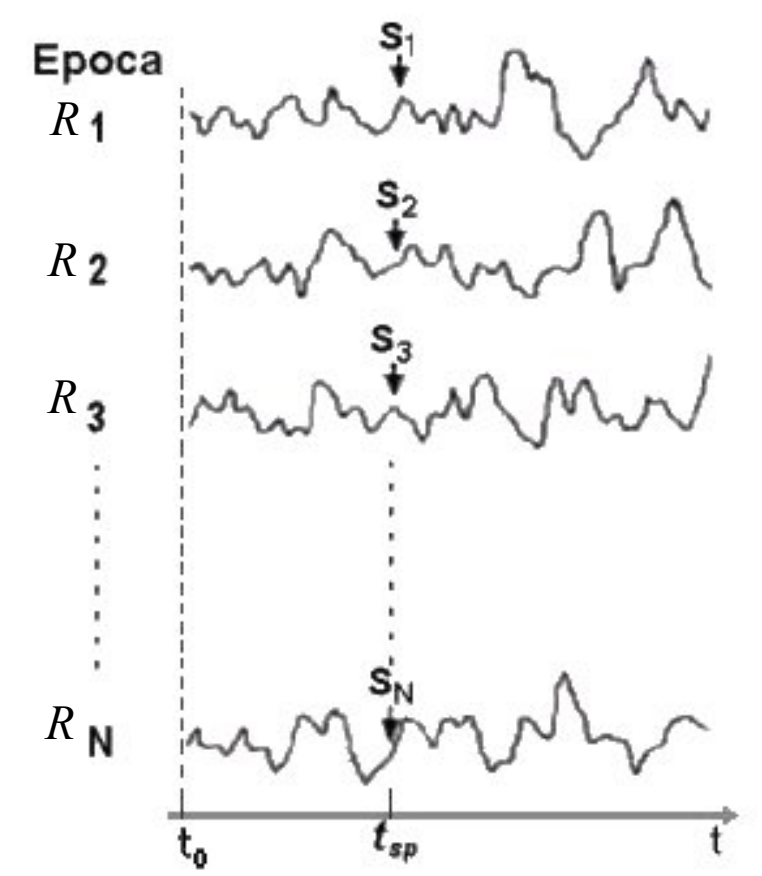

Fig. 4. 4. El vector de únicos puntos $s p=\left(s_{1}, s_{2}, \ldots s_{N}\right)$ se forma al unir estos puntos únicos tomados de las épocas a un tiempo $t_{s p}$.

Un estimado $\bar{R}$ del valor de la señal de $\operatorname{OAE}\left(S_{O A E}\right)$ para un tiempo dado $\boldsymbol{t}_{n}$, está dado por:

$$
\bar{R}=\sum_{k=1}^{N} \frac{R_{k}}{N}
$$

donde $N$ indica el número de épocas registradas y $\bar{R} \approx S_{O A E}$ para $t_{n}=t_{s p}$.

Si ahora se define el ruido residual $(R N)$ en el promedio, como la varianza de ese promedio:

$$
R N=\operatorname{var}(\bar{R})=\frac{1}{N^{2}} \cdot \operatorname{var}\left(\sum_{k=1}^{N} R_{k}\right)=\frac{1}{N^{2}}\left\{\sum_{k=1}^{N} \operatorname{var}\left(R_{k}\right)+\sum_{k=1}^{N} \sum_{j \neq k} \operatorname{cov}\left(R_{k}, R_{j}\right)\right\}
$$

donde: $\quad \operatorname{cov}\left(R_{k}, R_{j}\right)=E\left[\left(R_{k}-S_{E O A}\right)\left(R_{j}-S_{E O A}\right)\right]$

Si aplicamos las hipótesis del modelo de la ecuación (12), la contribución del ruido a $\left\{\boldsymbol{R}_{\boldsymbol{k}}\right\}$ es estacionaria, y hacemos que:

$$
\operatorname{var}\left(\boldsymbol{R}_{\boldsymbol{k}}\right)=\sigma^{2} \quad \text { y } \quad \operatorname{cov}\left(\boldsymbol{R}_{\boldsymbol{k}}, \boldsymbol{R}_{\boldsymbol{k}+i}\right)=\sigma^{2}(i)
$$

entonces la ecuación (26) del ruido residual puede ser reescrita como:

$$
\operatorname{var}(\bar{R})=\frac{\sigma^{2}}{N} \cdot\left\{1+2 \cdot \sum_{i=1}^{N}\left(1-\frac{i}{N}\right) \cdot \frac{\sigma^{2}(i)}{\sigma^{2}}\right\}=\frac{\sigma^{2}}{N} \cdot\left\{1+2 \cdot \sum_{I=1}^{n}\left(1-\frac{I}{n}\right) \cdot \rho(I)\right\}
$$


donde el factor

$$
\rho(i)=\frac{\sigma^{2}(i)}{\sigma^{2}}
$$

se denomina el i-ésimo término en la secuencia de autocorrelación. Este factor indica el grado de asociación entre los valores de los datos de punto único separados por $\boldsymbol{i}$ épocas. Este factor cae en el rango [-1,1], con valores de -1 y 1 indicando máxima asociación. Si los valores de punto único son independientes uno del otro, entonces $\sigma^{2}(\mathbf{i})=0$ para todo $\mathbf{i} \neq \mathbf{0}$.

La estimación del ruido residual de punto único del método Fsp se basa en suponer la independencia estadística entre épocas, lo que hace cero los términos de la autocorrelación. Por lo tanto, el segundo término de la ecuación (27) desaparece y se obtiene:

$$
R N=\frac{\sigma^{2}}{N}
$$

Una estimación sin sesgo (en el caso de cumplirse las hipótesis del modelo) de $\sigma^{2}$ es:

$$
\bar{\sigma}_{S P}{ }^{2}=\sum_{k=1}^{N} \frac{\left(R_{k}-\bar{R}\right)^{2}}{N}
$$

y es denotado por var(SP). Reemplazando en (29) se obtiene el estimador del ruido residual denominado estimador de media de suma de cuadrados (sigla en inglés: mss).

$$
R N_{m s s}=\frac{1}{N} \cdot\left\{\sum_{k=1}^{N} \frac{\left(R_{k}-\bar{R}\right)^{2}}{N}\right\}
$$

De esta forma, se define el valor de FSP como:

$$
F_{S P}=\frac{\operatorname{var}\left(R_{\text {prom }}\right)}{\operatorname{var}(S P) / N}=\frac{\sum_{i=a}^{b} \frac{\left(R_{\text {prom }_{i}}-\bar{R}_{\text {prom }}\right)^{2}}{b-a}}{\frac{1}{N} \cdot\left\{\sum_{k=1}^{N} \frac{\left(R_{k}-\bar{R}\right)^{2}}{N}\right\}}
$$

donde $\boldsymbol{R}_{\text {prom }}$ es la señal promedio de las $\boldsymbol{N}$ épocas disponibles, y $\boldsymbol{a}$ y $\boldsymbol{b}$ son los índices que definen el inicio y final de la ventana de la señal promediada, sobre la cual se calcula la varianza que estima la señal. En el trabajo de Elberling, a partir de un análisis estadístico se establece que un valor de $\boldsymbol{F} \boldsymbol{s p}=3.1$ corresponde a un $99 \%$ de probabilidad que se encuentre presente una respuesta evocada [28][29][30]. 


\section{Material y Método del Procedimiento de Experimentación}

Está diseñado para modos de estimulación lineal y no lineal con clicks, además para la determinación de la presencia de CEOAE a partir de la señal acústica registrada en el interior del conducto auditivo externo, cuando se varía la intensidad del click de estimulación.

El registro de la respuesta acústica se realizó en las siguientes etapas:

- Selección de la población de estudio.

- Capturar datos sin modificar los protocolos que el equipo de registro trae por omisión.

- Analizar los datos adquiridos en la etapa anterior. Para identificar los procesos de análisis aplicados a respuesta auditiva y reproducirlos.

- Configuración del equipo y capturar datos.

- Analizar los datos de la etapa anterior. Se utilizan los algoritmos: correlación cruzada y el F SP.

\subsection{Equipos utilizados en el estudio}

La exploración del oído externo se realizó con un Otoscopio Welch Allyn, las audiometrías se obtuvieron con un audiómetro Interacoustics Clinical Audiometer AC 40 y cuando se juzgó necesario se comprobó movilidad de la membrana timpánica con un timpanómetro Interacoustics Inpedance Audiometer AZ 26. Para la generación del estímulo auditivo y captura de las Emisiones Otoacústicas se empleó un equipo comercial ILO-96, de Otodynamics, Versión 5: V560Y/980213a . Para la obtención de las CEOAE se colocó al sujeto en el interior de una cámara sonoamortiguada. El análisis de datos fuera de línea se realizó con software escrito en MatLab v6.0.

Para la obtención de emisiones otoacústicas con el ILO-96, es necesario, mediante la ayuda de una punta de goma suave, colocar una sonda de estimulación-registro en el conducto auditivo externo del sujeto. Previo al inicio de la prueba se revisa que la sonda esté apropiadamente instalada de tal manera de asegurar una adecuada estimulación con cliks. Comprobado lo anterior se da inicio al estudio que consiste en el envío de sucesivos clicks de estimulación y el correspondiente registro de la respuesta del sistema auditivo. Después del análisis de cierto número de estas respuestas el sistema determina la presencia o no de emisiones otoacústicas, depositando los resultados en dos tipos de archivos: "DTA" y "MEG". Los parámetros de estimulación y criterios de determinación de la respuesta obedecen a pruebas clínicas aplicadas a poblaciones de sujetos normales.

\subsection{Población de estudio}

La población total objeto de este estudio consistió de 23 adultos jóvenes sanos, 12 mujeres y 11 hombres, con una edad que oscila entre los 17 y 35 años. De esta población solo 32 oídos, entre 
hombres y mujeres, cumplieron los criterios de inclusión. A partir de esta población se obtuvieron aleatoriamente dos grupos. Grupo No.1: 10 oídos masculinos y 10 femeninos con estimulación lineal. Grupo No.2:10 oídos masculinos y 10 femeninos con estimulación no lineal

Los sujetos incluidos en este estudio debían cumplir los siguientes requisitos. (1) Pabellón auricular, conducto auditivo externo y membrana timpánica íntegros; (2) Canal auditivo externo limpio y libre de obstrucciones; (3) No haber sufrido padecimiento alguno en vías respiratorias al menos en las tres últimas semanas previas a la prueba y (4) Poseer un umbral acústico $\leq 20 \mathrm{~dB}$ HL. El sujeto era incluido si al menos uno de sus dos oídos cumplía lo anterior.

\subsubsection{Preparación del sujeto}

Bajo cita programada se recibió al sujeto, informándole de la naturaleza, propósito y duración del estudio, obteniendo su consentimiento para la participación en el mismo. Se elaboró historia clínica y practicó examen otoscópico. Cuando fue necesario se retiraron restos de cerumen del conducto auditivo externo. Seguidamente se le practicó audiometría aérea de tonos puros, ubicándolo sentado en un sillón en el interior de la cámara anecoica.

Al tiempo de colocarle la sonda, se le instruyó en evitar moverse, deglutir o bostezar durante la realización de la prueba, así como guardar una posición cómoda y relajada. A fin de que el sujeto no se fatigara, se le indicaba mediante un sistema de intercomunicación el momento en que iniciaba y concluía cada prueba.

\subsubsection{Colocación de la sonda}

La sonda utilizada es de propósito general, según clasificación de Otodynamics, del tipo no desechable, con dimensiones propias para un adulto. Consta de un excitador acústico y un micrófono de registro de banda ancha del tipo electret, ver figura 5.1.

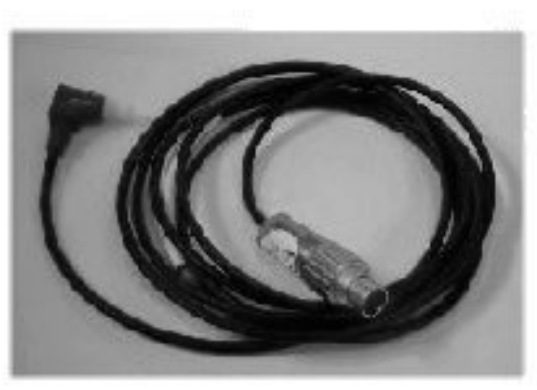

A

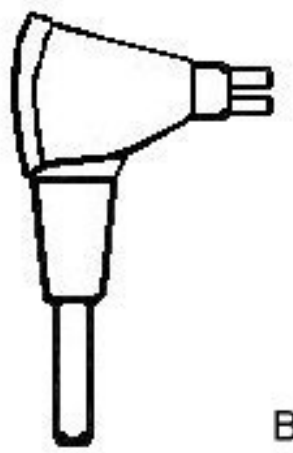

B
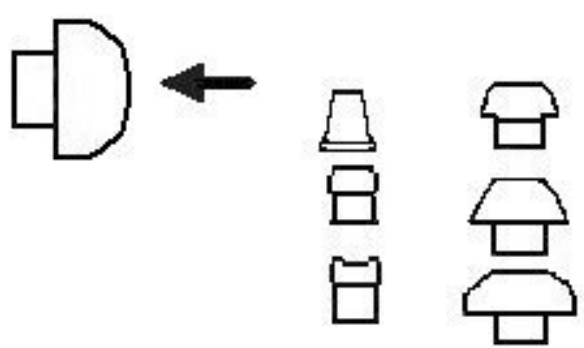

C

Figura 5. 1. (A) es la sonda acústica utilizada de propósito general, (B) muestra cómo se coloca la oliva en la sonda acústica para lograr un buen sello, (C) los diferentes tipos de olivas disponibles.

Seguido de la realización de la audiometría y elegido el oído a estudiar se le pedía al sujeto abrir ampliamente la boca para así lograr insertar la sonda en el conducto auditivo externo, procurando dejar la sonda alineada con las paredes del conducto, evitando con ello obstruir el puerto de 
entrada de la sonda. Hecho lo anterior se pedía cerrar la boca al sujeto y mediante cinta "micropore" se mantenía en posición el cuerpo y cable de la sonda, ver figura 5.2. El acoplamiento entre la sonda y el conducto auditivo externo debe conformar un sello perfecto, de lo contrario no es posible lograr una señal de excitación de espectro amplio que excite convenientemente el sistema auditivo. Como el diámetro del canal auditivo varía de sujeto en sujeto, se utiliza una oliva de goma blanda para lograr este sello.

Una buena colocación de la sonda debe cumplir las siguientes condiciones:

a) Sellar adecuadamente, para convertir los pequeños movimientos de la membrana timpánica en fluctuaciones de presión que puedan ser detectadas por el micrófono de registro.

b) Su orientación debe ser hacia la membrana timpánica, pues cuando está orientada hacia la pared del canal, la forma del estímulo no es la adecuada para el registro e incluso no permite que se lleve a cabo el registro debido al ruido.

c) Evitar el ruido externo que puede interferir con el registro.

El ILO-96 permite verificar la "calidad" de la excitación acústica mediante la opción "CHECKFIT" de su menú de operación. De esta manera es posible reposicionar la sonda cuantas veces sean necesarias hasta lograr el sello y calidad de excitación debidos.

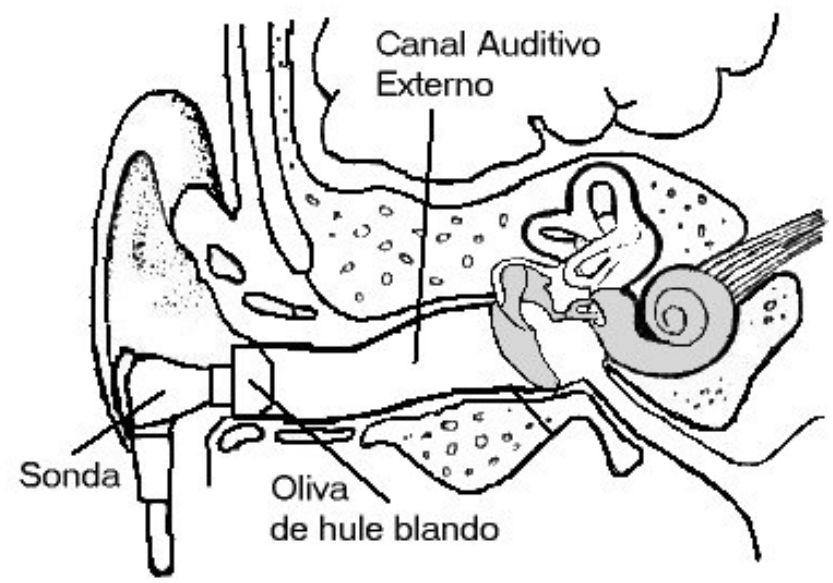

Figura 5. 2. La colocación de la sonda debe ser lo más perpendicular posible con respecto a la membrana timpánica, además debe utilizarse la oliva apropiada para asegurar un buen "sello" entre la sonda y el canal auditivo externo. Si no se consigue sellar el "canal", no se puede realizar el registro de la respuesta coclear, ya que el aire en la cavidad no se puede comprimir.

\subsubsection{Realización de la prueba}

Primeramente se realizaron registros utilizando los parámetros, de estimulación y registro, clínicamente probados para la obtención de CEOAE en la mayoría de los sujetos sanos, utilizando un click de polaridad positiva o negativa, intensidad de aproximadamente $80 \mathrm{~dB}$ SPL Pe nominales, con una duración de $80 \mu \mathrm{s}$ y registro de la respuesta en una ventana de $20 \mathrm{~ms}$. Estos 
parámetros por omisión se activan desde el menú de bienvenida del ILO-96 al elegir la opción "TOAEE". La intensidad del estímulo (adulto, infante o neonato) queda determinada al seleccionar el tipo de sonda que se ha de utilizar en el estudio. Para dar inicio a la prueba se elige "TE_fullmenu" en la opción "Test", ubicada dentro del menú "T) TOAEE" del menú principal como se muestra en la figura. 5.3, para introducir el nombre del paciente, oído izquierdo o derecho y número de identificación. Al introducir este último dato y oprimir la tecla $<$ Enter $>$ solicita se identifique el tipo de sonda (adulto, productos de distorsión o de propósito general).

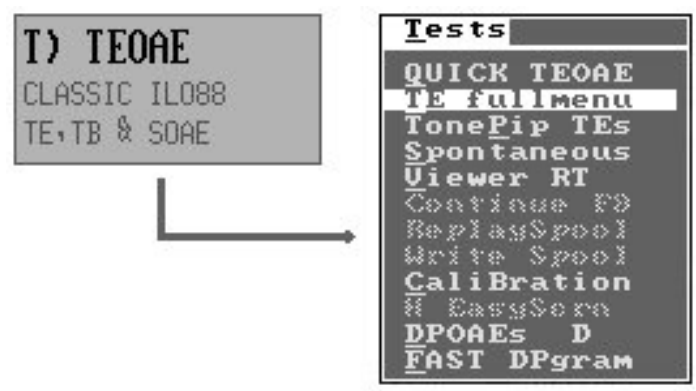

Figura 5. 3. Para iniciar los registros de las OAE se selecciona el campo "T) TEOAE" del menú principal, después en el submenú "TESTS" se selecciona "TE FULLMENU".

En este momento el sistema permite verificar la calidad de la excitación acústica mediante la opción "CHECKFIT". Habiendo comprobado la calidad de la excitación se oprime la tecla $<$ Enter $>$ o "g" para dar inicio a la prueba. Una vez concluida la prueba el sistema solicita el nombre del archivo con el que se van a guardar los datos resultado de la prueba i.e. XXX.DTA. Este archivo contiene la información resultado de la promediación y análisis de los datos entregados por la sonda de registro, tal y como se muestra en la pantalla del ILO-96.

\subsubsection{Generación de los archivos "DTA"}

Por cada click de estimulación el micrófono de registro captura una respuesta de 512 puntos contenidos en la ventana de análisis. De tal manera que por cada paquete de estimulación (3:1) se generan cuatro respuestas correspondientes a otros tantos estímulos individuales. El ILO-96 genera una "época" como resultado de promediar las cuatro respuestas individuales de un paquete de estimulación, esto significa que una prueba típica de emisiones otoacústicas contiene 260 "épocas". A fin de corroborar la obtención de una respuesta válida el ILO-96 realiza de forma alterna una réplica de la prueba original; considerando lo anterior en forma global un estudio completo significa el envío de 2080 estímulos individuales agrupados en 520 paquetes de cuatro estímulos. El resultado final exhibido en la pantalla del ILO-96 corresponde a la respuesta (A) y su réplica (B). El almacenamiento de la respuesta A y su réplica B se hace de forma alterna en dos diferentes áreas de memoria, el procedimiento se ilustra en la figura 5.4. 


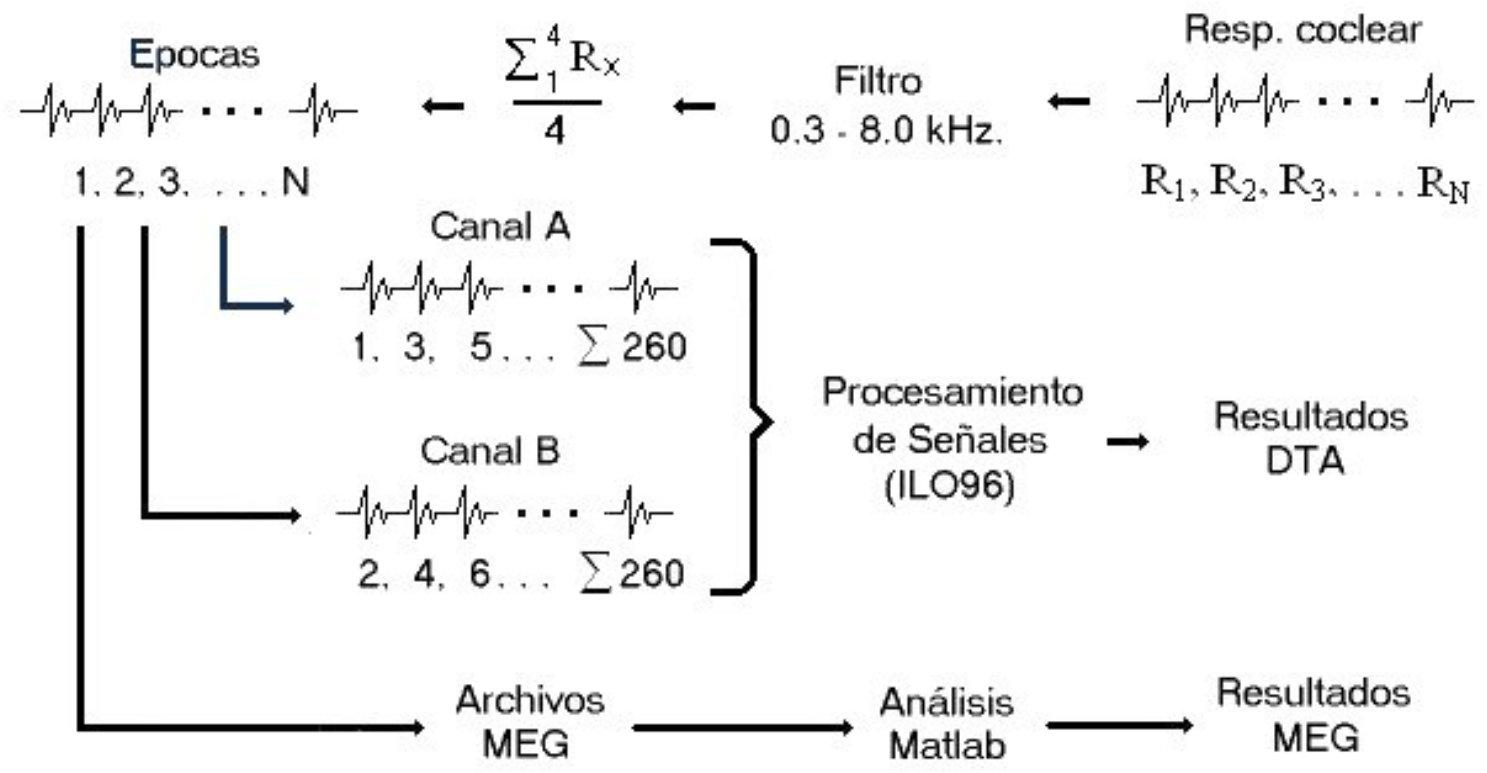

Figura 5. 4. Procedimiento simplificado de la obtención de épocas, así como el almacenamiento y generación de archivos "DTA" y "MEG", tal como se guardan en la memoria del ILO-96.

La captura de datos concluye cuando en ambos canales se han alcanzado las 260 épocas válidas, i.e. con un nivel de ruido aceptable, o bien el número de ellas preestablecido en el protocolo de paro, el procedimiento se ilustra en la figura 5.5. El número de épocas aceptadas se muestra en la parte superior derecha de la pantalla principal, donde también se observa el porcentaje de épocas aceptadas relativo al número total de paquetes de estimulación enviados.

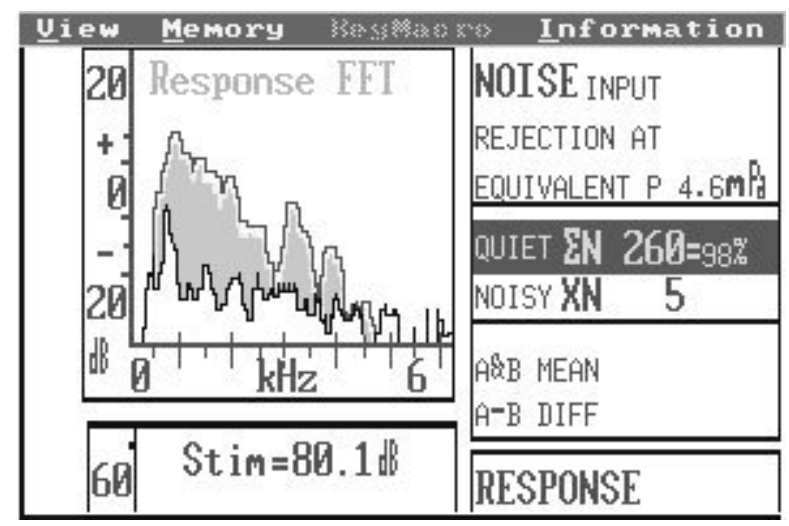

Figura 5. 5. El número de épocas válidas aceptadas en cada canal de memoria se muestra en la parte superior derecha de la pantalla principal ("QUIET"). Total de paquetes enviados igual a 265; porcentaje de "épocas" válidas = 98\%.

\subsubsection{Generación de los archivos “MEG"}

Los archivos MEG se generan con las épocas que formaron los archivos DTA pero con dos variantes, la primera es que se almacenan todas de manera secuencial, es decir, conforme se van 
generando se guardan en un espacio de memoria destinado para estos archivos sin atender si se trata de una válida o rechazada y la segunda variante es que los archivos MEG incluyen las épocas que fueron consideradas "no válidas" de acuerdo con los parámetros de nivel de ruido y rechazo de artefacto. Para la creación y posterior almacenamiento de los archivos tipo MEG es necesario indicarlo desde el menú principal.

Por omisión el sistema sólo almacena los archivos del tipo DTA, siendo necesario habilitar las opciones que posibiliten almacenar los archivos MEG. Esto está previsto de esta manera ya que los archivos MEG ocupan una área de memoria importante que en el corto plazo podría agotar el área de almacenamiento disponible en la computadora.

Para habilitar el almacenamiento de los archivos MEG, es necesario activar la opción CREATE SPOOL de la opción DATA SPOOL contenida en el submenú SETTINGS. Verificando en los submenús FILES y TEST que las opciones LOADSPOOL y WRITESPOOL estén activadas respectivamente, ver figura 5.6.

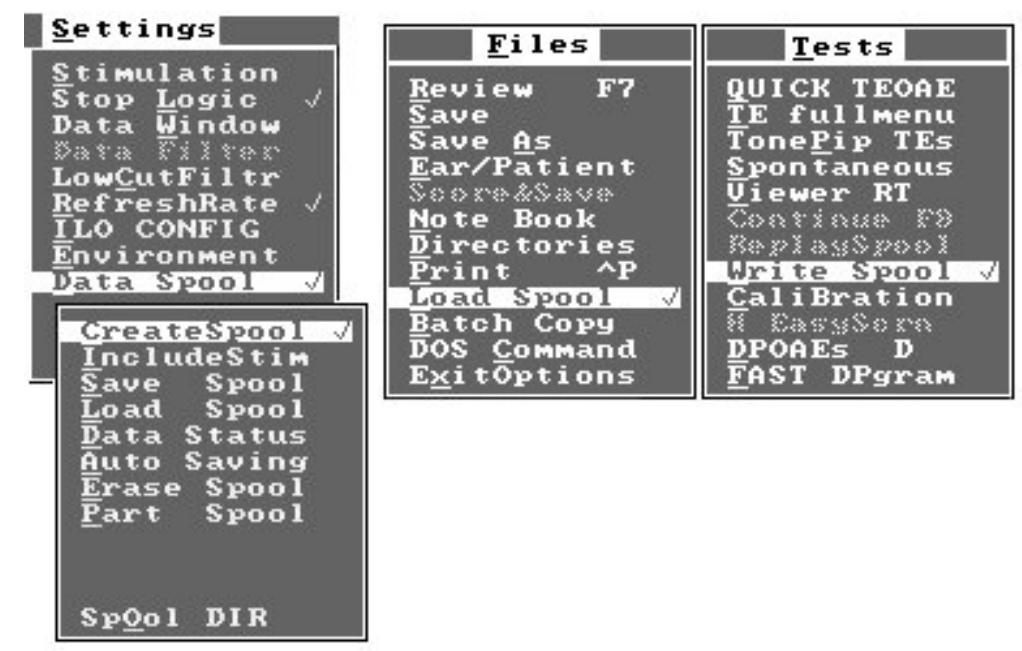

Figura 5. 6. Los parámetros que se deben activar en el ILO96, para almacenar los archivos tipo MEG, se identifican por la marca $\sqrt{ }$.

Si la activación se realiza exitosamente aparecerá en la pantalla principal la leyenda "WRITE TO SPOOL" junto al nombre del sujeto, como se muestra en la figura 5.7.

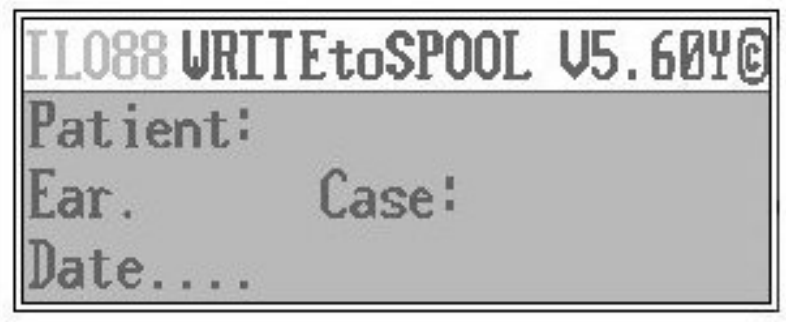

Figura 5. 7. La leyenda que aparece sobre el nombre del paciente, es una manera rápida de verificar si los archivos tipo MEG se están almacenando en la memoria del equipo. 
El condicionamiento y criterios de rechazo de los datos registrados se pueden conocer acudiendo a "PROCESSES" dentro de la opción "SETTINGS", ver figura 5.8. En este submenú los procesos señalados con " $\sqrt{ }$ " son los activos.

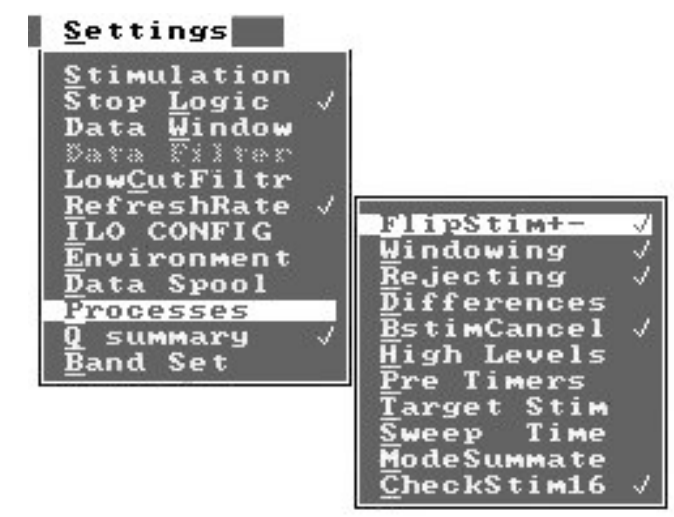

Figura 5. 8. Secuencia del menú y sub-menú del ILO-96, que indican los análisis realizados a las señales registradas de los archivos tipo DTA.

5.2.6 Detección alterna de las OAE: Selección de los parámetros de captura de datos y validación del software alterno de detección

Ya que el propósito de este trabajo es la detección de CEOAE para intensidades de estimulación diferentes a las clínicamente empleadas, fue necesario en primera instancia obtener resultados similares a los proporcionados por el ILO-96 para el caso de sujetos normales. Esto se realizó mediante la comparación de los resultados de una prueba típica de CEOAE contenidos en el archivo DTA vs. los resultados obtenidos mediante un análisis fuera de línea practicado sobre los datos del archivo MEG. No hay que olvidar que ambos archivos corresponden a una misma prueba donde el archivo DTA sólo utilizan las "épocas" válidas para el cálculo del resultado de la prueba y los archivos MEG contienen además de las "épocas" útiles, las "épocas" consideradas no útiles para la prueba. El análisis fuera de línea se realizó con "software" escrito ex profeso en ambiente MatLab v6.0.

Resultado de este análisis fuera de línea fue la adecuación de los datos MEG (contenidos en el archivo MEG) mediante las acciones necesarias tales que los resultados de los archivos DTA concordaran con los obtenidos a partir de los datos MEG. La adecuación de los datos implicó: (1) Factor de amplificación. Los datos MEG se multiplicaron por un factor de 55. (2) Ventaneo. Se aplicó una ventana de ceros (de 0 a $2.5 \mathrm{~ms}$ ) y unos (de 5 a $17.5 \mathrm{~ms}$ ), con pendiente uniforme de subida (de 2.5 a $5 \mathrm{~ms}$ ) y bajada (de 17.5 a $20 \mathrm{~ms}$ ); esto es necesario para eliminar la influencia del estímulo sobre la respuesta coclear como puede verse en la figura 5.9. (3) Filtrado. Solo el efectuado por el ILO-96. (4) Rechazo de artefacto. Esto es la amplitud del umbral máxima a partir de la cual se desecha una época. Cuando se presenta un registro con una amplitud mayor al promedio de las respuestas acústicas, se considera está contaminado con ruido. El rechazo de artefacto no se aplica desde el inicio del registro, ya que el click de estimulación es muy grande comparado con la respuesta acústica, por esta razón el rechazo de artefacto se aplica después que la influencia del estímulo (artefacto del estímulo) sobre la respuesta acústica cuando ha disminuido lo suficiente. Este puede ser establecido por eliminación de respuestas que exceden niveles de ruido preestablecidos o por estrategias adaptivas (estimulación no lineal) que 
manipulan los promedios que generan las épocas, siguiendo una cancelación lineal. Para los registros realizados el rechazo de artefacto se aplicó después de 2.5 milisegundos posteriores al estímulo con un valor umbral de $1.2 \mathrm{mPa}$, ver figura 5.10 .

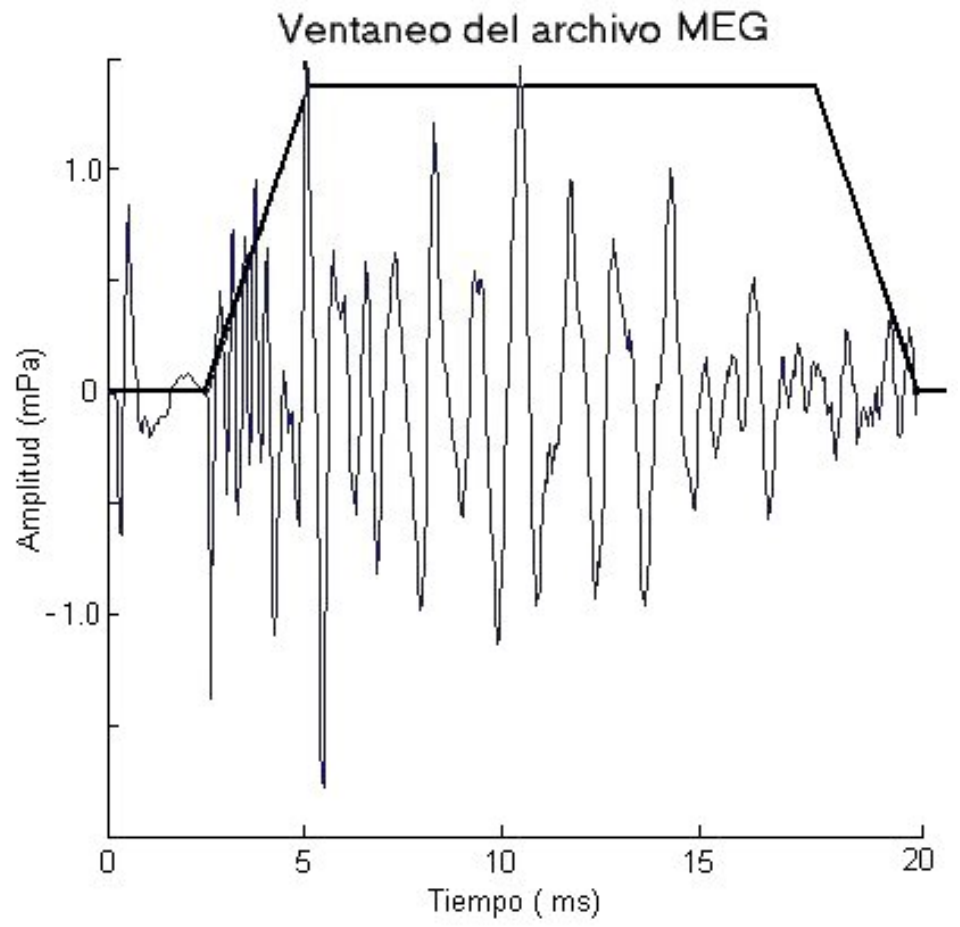

Figura 5. 9. La ventana se muestra en línea remarcad sobre la señal, es aplicada a los épocas aceptadas después del rechazo de artefacto.

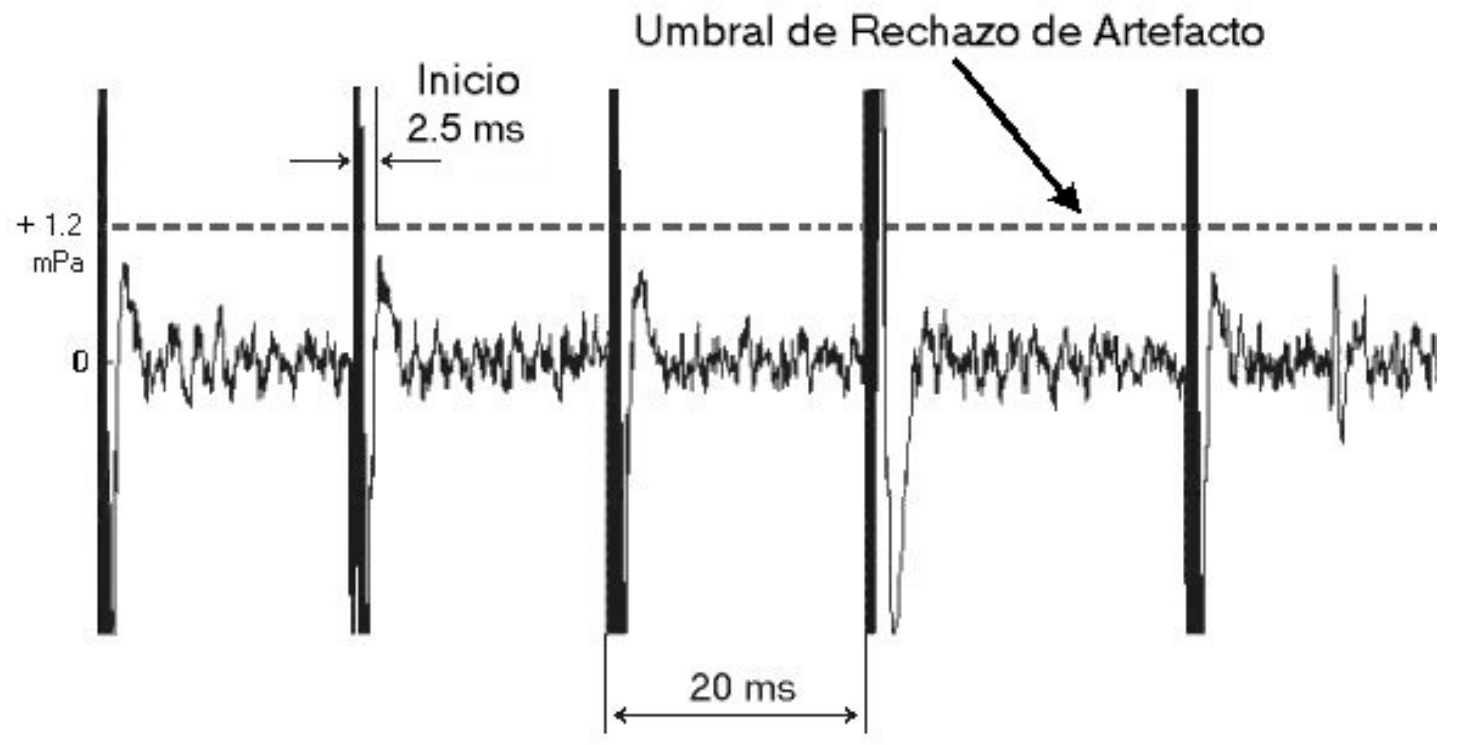

Figura 5. 10. El umbral de rechazo se indica por la línea puntada y su inicio es después de haber transcurrido $2.5 \mathrm{~ms}$ posteriores al estímulo como se muestra en la parte superior de la figura.

La comparación de resultados entre el archivo DTA y los calculados fuera de línea a partir de los 
archivos MEG se realizó mediante la comparación entre el promedio de las respuestas A y B del archivo DTA y el promedio de las respuestas tomadas a partir de los archivos MEG. Los resultados entre ambos conjuntos de datos se consideraron suficientemente parecidos cuando la correlación entre el promedio de los datos DTA y el promedio de datos MEG fue $\geq 90 \%$, ver figura 5.11 .

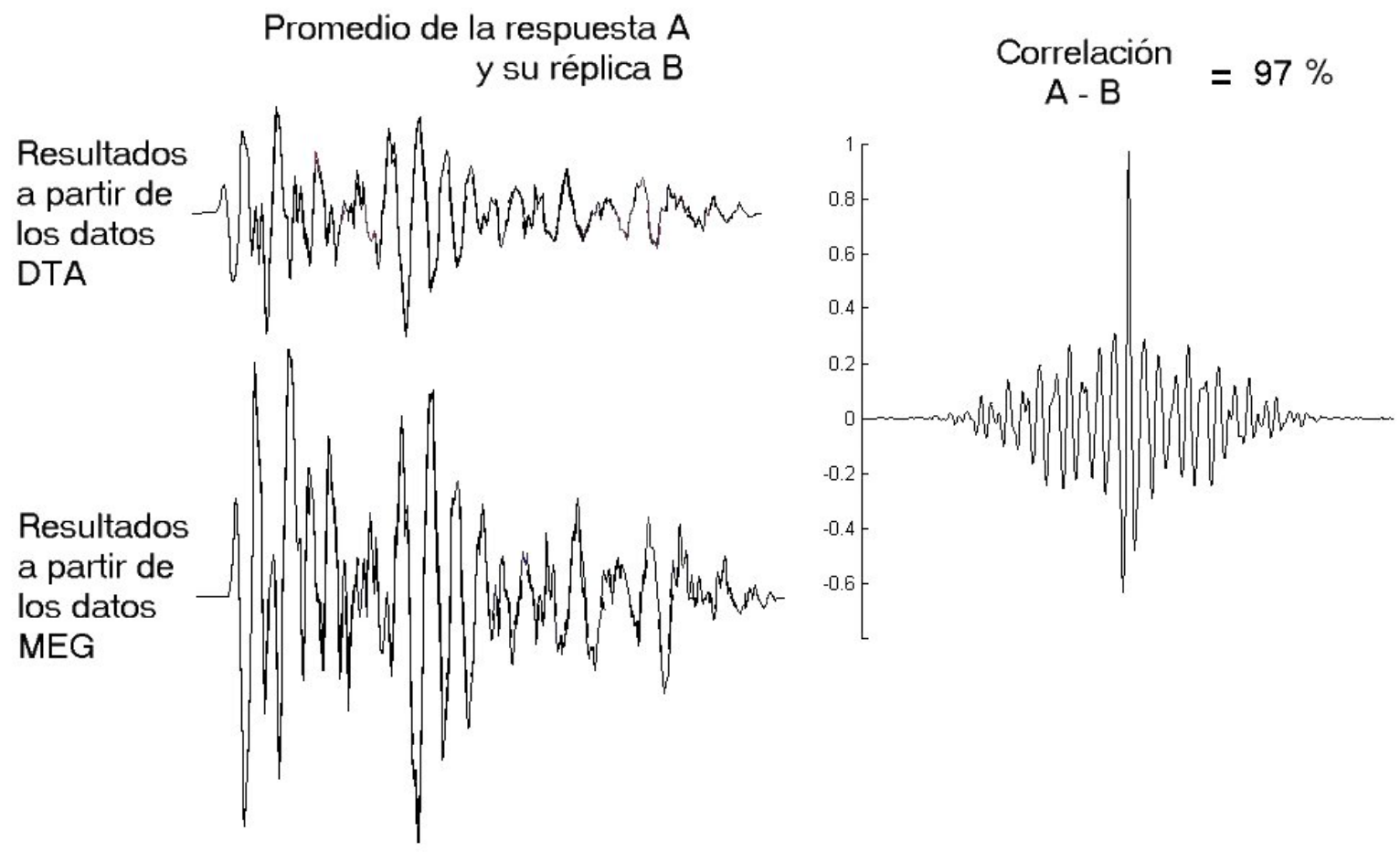

Figura 5. 11. Comparación de los resultados contenidos en el archivo DTA con los resultados calculados a partir de los archivos MEG. Primero se obtiene el promedio del canal A y su réplica $B$ de cada archivo y luego se obtiene la correlación cruzada entre los promedios de los archivos DTA y MEG. El objetivo es alcanzar una semejanza igual o mayor al $90 \%$ para validar el método propuesto.

Una vez conseguida esta correlación que aseguraba un tratamiento de datos equiparable entre el ILO-96 y el método implementado en Matlab, se tuvieron las condiciones necesarias para modificar el protocolo de estimulación del ILO-96 y ensayar formas alternas de detección de las CEOAE.

\subsubsection{Parámetros de captura.}

Intensidad del estímulo. Se utilizaron las siguientes intensidades en el orden que se indica, 80, 35, 40, 50, 60 y $70 \mathrm{dBspl}$ Pe. Esto es en razón a que el correcto posicionamiento de la sonda se verifica con la intensidad más alta; el subsiguiente orden prevé movimientos indeseables de la sonda así como efectos de fatiga en el sujeto, el ruido muscular es más apreciable a bajas intensidades de estimulación.

Para cambiar la intensidad de estimulación se debe seguir la siguiente secuencia a partir del submenú principal. SETTINGS $\rightarrow$ STIMULATION $\rightarrow$ DUAL GAIN-AB, ver figura 5.12 


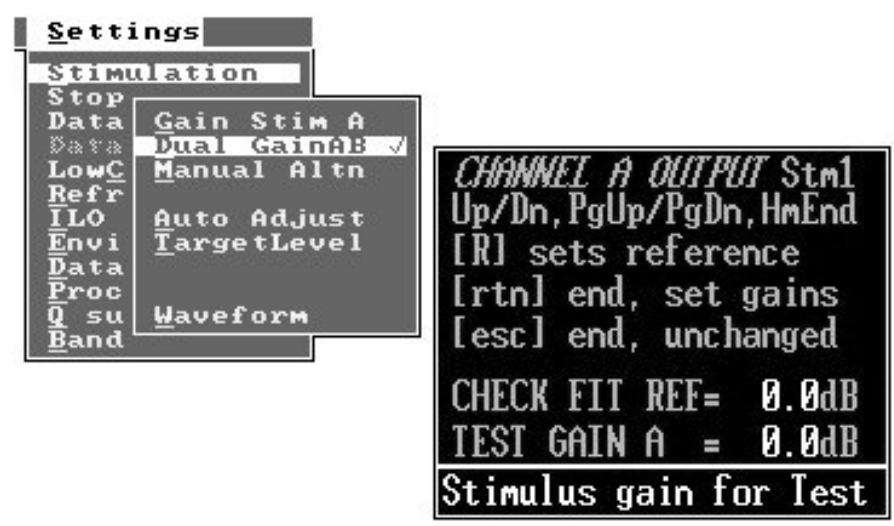

Figura 5. 12 Secuencia para modificar el parámetro "GAIN" que cambia la intensidad del estímulo.

\subsubsection{Número de épocas y lógica de fin de prueba.}

Se consideraron 260 épocas para las pruebas con intensidades de 80, 70, $60 \mathrm{~dB}$ SPL Pe y 420 épocas

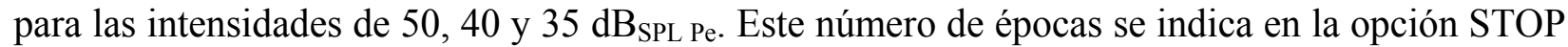
LOGIC del submenú SETTINGS, ver figura 5.13.

En la misma figura se muestran marcados otros parámetros que influyen en el modo de paro automático de la prueba. manyrejects (1000): número máximo de épocas ruidosas rechazadas antes de detener la prueba. muchdata (260 ó 420): número de épocas válidas para detener la prueba. muchnoise $(32 \mathrm{mPa})$ : nivel máximo permisible de ruido ambiente y/o muscular. goodrepro (100\%): criterio de semejanza entre la respuesta en el canal A y la réplica en el canal $\mathrm{B}$. Alcanzado el número de épocas válidas, la CEOAE observada en el trazo A y su réplica $\mathrm{B}$ representan el promedio de las épocas almacenadas en esas dos áreas de memoria.
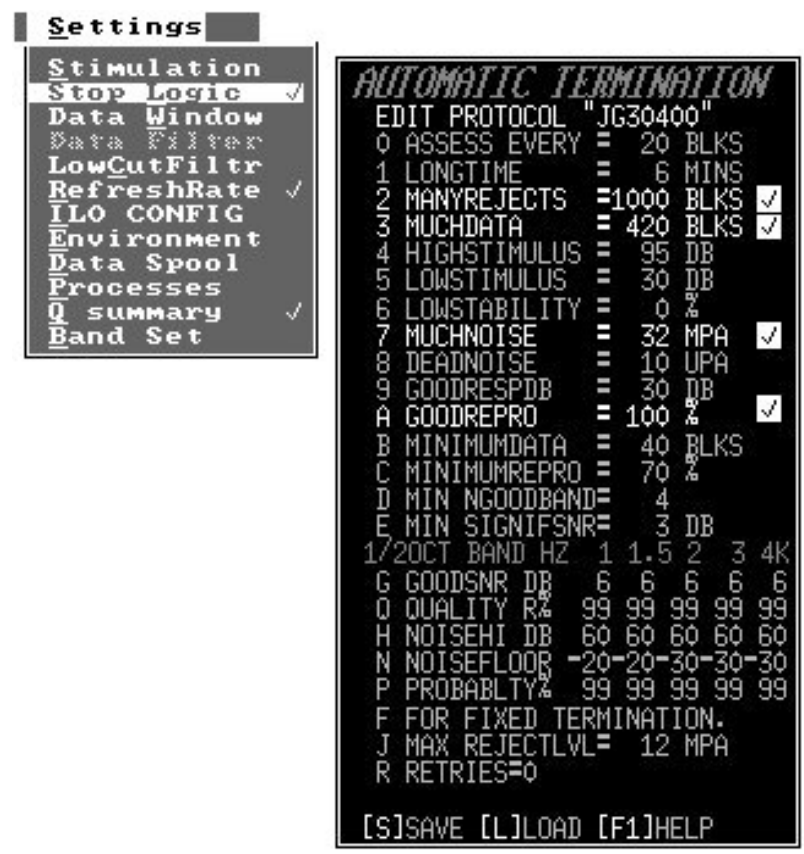

Figura 5. 13. Parámetros que determinan el fin de una prueba. 


\subsubsection{Protocolo de estimulación.}

En la figura 5.14 se muestra la secuencia seguida para activar los campos que modifican el protocolo de estimulación. En la parte inferior izquierda de la figura aparece un recuadro de la pantalla del menú principal donde se indica el tipo de estímulo utilizado para la realización de la prueba.

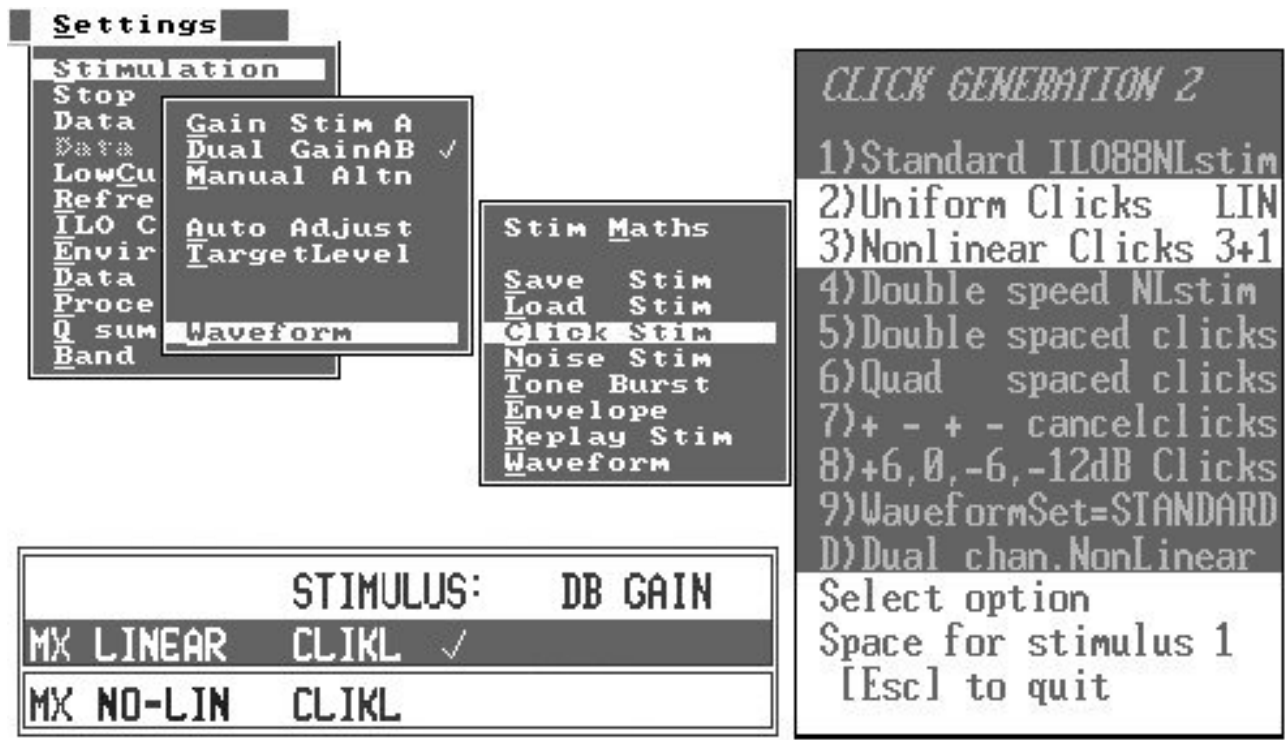

Figura 5.14. Elección del tipo y modo de estimulación utilizada en la prueba. La figura ilustra la elección de un click en modo de estimulación lineal. Selección (2) de CLICK GENERATION.

\subsubsection{I dentificación de archivos}

En la figura 5.15 se muestra un ejemplo de la construcción del nombre del archivo. Los nombres están compuestos por seis o siete caracteres, que se identifican así: Los dos primeros caracteres se obtienen del primer nombre propio y apellido del sujeto. El tercer caracter indica el oído al que corresponde el estudio (I: izquierdo o D: derecho). El cuarto y quinto caracteres denotan una estimulación lineal (L) o no lineal (NL). Los últimos dos caracteres indican el nivel de estimulación empleado.

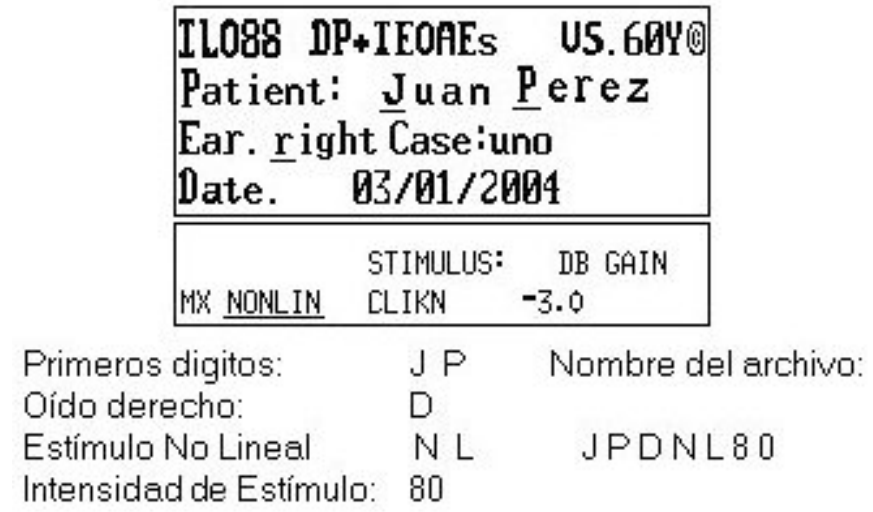

Figura 5. 15. Ejemplo de construcción del nombre de archivo, para almacenarlo en la memoria del equipo de registro. 


\subsubsection{Registros para su análisis}

Estos registros se hicieron en dos etapas; en la primera se realizaron los registros que utilizaron la estimulación "no lineal" y en la segunda (dos semana después) e realizaron los estudios con estimulación "lineal". Para cada oído se realizaron seis sesiones de registro, uno para cada intensidad de estimulación, en el orden mencionado anteriormente; se generaron la misma cantidad de archivos tanto de tipo DTA como de tipo MEG. La señal obtenida después de realizar el promedio de las épocas fijadas para cada canal de memoria, se muestran en la pantalla principal como dos ondas sobre-puestas. Si la respuesta acústica de ambos canales alcanza una semejanza superior al $50 \%$ el manual del ILO-96 sugiere que en la señal se encuentra una respuesta coclear o CEOAE, a esto le denomina reproducibilidad; para usos clínicos la reproducibilidad debe ser mayor al $70 \%$.

Como a cada sujeto se le realizaron seis diferentes registros, el tiempo entre un registro y otro se aprovechó para guardar los datos obtenidos y cambiar los parámetros del equipo para la siguiente intensidad de estímulo. En la figura 5.16 se muestra la presentación de las señales obtenidas después del promedio de las épocas de cada canal (260), así como su reproducibilidad en la parte superior derecha de la figura.

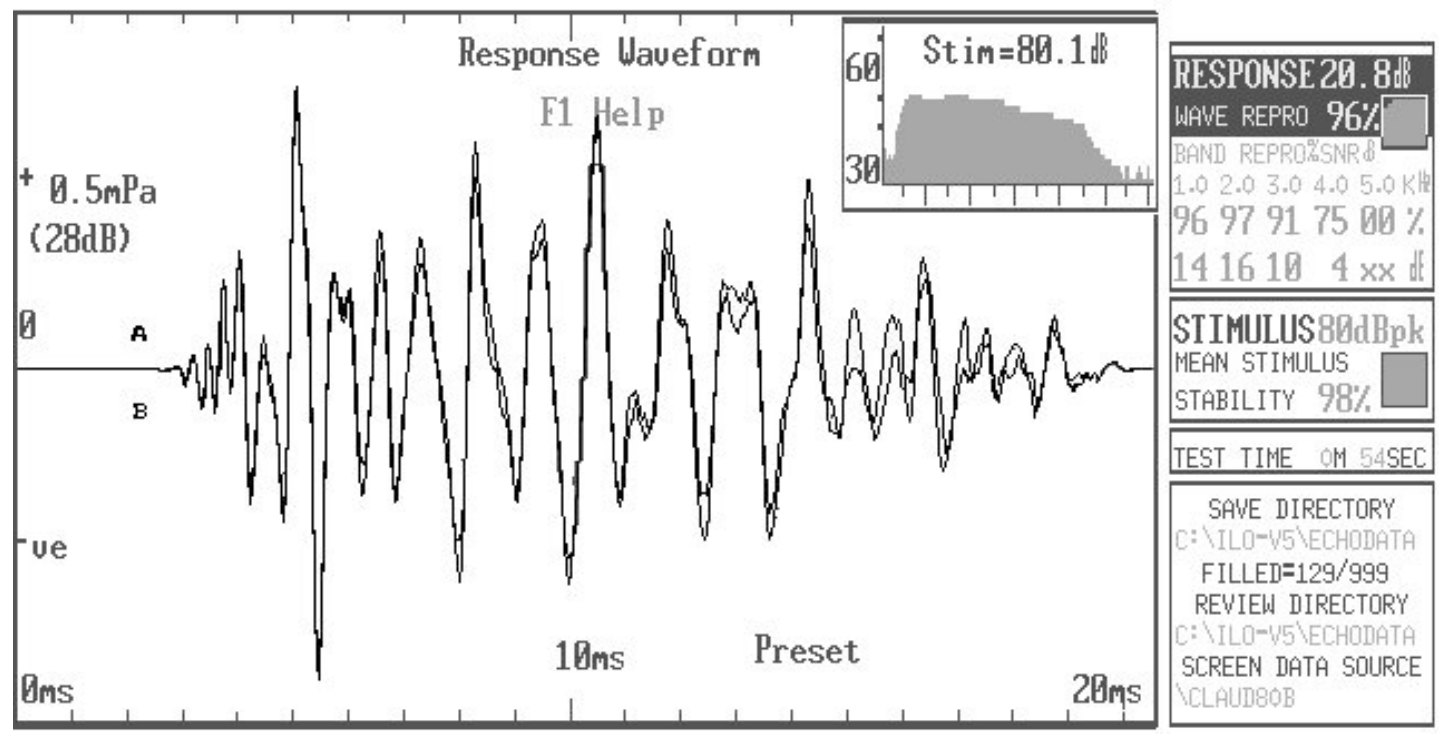

Figura 5. 16. Representación de dos CEOAE's típicas en la pantalla principal del ILO-96 y su reproducibilidad en la parte superior derecha ("WAVE REPRO").

\subsubsection{Análisis de los datos adquiridos con el protocolo modificado}

Los datos de los archivos DTA no se procesaron, solamente se leyeron ya que representan los resultados obtenidos por el ILO-96, de esta manera se pudo comparar los resultados obtenidos de los archivos MEG por el método propuesto. Los algoritmos utilizados fueron la correlación cruzada y el FSP. 
Correlación cruzada: Se calculó entre la respuesta obtenida del canal A y su réplica B, con una ventana de tiempo de $0-20 \mathrm{~ms}$, para el protocolo de estimulación no-lineal. Para la estimulación lineal se utilizaron dos ventanas; la primera ventana de 0 a $20 \mathrm{~ms}$ y la segunda ventana de 7.5 a 20 ms. Esta última se empleó para corroborar los resultados obtenidos por el algoritmo FSP.

FSP: Con este algoritmo se analizaron dos ventanas de tiempo para el protocolo de estimulación lineal y una sola ventana para la estimulación no-lineal; la primera ventana de 4 a 18 ms se aplicó para ambos protocolos de estimulación y la segunda ventana de 7.5 a $18 \mathrm{~ms}$ solamente para el estimulación lineal. Esta última se utilizó para evitar posibles contaminaciones del artefacto de estímulo sobre la respuesta. La duración de la ventana de análisis se decidió a partir de un análisis visual realizado sobre las respuestas obtenidas en una cavidad de prueba y de acuerdo con la literatura. El algoritmo FSP es evaluado en un número fijo de épocas (bloque) que se estableció en un valor de 18.

No se tomaron en cuenta para el análisis estadístico los registros que presentaron diferencia mayor a $2.5 \mathrm{~dB}$ SPL Pe entre el estímulo programado y el estímulo real que envió el equipo de registro. 


\section{Resultados}

El valor de la correlación cruzada entre los promedios obtenidos de los datos DTA y los correspondientes datos MEG, para la intensidad de estimulación (lineal y no lineal) de $80 \mathrm{~dB}$ SPL Pe, durante la etapa de los estudios preliminares fue superior al criterio establecido ( $\geq 90 \%)$. En el caso mostrado en la figura 6.1. donde se comparan las CEOAE del sujeto 1 obtenidas por el ILO96 y vía Matlab (datos DTA y datos MEG respectivamente) se obtuvo un valor de correlación cruzada entre ambas de 0.97 que corresponde a una semejanza entre respuestas del $97 \%$.

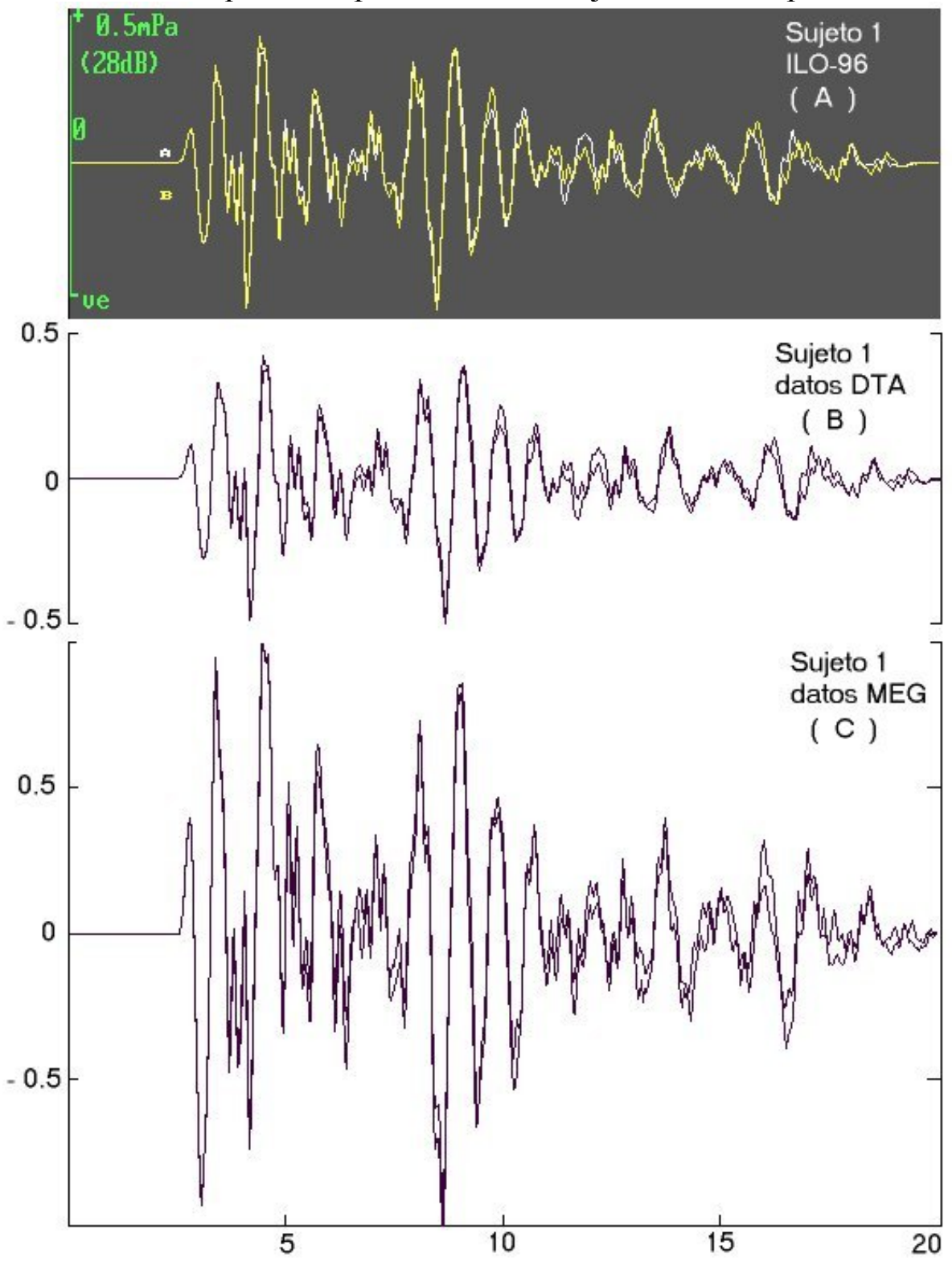

Figura 6. 1. A) Respuestas obtenida por el ILO-96, la señal (blanco) y su réplica (amarillo). B) Señal y su réplica obtenida de la lectura del archivo DTA por medio de Matlab. C) Resultado del procesamiento propuesto sobre los datos MEG utilizando Matlab. La ventana de estudio es de $20 \mathrm{~ms}$, la amplitud esta data en $\mathrm{mPa}$ y todos los datos corresponden al sujeto 1. 
El crecimiento de las CEOAE se muestra en la figura 6.2. cuando se utilizan los dos tipos de estimulo (lineal y no lineal) aplicados al mismo oído, las respuestas cocleares con mayor amplitud corresponden a la estimulación no lineal (lado derecho de la figura).
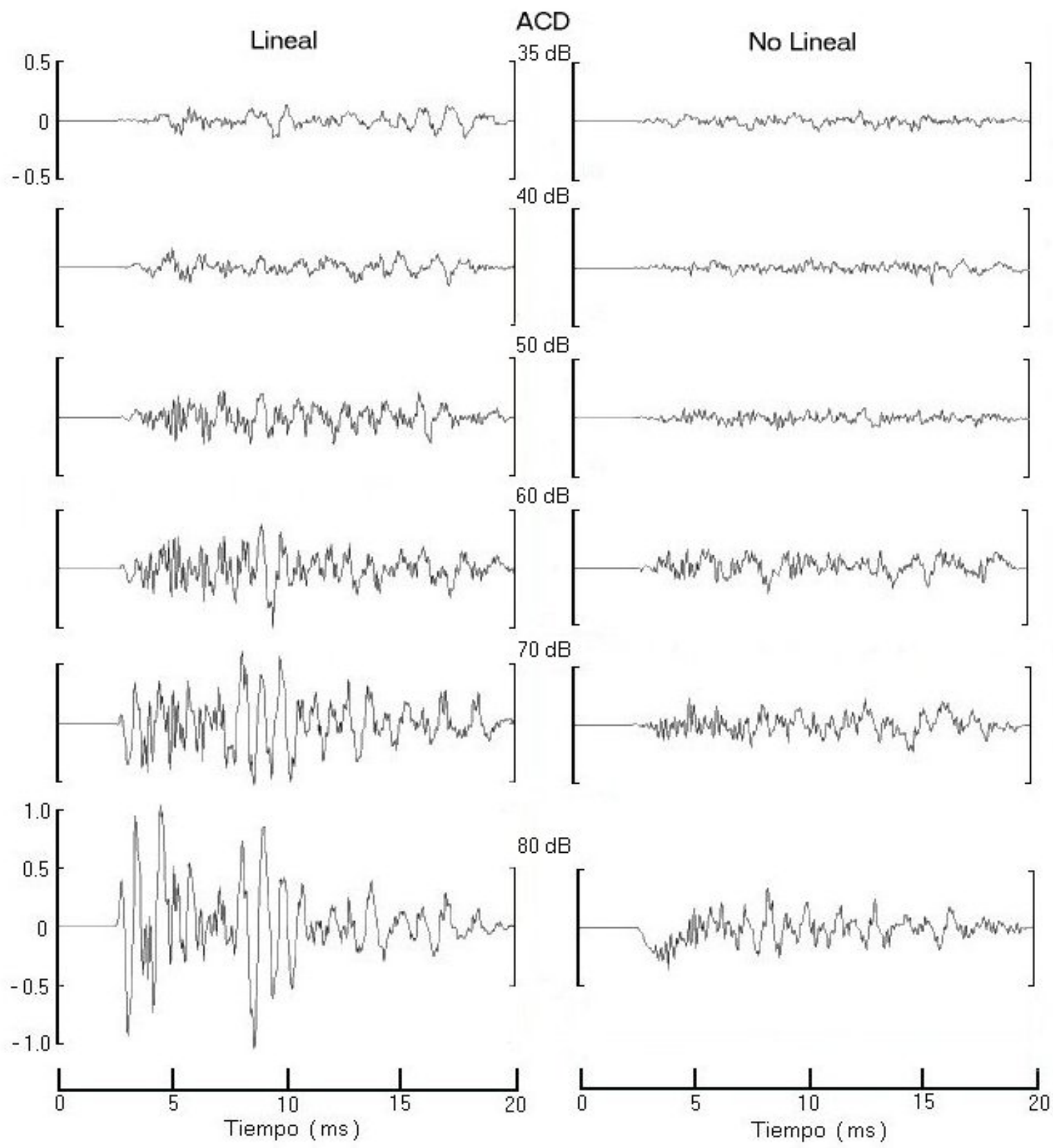

Figura 6.2. La figura compara el crecimiento de las CEOAE utilizando la estimulación lineal y no lineal. La ventana estudio es $20 \mathrm{~ms}$ y la escala de amplitud esta dada en $\mathrm{mPa}$; La estimulación lineal presenta mejores resultados ya que la amplitud de las CEOAE es mucho mayor que para la no lineal.

La tabla 6.1 muestra los resultados del análisis aplicado a los datos DTA y MEG obtenidos del mismo sujeto (oído) con estimulación lineal y no-lineal para las distintas intensidades de estimulación utilizadas. La palabra "OK" se utiliza para indicar que el punto de corte del FSP de 3.1 es superado en los primeros 10 bloques (180 épocas) de análisis. En el caso de requerirse más 
de 10 bloques para superar el punto de corte, este se indica como "OK/número de bloques". Por ejemplo para el caso de la estimulación lineal, con intensidad de $50 \mathrm{~dB}$, el punto de corte es superado al analizar 25 bloques. En la tabla 6.1 también se muestran los valores obtenidos por medio de la correlación cruzada sobre los datos de los archivos DTA y MEG.

Tabla 6.1. Correlación C. y FSP de los datos DTA y MEG del sujeto 1

\begin{tabular}{|c|c|c|c|c|c|c|c|}
\hline \multicolumn{2}{|c|}{ Intensidad del Est. } & $80 \mathrm{~dB}$ & $70 \mathrm{~dB}$ & $60 \mathrm{~dB}$ & $50 \mathrm{~dB}$ & $40 \mathrm{~dB}$ & $35 \mathrm{~dB}$ \\
\hline \multicolumn{8}{|c|}{ Lineal } \\
\hline datos DTA & $\overline{C C}$ & 0.9708 & 0.9272 & 0.903 & 0.6947 & -0.0396 & 0.1626 \\
\hline datos $\mathrm{MEG}$ & $\mathrm{Cc}$ & 0.969 & 0.8264 & 0.5836 & 0.63 & 0.3066 & 0.2047 \\
\hline datos $\mathrm{MEG}$ & Fsp & OK & $\mathrm{OK}$ & OK & $\mathrm{OK} / 25$ & 一 & 一 \\
\hline \multicolumn{8}{|c|}{ No Lineal } \\
\hline datos DTA & $\mathrm{CC}$ & 0.8725 & 0.7583 & 0.6535 & 0.462 & 0.068 & -0.0808 \\
\hline datos $\mathrm{MEG}$ & $\mathrm{cc}$ & 0.8889 & 0.5252 & 0.489 & 0.3062 & 0.1055 & 0.2354 \\
\hline datos $\mathrm{MEG}$ & Fsp & $\mathrm{OK}$ & OK & 一 & 一 & - & - \\
\hline
\end{tabular}

La figura 6.3 muestra el gráfico de los valores FSP obtenidos de los datos MEG del sujeto 1 para estimulación lineal y no-lineal. Los trazos mostrados se obtienen analizando un número progresivo de bloques de épocas para cada intensidad de estimulación y de los mismos se pueden corroborar la información presentada en la tabla 6.1 (en línea punteada se muestra el punto de corte de 3.1).
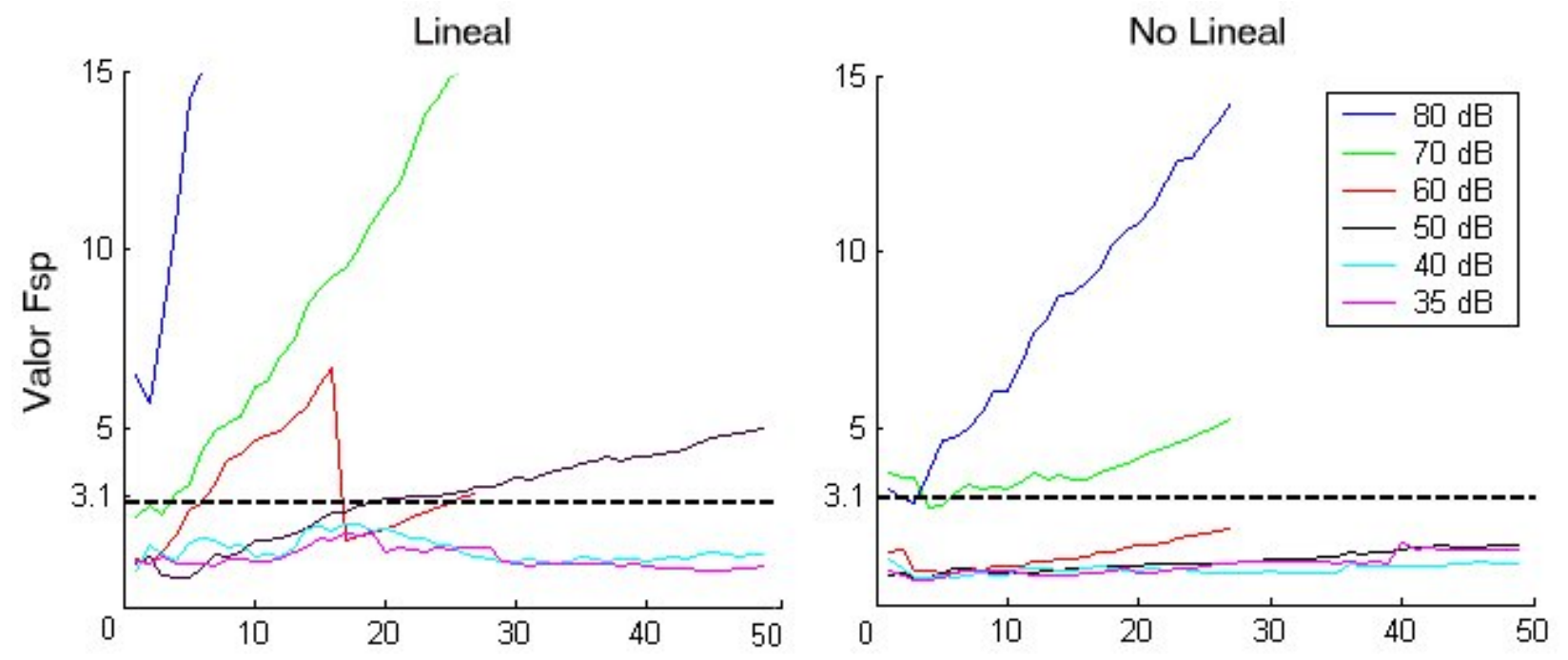

Figura 6.3. Los resultados obtenidos al aplicar el algoritmo Fsp a los datos MEG del sujeto 1, con los protocolos de estimulación lineal y no-lineal. Los trazos de valores de Fsp obtenidos con la estimulación lineal poseen mayores pendientes que los de estimulación no lineal.

La figura 6.4 muestra la media y la desviación estándar de la reproducibilidad (correlación cruzada), obtenida después de haber analizado los datos DTA y los datos MEG de la población de estudio con diferentes intensidades de estimulación. 
Población : ILO96 vs MEG

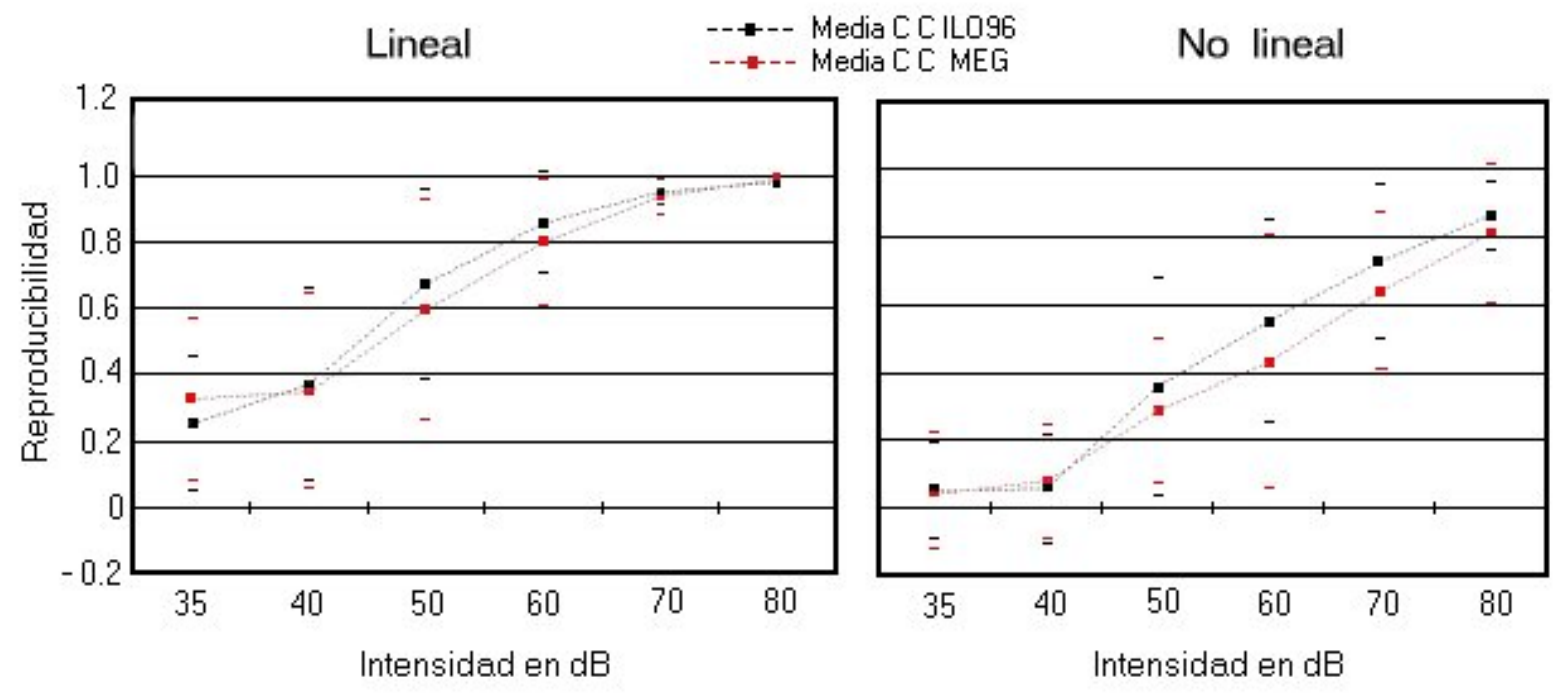

Figura 6.4. La reproducibilidad de los datos bajo la estimulación lineal presenta mayores amplitudes que las obtenidas con el estímulo No Lineal.

Los resultados que se obtuvieron de la cavidad de prueba aplicando estimulación no lineal se muestran en la tabla 6.2 .

Tabla 6.2. Correlalción cruzada y FSP aplicados a la cavidad de prueba

\begin{tabular}{|c|c|c|c|c|c|c|c|}
\hline \multicolumn{2}{|c|}{ Intensidad } & $80 \mathrm{~dB}$ & $70 \mathrm{~dB}$ & $60 \mathrm{~dB}$ & $50 \mathrm{~dB}$ & $40 \mathrm{~dB}$ & $35 \mathrm{~dB}$ \\
\hline \multicolumn{8}{|c|}{ No lineal } \\
\hline Datos DTA & $\overline{C C}$ & -0.0092 & 0.0539 & 0.0204 & 0.0005 & 0.0696 & -0.1501 \\
\hline Datos MEG & $\mathrm{cc}$ & 0.5565 & 0.0676 & 0.0614 & 0.1322 & 0.056 & -0.1913 \\
\hline Datos MEG & Fsp & - & - & - & - & - & - \\
\hline
\end{tabular}

En la figura 6.5, se muestran los trazos de los valores FSP obtenidos de la cavidad de prueba aplicando estimulación no lineal. En la misma puede observarse que ningún valor del FSP supera el punto de corte

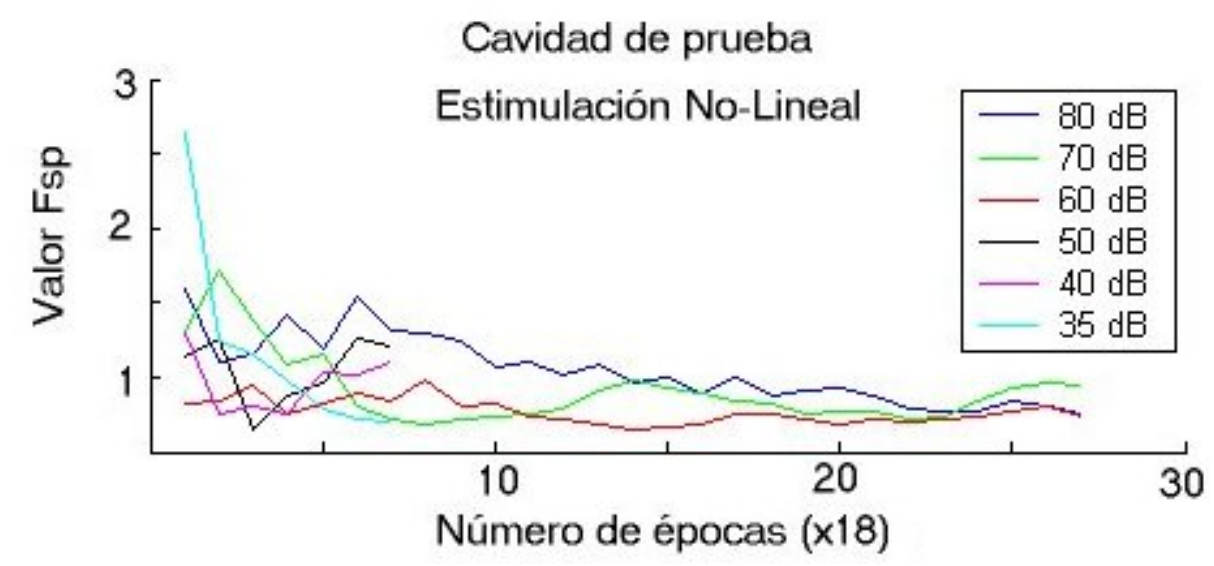

Figura 6.5. El algoritmo FSP demuestra un buen desempeño junto con la correlación cruzada al no encontrar respuesta en la cavidad de $2 \mathrm{~cm}^{3}$, utilizada para validar el FSP. 
Los resultados obtenidos después de aplicar los algoritmos de Correlación cruzada y FSP a los datos capturados de la cavidad de prueba con el modo de estimulación lineal, mostraron una "respuesta" de acuerdo con los criterios adoptados para la determinación de la presencia de CEOAE. Los valores de la Correlación cruzada se muestran en la tabla 6. 4. y los trazos del FSP se muestran en la figura 6.6.

\begin{tabular}{|c|c|c|c|c|c|c|c|}
\hline \multicolumn{8}{|c|}{ Lineal } \\
\hline \multicolumn{2}{|c|}{ Ventana (ms) } & \multicolumn{3}{|c|}{$0-20$} & \multicolumn{3}{|c|}{$7.5-20$} \\
\hline Intensic & & $80 \mathrm{~dB}$ & $70 \mathrm{~dB}$ & $60 \mathrm{~dB}$ & $80 \mathrm{~dB}$ & $70 \mathrm{~dB}$ & $60 \mathrm{~dB}$ \\
\hline Datos DTA & $\mathrm{CC}$ & 0.9827 & 0.9852 & 0.9849 & 0.0653 & -0.0137 & 0.0166 \\
\hline Datos MEG & $\mathrm{cc}$ & 0.998 & 0.9978 & 0.9983 & 0.6085 & 0.1551 & 0.5362 \\
\hline Datos MEG & Fsp & $\mathrm{OK}$ & OK & OK & - & - & - \\
\hline
\end{tabular}

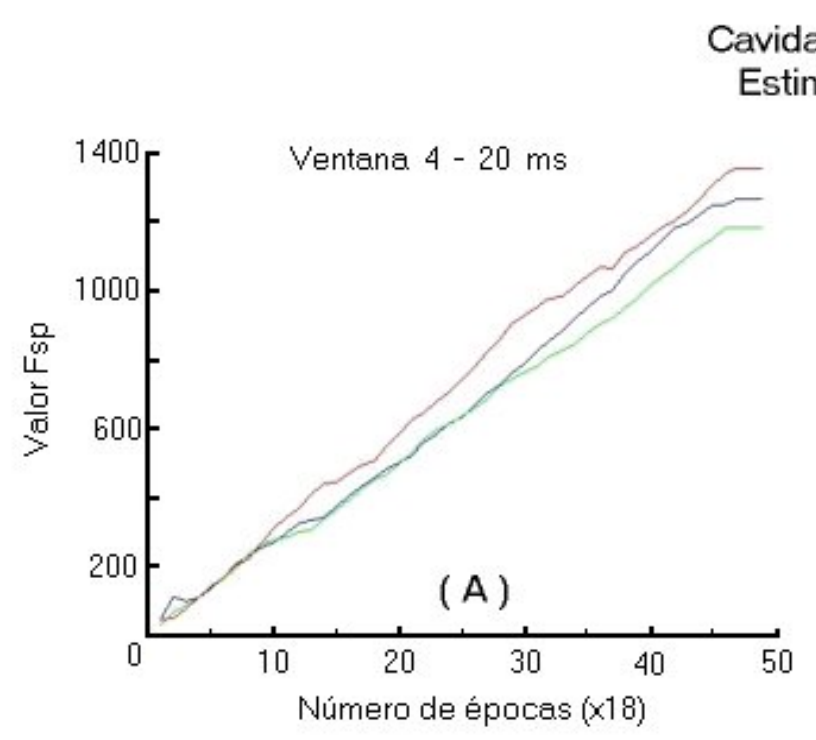

\section{Cavidad de prueba}

Estimulo Lineal
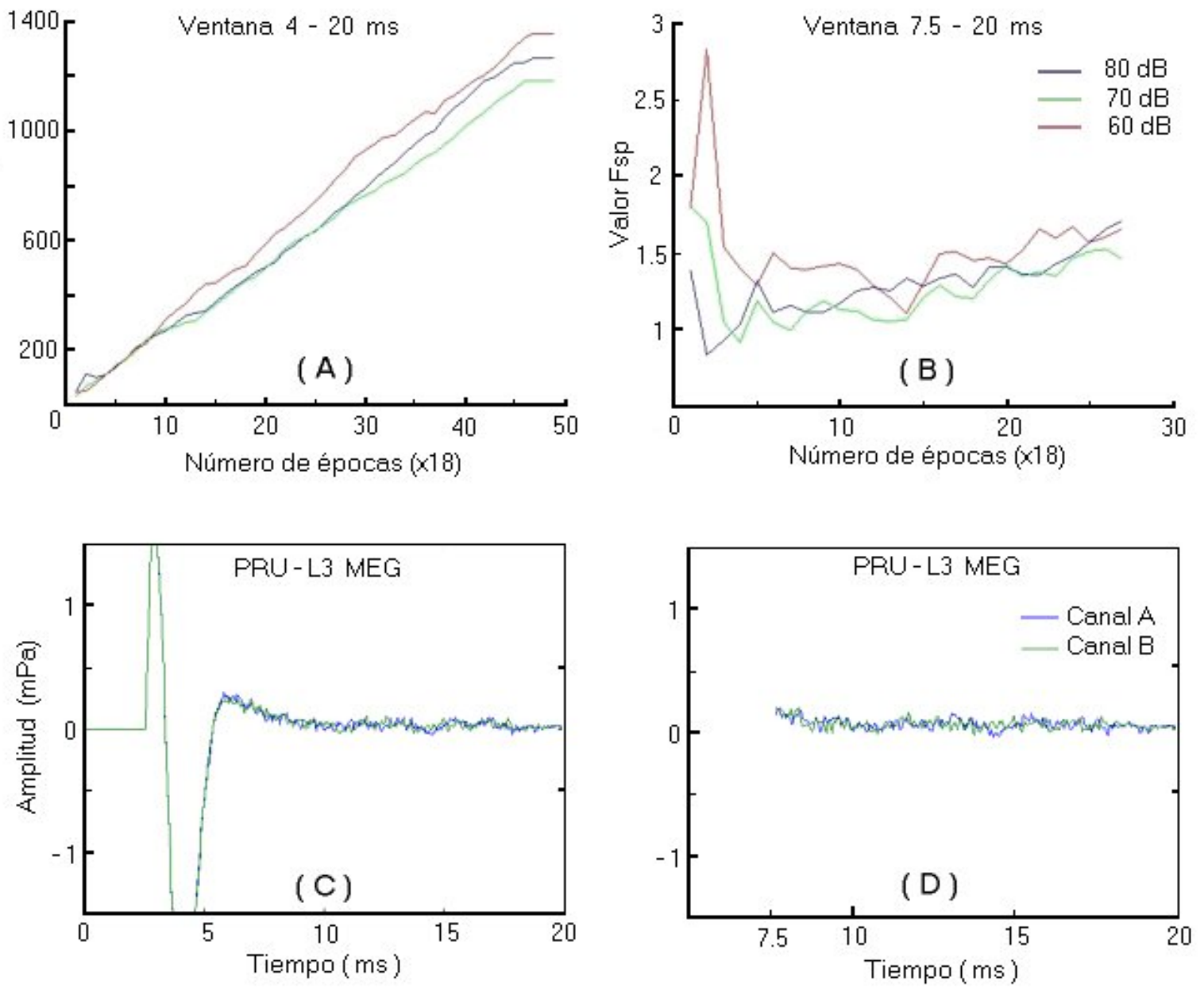

Figura 6.6. El desempeño del FSP no fue el esperado para la cavidad de prueba, utilizando el estímulo lineal porque la parte final del estímulo (artefacto) la califica como "respuesta". Una vez que se ha retirado esa porción de la señal, mejora su desempeño. La figura (A) muestra los resultados del Algoritmo Fsp,al analizar la ventana de 4-18 ms. La figura (C) presenta la señal "contaminada" de la cual es obtenida la figura(A). Los valores obtenidos de las figuras (B) y (C) muestran un mejor desempeño de los algoritmos. 
La tabla 6.4 muestra el número de oídos que se determinó con CEOAE presentes mediante los métodos de correlación cruzada y FSP. En el caso de correlación cruzada se utilizaron dos criterios diferentes: el criterio utilizado por el ILO-96 que sugiere la presencia de CEOAE cuando se supera una correlación del $50 \%$ y el criterio clínico que para determinar la presencia de CEOAE requiere superar una correlación del 70\%. Para el método de FSP se muestran el número de oídos que superaron el punto de corte de 3.1. Todos los resultados se muestran para las diferentes intensidades de estimulación y ambos protocolos (lineal y no lineal). La clasificación por sexos de la población se muestra en la parte superior de la tabla: $\mathrm{H}$ significa oídos masculinos, M oídos femeninos y P la población total del estudio

Tabla 6.4. Resultdos de la Correlación cruzada y FSP de los datos MEG

\begin{tabular}{|c|c|c|c|c|c|c|c|c|c|}
\hline \multirow{3}{*}{\begin{tabular}{|l|} 
Tipo de Est. \\
Ventana de est. \\
\end{tabular}} & \multicolumn{6}{|c|}{ Lineal } & \multirow{2}{*}{\multicolumn{3}{|c|}{$\begin{array}{l}\text { No Lineal } \\
0-20 \mathrm{~ms}\end{array}$}} \\
\hline & \multicolumn{3}{|c|}{$0-20 \mathrm{~ms}$} & \multicolumn{3}{|c|}{$7.5-20 \mathrm{~ms}$} & & & \\
\hline & $\mathrm{H}(10)$ & $M(10)$ & $P(20)$ & $\mathrm{H}(10)$ & $M(10)$ & $P(20)$ & $\mathrm{H}(10)$ & $M(10)$ & $P(20)$ \\
\hline Intensidad & & & & & $35 \mathrm{~dB}$ & & & & \\
\hline $\mathrm{CC}>0.50$ & 2 & 4 & 6 & 0 & 1 & 1 & 0 & 0 & 0 \\
\hline $\mathrm{CC}>0.70$ & 0 & 1 & 1 & 0 & 0 & 0 & 0 & 0 & 0 \\
\hline $\mathrm{FSP}(3.1)$ & 0 & 1 & 1 & 0 & 1 & 1 & 0 & 0 & 0 \\
\hline Intensidad & & & & & $40 \mathrm{~dB}$ & & & & \\
\hline $\mathrm{CC}>0.50$ & 5 & 3 & 8 & 1 & 2 & $\overline{3}$ & 0 & 0 & 0 \\
\hline $\mathrm{CC}>0.70$ & 0 & 2 & 2 & 1 & 1 & 2 & 0 & 0 & 0 \\
\hline $\mathrm{FSP}(3.1)$ & 0 & 2 & 2 & 0 & 2 & 2 & 0 & 1 & 1 \\
\hline Intensidad & & & & & $50 \mathrm{~dB}$ & & & & \\
\hline $\mathrm{CC}>0.50$ & 5 & 8 & 13 & 4 & 8 & 12 & 0 & 3 & 3 \\
\hline$C C>0.70$ & 4 & 7 & 11 & 3 & 6 & 9 & 0 & 1 & 1 \\
\hline $\mathrm{FSP}(3.1)$ & 5 & 10 & 15 & 4 & 9 & 13 & 1 & 3 & 4 \\
\hline Intensidad & & & & & $60 \mathrm{~dB}$ & & & & \\
\hline $\mathrm{CC}>0.50$ & 8 & 9 & 17 & 7 & 8 & 15 & 3 & 6 & 9 \\
\hline $\mathrm{CC}>0.70$ & 7 & 8 & 15 & 5 & 7 & 12 & 2 & 5 & 7 \\
\hline $\mathrm{FSP}(3.1)$ & 7 & 10 & 17 & 6 & 9 & 15 & 3 & 6 & 9 \\
\hline Intensidad & & & & & $70 \mathrm{~dB}$ & & & & \\
\hline $\mathrm{CC}>0.50$ & 10 & 10 & 20 & 10 & 10 & 20 & 7 & 8 & 15 \\
\hline $\mathrm{CC}>0.70$ & 10 & 10 & 20 & 7 & 10 & 17 & 2 & 7 & 9 \\
\hline $\mathrm{FSP}(3.1)$ & 10 & 10 & 20 & 10 & 10 & 20 & 6 & 8 & 14 \\
\hline Intensidad & & & & & $80 \mathrm{~dB}$ & & & & \\
\hline $\mathrm{CC}>0.50$ & 10 & 10 & 20 & 10 & 10 & 20 & 8 & 10 & 18 \\
\hline $\mathrm{CC}>0.70$ & 10 & 10 & 20 & 9 & 10 & 19 & 8 & 9 & 17 \\
\hline $\mathrm{FSP}(3.1)$ & 10 & 10 & 20 & 10 & 10 & 20 & 9 & 10 & 19 \\
\hline
\end{tabular}


Los mismos resultados de la tabla 6.4 son presentados en la figura 6.7 separados por ventana y métodos de análisis.

\section{Intensidad de estimulación}
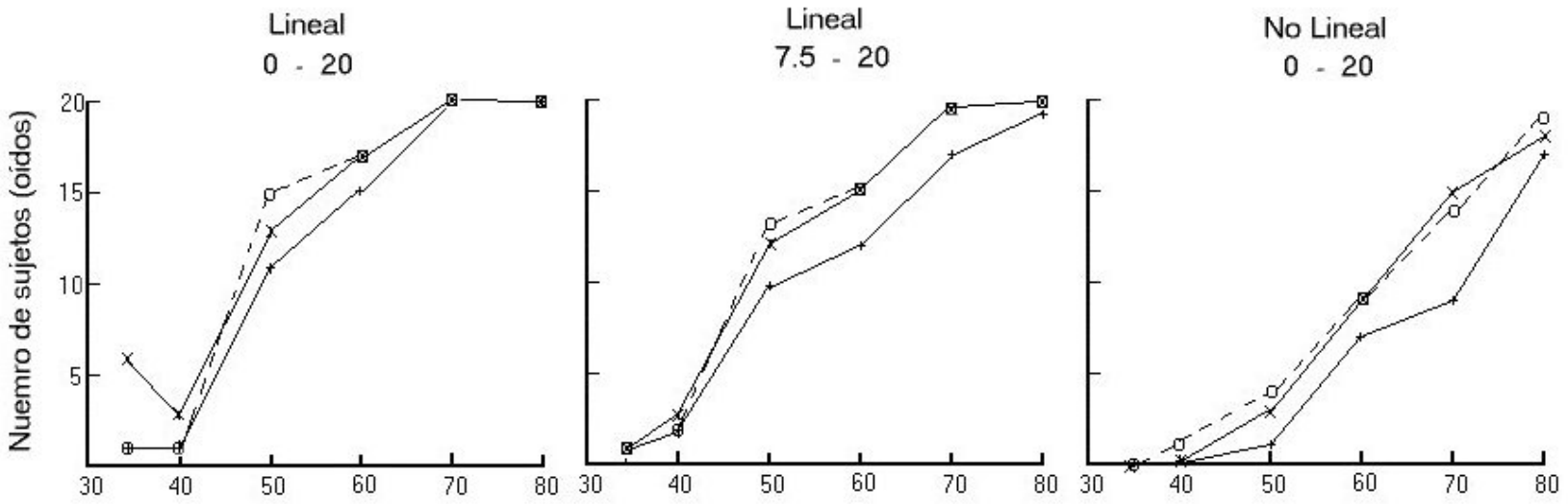

Reproducibilidad $50 \%(x)$

Reproducibilidad $70 \%(+)$

Fsp ( 3.1 ) (-o-)

Figura 6.5. La reproducibilidad de los datos bajo la estimulación Lineal presenta mayores amplitudes que las obtenidos con el estímulo No Lineal. 


\section{Discusión}

La propuesta de analizar una ventana alternativa que va de 7.5 a $18 \mathrm{~ms}$ se basó principalmente en el análisis del artefacto producido sobre la cavidad de prueba de $2 \mathrm{cc}$. Sin embargo se espera que esta sea una sobre estimación del inicio $(7.5 \mathrm{~ms})$ de dicha ventana dada las diferentes características mecánicas de la cavidad con respecto al oído humano. Por esta razón se propone que se realice un análisis más detallado en oídos humanos, donde no estén presentes las CEOAE (casos patológicos).

En el presente estudio se utilizó un umbral de 3.1 para el FSP, tomando como referencia los resultados presentados por Elberling y Don en 1984 para señales de ABR y bajo la hipótesis de que el modelo de las señales de CEOAE (ver ec. 12, Pág. 28) es análogo al de las señales de ABR. Sin embargo la diferencia del tipo de procesamiento en las CEOAE con estimulación no lineal, difiere respecto del método de procesamiento en la estimulación lineal para CEOAE y del método en ABR. Dada esta diferencia el valor de 3.1 podría disminuirse para el caso de estimulación no lineal ya que en este modo de estimulación se tiende a eliminar la presencia del artefacto de estímulo

Los valores obtenidos al aplicar la correlación cruzada al los datos de los registros SSDNL80 (0.23) y SSINL80(0.33) que se obtuvieron al usar el protocolo de estimulación no lineal, no superan una reproducibilidad de 50\% (0.5) para afirmar la presencia de OAE, sin embargo al realizar el registro utilizando el protocolo de estimulación lineal estos registros presentaron una reproducibilidad de 99\% (0.9944) y 97\% (0.9742) respectivamente, lo que indica es que el oído analizado si presenta "respuesta coclear"; entonces se concluye que los primeros resultados se deben a un mal registro. 


\section{Conclusiones}

La forma de onda observadas sobre los registros de CEOAE obtenidas en el trabajo concuerdan con las reportadas por la literatura, observándose la forma de onda característica en cuanto a sus amplitudes y su contenido en frecuencias

Se implementaron algoritmos en lenguaje Matlab con la finalidad de reproducir los análisis propios del ILO-96 y de incorporar nuevas rutinas de análisis como el FSP. Se logró obtener una amplia similitud entre las CEOAE obtenidas mediante el post-procesamiento de Matlab respecto a las obtenidas por el propio ILO-96 (correlación mayor a 0.9).

Se logró una base con dos protocolos de estimulación: lineal y no lineal, para ambos protocolos se hicieron registros a 20 oídos sanos divididos a su vez en 10 oídos de hombres y 10 de mujeres. Los datos adquiridos para cada oído se almacenaron en dos tipos de archivos (XXX.DTA y XXX.MEG) para su posterior análisis

Como se puede ver en la tabla 6.4 (Pág.52) el protocolo de estimulación lineal presenta mejores resultados al utilizar la ventana de análisis de 7.5-18 ms posteriores al estímulo.

El algoritmo FSP presenta un desempeño moderadamente mejor que la correlación cruzada (0.7) para la detección de CEOAE cuando se utilizó la estimulación lineal y una ventana de análisis de 7.5-18 ms posteriores al estímulo

En el caso particular de las mujeres se logró un mayor número de detecciones de CEOAE y las respuestas presentan una mayor amplitud que las obtenidas en los registros realizados a los hombres.

Con el algoritmo Fsp, utilizando una ventana de análisis de 7.5-18 ms y una estimulación lineal con intensidad de $60 \mathrm{~dB}$ SPL Pe se detectaron CEOAE con una confiabilidad del $75 \%$. 


\section{Referencias}

[1] Beltran Vargas, Nohra; Exploración de la vía auditiva con una prueba simultánea de emisiones otoacústicas transientes y potenciales evocados auditivos de tallo, Universidad Autónoma Metropolitna-Iztapalapa, División de Ciencias Básicas e Ingeniería, postgrado en Ingeniería biomédica. Enero del 2002.

[2] A. Vega Cuadri, M. Y. Álvarez Suárez, A. Blasco Huelva, P. Torrico Román, M. A. Serrano Berrocal, G. Trinicad Ramos; Otoemisiones acústicas como prueba de cribado para la detección precoz de la hipoacusia en recién nacidos, Acta otorrinolaringológica Española, 52, 273-278, 2001.

[3] A. Morant Ventura, Ma. I. Pitarch ribes, F. J. García callejo, J. Marco Algarra; Retrazo en el diagnóstico de hipoacusia en niños, Justificaión para instaurar modelos de cribaje, Hospital Clínico Universitario, Valencia, Vol. 51, No. 1, 1999.

[4] J. Mata, I. Rando, M. Shepherd, J. Miguélez, F. Jiménez, f. Delgado; Importancia de la impedanciometría dentro de un programa de screening auditivo con otoemisiones en niños, Acta Otorrinolaringología Española, 52, 96-100, 2001.

[5] Gentiletti Faenze, G. Gabriel; Reconocimiento Automático del Potencial Evocado Auditivo de Tallo Cerebral en la Detección de la Discapacidad Auditiva, Universidad Autónoma Metropolitna-Iztapalapa, postgrado en Ingeniería biomédica. División de Ciencias Básicas e Ingeniería. México, D. F. 2002.

[6] Ratyňska, Joanna; Mueller-Malesiňska, Malgorzata; Kochanek, Krzysztof; Skarżyňski, Henryk; Applications of OAE and ABR techniques in neonatal screening and diagnostics of heraring in newborns and infants, Institute of Physiology and Pathology of Hearing, Warsaw, New Medicine, Vol. 3, 1999.

[7] William F. Dolphin, Ph, D.; Overview of evoked response audiometric Techniques: Auditory screening and diagnostics using Otoacoustic Emissions (OAE) and Auditory Evoked Potentials (AEP), Departament of Biomedical Engineering and Biology at Boston University; www.sonamed.com/Article1.html.

[8] Vander, Arthur J.; Sherman, James H.; Luciano, Dorothy S; Human Physiology, The Mechanisms of body function, Second Edtion, McGraw-Hill book Company.

[9] Fettiplace, Robert, Ricci, Anthony J., and Hackney Crole M.;Clues to the cochlear amplifier from the turtle ear; Trends in Neurosciences, Vol. 24, No. 3, March 2001.

[10]Clopton, Ben M.; Spelman Francis A.; The biomedical Engineering Handbook, Joseph D. Bronzino, CRC Press, IEEE Preess.

[11] Guyton, A.; Hall, J.; Tratado de Fisiología Médica, 9a . Edición McGraw Gill, 1996.

[12]Deweese, D. D.; Saunders, W.; Tratado de Otorrinolaringología, 6a. Edición, Nueva Editorial Interamericana, S. A. de C. V., México D. F. 1986.

[13] Christian Giguere and Philip C. Woodland; A computational model of the auditory periphery for speech and hearing research. I. Descending paths, Journal of the Acoustical Society of America Vol. 95, No. 1, January 1994.

[14] Christian Giguere and Philip C. Woodland; A computational model of the auditory periphery for speech and hearing research. II. Descending paths, Journal of the Acoustical Society of America Vol. 95, No. 1, January 1994.

[15] Neely, Stephen T.; A model of cochlear mechanics with outer hair cell motility, Journal of the Acoustical Society of America Vol. 94, No. 1, July 1993. 
[16] Berlin, Charles I. ; Otoacoustic Emissions Basic Science and clinical applications, National Organizations for Heraring Research, Singular Publishing Group, Inc. San Diego, London, October 12, 1997.

[17] Otodynamics; Otoacustic Emisión Systems; ILO OAE Instrument User Manual, Issue 5a.

[18]D. T. Kemp; Stimulated acoustic emissions from within the human auditory system, Journal of the Acoustical Society of America Vol. 64, No. 5, Nov. 1978.

[19] Rudolf Probst, Brenda L. Lonsbury-Martin and Glen K. Martin; A review of otoacoustic emissions, Journal of the Acoustical Society of America Vol. 108, No. 5, Parte 1, Nov. 2000.

[20] Avan, Paul; Elbez, Michel and Bonfils, Pierre, Click-evoked otoacoustic emissions and the influence of high-frequency hearing losses in humans, Journal of the Acoustical Society of America Vol. 101, No. 5, Parte 1, May 1997.

[21] M. L. Whitehead, B. B. Stagner, B. L. Lonsbury-Martin, G. K. Martin; Measurement of otoacoustic emissions for hearing assessment, IEEE Engineering in Medicine and Biology, 221-226, April/May 1994.

[22] J. M. Cornejo, M. Palacios, P. Granados, N. Castañeda \& M. Cadena; Potenciales evocados auditivos: respuesta de baja frecuencia para tonos ráfaga de larga duración, Departamento de Ingeniería Eléctrica, Área de Ing. Biomédica. Universidad Autónoma Metropolitana Iztapalapa-, 2001.

[23]Bray, Peter John, Click evoked otoacoustic emissions and the development of a clinical otoacoustic hearing test instrument, Thesis, University London, 1989.

[24] Jonathan Raz, Bruce Turetsky and George Fein; Confidence intervals for the Signal-to-Noise ratio when a signal Embedded in noise is observed over repeated trials, IEEE Transactions on Biomedical Engineering, Vol. 35, no. 8, August, 1988.

[25]P. Ravazzani and F. Grandori; Evoked otoacoustic emissions: nonlinearities and response interpretation, IEEE Transactions on Biomedical Engineering, Vol. 40, No. 5, May 1993.

[26] Therrien, Charles W.; Discrete Random Signals and Statistical Signal Processing; Prentice Hall Signal Processing Series.

[27] Kleppe, J. A.; Engineering Applications of Acoustics, Edit. Artech House Acoustics Library, 1989.

[28] Elberling, C., and Don, M., Quality Estimation of Averaged Auditory Brainstem Responses, Scand. Audiol, vol.13, pp.187-197, 1984.

[29] Gerald R. Popelka, Standard Metrics for Hearing Screening Tests, Vice President, Research and Development. Everest Biomedical Instruments.

[30]Don, M., Elberling, C., and Waring, M., Objective Detection of Averaged Auditory Brainstem Responses, Scand. Audiol, vol.13, pp.219-228, 1984.

[31] Kapadia, Sarosh; Lutman, Mark E.; Are normal Hearing thresholds a sufficiente condition for click-evoked otoacoustic emissions?; Journal of the Acoustical Society of America Vol. 101, No. 6, June 1997.

[32] C. Elberling and O. Wahlreen, Estimation of auditory brainstem response, ABR, by means of Bayesian detection theory, Scand. Audiol., vol.14, No.2, pp.89-96, 1985. 